\title{
1 The RNA-binding protein, Rasputin/G3BP, enhances the stability and translation of its 2 target mRNAs
}

5 John D. Laver ${ }^{1+}$, Jimmy Ly ${ }^{1,2++}$, Allison K. Winn ${ }^{2}$, Angelo Karaiskakis ${ }^{1}$, Sichun Lin ${ }^{3}$, Kun Nie ${ }^{1}$,

6 Giulia Benic ${ }^{1}$, Nima Jaberi-Lashkari ${ }^{1,2++}$, Wen Xi Cao ${ }^{1}$, Alireza Khademi ${ }^{1}$, J. Timothy

7 Westwood $^{4}$, Sachdev S. Sidhu ${ }^{1,5}$, Quaid Morris ${ }^{1,5,6}$, Stephane Angers ${ }^{2,3}$, Craig A. Smibert ${ }^{1,2 *}$,

8 Howard D. Lipshitz ${ }^{1 *}$

$12{ }^{1}$ Department of Molecular Genetics, University of Toronto, 661 University Avenue, Toronto,

13 Ontario, Canada M5G 1M1

$14{ }^{2}$ Department of Biochemistry, University of Toronto, 661 University Avenue, Toronto, Ontario,

15 Canada M5G 1M1

$16{ }^{3}$ Department of Pharmaceutical Sciences, University of Toronto, 144 College Street, Toronto,

17 Ontario, Canada M5S 3M2

$18{ }^{4}$ Department of Biology, University of Toronto, 3359 Mississauga, Mississauga, Ontario, Canada

19 L5L 1 C6

$20{ }^{5}$ Donnelly Centre, University of Toronto, 160 College Street, Toronto, Ontario, Canada M5S

$21 \quad 3 \mathrm{E} 1$

$22{ }^{6}$ Vector Institute, 661 University Ave, Toronto, Ontario, Canada, M160 College Street, Toronto,

23 Ontario, Canada M5G 1M1

${ }^{+}$Current address: Department of Cell and Systems Biology, University of Toronto, 25 Harbord

\section{Street, Toronto, Ontario, Canada M5S 3G5}

$27{ }^{++}$Current address: Department of Biology, Massachusetts Institute of Technology, Cambridge,

28 MA 02139, USA

29

$30 *$ Correspondence:

31 Craig Smibert (‥smibert@utoronto.ca) or Howard Lipshitz (howard.lipshitz@utoronto.ca) 


\section{SUMMARY}

G3BP RNA-binding proteins are important components of stress granules (SGs). Here we analyze the role of Drosophila G3BP, Rasputin (RIN), in unstressed cells, where RIN is not SG associated. Immunoprecipitation followed by microarray analysis identified over $550 \mathrm{mRNAs}$ that copurify with RIN. The mRNAs found in SGs are long and translationally silent. In contrast, we find that RIN-bound mRNAs, which encode core components of the transcription, splicing and translation machinery, are short, stable and highly translated. We show that RIN is associated with polysomes and provide evidence for a direct role for RIN and its human homologs in stabilizing and upregulating the translation of their target mRNAs. We propose that when cells are stressed the resulting incorporation of RIN/G3BPs into SGs sequesters them away from their short target mRNAs. This would downregulate the expression of these transcripts, even though they are not incorporated into stress granules.

\section{KEY WORDS}

RNA-binding protein, post-transcriptional regulation, mRNA translation, mRNA stability, stress granule, Drosophila, embryo, G3BP, Rasputin

\section{INTRODUCTION}

Post-transcriptional regulation (PTR) plays a key role in control of gene expression in all cell types. In the cytoplasm of a cell, PTR is exerted at the level of mRNA stability, translation and subcellular localization (Bovaird et al., 2018; Tutucci et al., 2018). PTR is achieved by RNA-binding proteins (RBPs) and small RNAs such as microRNAs (miRs), which act as specificity factors that modulate the interaction of mRNAs with the cellular machinery that localizes, translates and degrades mRNAs (Achsel and Bagni, 2016; Iadevaia and Gerber, 2015;

57 Van Treeck and Parker, 2018).

PTR is particularly important in early animal embryos, where maternally provided mRNAs and proteins control developmental events prior to transcriptional activation of the

60 embryo's genome (Tadros and Lipshitz, 2009; Vastenhouw et al., 2019). In several model

61 animals, including Drosophila, the transfer of control from maternal products to those

62 synthesized by the embryo's own genome - the maternal-to-zygotic transition (MZT) — is very 
rapid, occurring over a matter of hours, thus facilitating studies of the mechanisms and functions of PTR. For example, it has been shown that the Drosophila RBP, Smaug (SMG), which binds to specific stem-loop structures in its target mRNAs to repress their translation and trigger their degradation (Aviv et al., 2006; Aviv et al., 2003; Chen et al., 2014; Semotok et al., 2005; Semotok et al., 2008; Smibert et al., 1999; Smibert et al., 1996), is essential for repression/clearance of hundreds of maternal mRNAs and for timely activation of the zygotic genome (Benoit et al., 2009; Laver et al., 2015b; Luo et al., 2016; Tadros et al., 2007). SMG is not the only negative regulator of maternal transcripts in Drosophila; additional RBPs (e.g., Brain tumor, Laver et al., 2015a) or miRs (e.g., miR-309, Bushati et al., 2008) function in maternal mRNA clearance.

PTR also serves as a rapid response to cellular stress. Under stress conditions, cells shut down translation of many mRNAs while up-regulating transcription and/or translation of sets of protein chaperones that maintain basal cellular integrity. Repression occurs, at least in part, in membraneless organelles known as stress granules (SGs) (Harvey et al., 2017; Panas et al., 2016; Protter and Parker, 2016; Van Treeck and Parker, 2018). SGs are thought to contain transcripts that are stalled in translation initiation (Anderson and Kedersha, 2009a, b; Buchan and Parker, 2009; Kedersha and Anderson, 2009) and recent global analyses have shown that SGs are enriched for long transcripts (Khong et al., 2017; Namkoong et al., 2018).

An important component of SGs is the RBP, G3BP, which is conserved throughout eukaryotes. Mammals have two genes, G3BP1 and G3BP2, whereas in Drosophila there is a single gene, Rasputin (rin). In human cells, G3BPs are necessary for SG formation and, if overexpressed, they are sufficient to induce SGs even in the absence of stress (Tourriere et al., 2003). RIN is necessary for SG formation in the Drosophila S2 tissue culture cell line and, while RIN or G3BP overexpression can induce SGs in human cells, this is not the case in S2 cells (AguileraGomez et al., 2017). RIN and G3BPs interact with several of the same protein partners under both stress and non-stress conditions; these include Caprin (CAPR), FMRP (FMR1 in Drosophila) and UPA2 (Lingerer [LIG] in Drosophila) (Aguilera-Gomez et al., 2017; Baumgartner et al., 2013; Costa et al., 2013; Jain et al., 2016; Kedersha et al., 2016; Markmiller et al., 2018; Youn et al., 2018). However, the roles of these interactors in SG assembly or disassembly can vary under different conditions. For example, in human cells, G3BP interaction with CAPR nucleates SG formation under oxidative stress (Solomon et al., 2007; Tourriere et al., 
94 2003) but G3BP and CAPR are not required for SG formation under osmotic stress (Kedersha et 95 al., 2016).

96 The roles of RIN/G3BPs in unstressed cells have received less attention than their roles 97 upon stress. Multiple functions have been attributed to G3BPs (reviewed in Alam and Kennedy, 2019), including transcript destabilization/repression (e.g. c-myc, BART, CTNNB1, PMP22, HIV1, miR-1), transcript stabilization (e.g., Tau, SART3), subcellular transcript localization (e.g.,

100 Twist1), and transcript sequestration into virus-induced foci (e.g., HIV-1). In Drosophila,

101 mutations in the rin gene cause severe defects in oogenesis, mutant females lay few eggs and

102 those that are laid fail to hatch (Costa et al., 2013). rin mutations can also result in tissue 103 patterning and growth defects (Baumgartner et al., 2013; Pazman et al., 2000). Despite RIN's essential function in the fly life cycle, there have been no analyses of the RIN-bound transcriptome or RIN's global role in gene regulation, nor are the molecular mechanisms that underlie RIN function known.

To better understand the function of RIN/G3BP in unstressed cells, we have carried out 108 global analyses of the RIN-associated proteome and transcriptome in early Drosophila embryos.

109 Using an anti-RIN synthetic antibody that we isolated from a phage-displayed library of 110 fragments antigen binding (Fab) (Na et al., 2016; Persson et al., 2013), we immunoprecipitated 111 (IPed) RIN and then carried out mass spectrometry (IP-MS) to confirm IP of RIN and to identify 112 RIN's partner proteins. Interactions were found with several RBPs previously shown to interact 113 with G3BP/RIN (e.g., Caprin, FMR1, and Lingerer), consistent with IP of a biologically relevant 114 RIN-containing complex or complexes. RNA-dependent interactions with RIN were found for 115 both small and large ribosomal subunit proteins, suggesting that RIN may be polysome 116 associated, a fact we confirmed using polysome gradients. By coimmunoprecipitating RIN 117 together with bound mRNAs followed by microarray analysis (RIP-chip) we identified hundreds 118 of in vivo target transcripts in embryos, which are characterized by two features: they are short 119 and are enriched for a RIN-binding motif that was previously identified in vitro (Cook et al., 120 2011; Ray et al., 2013). RIN-associated mRNAs are enriched for Gene Ontology (GO) terms for 121 core components of the transcription, splicing and translation machinery as well as of 122 mitochondria. RIN's endogenous targets in early embryos are more stable and more highly 123 translated than co-expressed unbound transcripts. Their shorter length and higher rates of 124 translation contrast with the behaviour of mRNAs associated with SGs. Consistent with a role for 
125 RIN as a positive regulator of transcript stability, in rin mutants the abundance of several highly

126 bound target mRNAs is reduced relative to controls. Using a heterologous RNA-binding domain

127 to tether RIN, G3BP1 or G3BP2 to a luciferase reporter mRNA in S2 tissue culture cells, we

128 confirmed that RIN/G3BP increases the stability and/or translation of bound transcripts in the

129 absence of stress.

130 Our data support a conserved function for G3BP proteins as potentiators of the translation

131 and stability of their target transcripts. We speculate that stress-dependent recruitment of

132 G3BPs/RIN into SGs may serve as a mechanism to down-regulate gene expression both directly,

133 by removing RIN from its endogenous target mRNAs, as well as indirectly, through reduced

134 transcription, splicing and translation.

\section{RESULTS}

Expression of RIN in early embryos

We analyzed endogenous RIN expression in early embryos by western blots and whole-

140 mount immunofluorescence using a previously published rabbit polyclonal antibody (Aguilera-

141 Gomez et al., 2017). The expression level of RIN does not change significantly through the time

142 course examined (0-4 hr; Figure S1A, B). RIN is enriched in the cortex of the early embryo

143 (Figures S1C, D and S2) and is concentrated apical to the nuclei at the syncytial blastoderm stage

144 (Figures S1E and S2), and is not present in foci. We compared the distribution of RIN with a 145 known interacting protein, FMR1 (Monzo et al., 2006), and found that their distributions overlap

146 in the cortex (Figure S1C-E).This pattern for RIN is consistent with previously published data on

147 the Drosophila ovary, showing that RIN is enriched in the cortical cytoplasm of the nurse cells

148 and the oocyte (Costa et al., 2013).

150 RBPs, translation factors and ribosomal proteins co-purify with RIN, which exhibits polysome

151 association

152 Our next goal was to identify protein partners and mRNA targets of RIN in early

153 embryos. An anti-RIN synthetic antibody, D072, was generated against its NTF2-like domain

154 (see Figure 1A and Methods for details) and was used to IP endogenous RIN from 0-3 h old

155 embryos followed by mass spectrometry (LC-MS/MS). To differentiate proteins that associate 
with RIN via protein-protein interactions versus through co-binding to RIN's target RNAs, IPs were performed either in the presence $(+)$ or absence $(-)$ of RNase A. In both sets of IPs, RIN was among the most abundant proteins identified and was greatly enriched in anti-RIN IPs compared to those performed with a control synthetic antibody, C1 (Laver et al., 2012; Laver et al., 2013; Laver et al., 2015a; Na et al., 2016) (Figure 1B). defined RIN-interactors as proteins that were significantly enriched in the RIN IPs with a SAINT score $\geq 0.95$ and a Bayesian false discovery rate $(B F D R) \leq 0.01$. In addition to RIN itself, 21

164 proteins were enriched in the $(+)$ RNase IPs and 96 proteins were enriched in the $(-)$ RNase IPs

165 (Figure 1C and D; Table S1). Of the 21 RNA-independent interactors, 13 were also positives in the (-) RNase IPs while eight were not. However, based on total peptide counts, five out of these eight were enriched in one of three (-) RNase IP biological replicates; the stronger enrichment in the $(+)$ RNase samples may have been due to decreased background in the control IPs in the presence of RNase.

Consistent with a role for RIN in post-transcriptional regulation in the early embryo, of the total of 104 proteins identified in our RIN IPs, 68\% (71) are known to be involved in posttranscriptional processes (as annotated by FlyBase Release FB2019_06; http://flybase.org/): 36 of them are known RBPs, mRNP complex components or translation factors (Figure 1C and D, highlighted in magenta), while 35 are ribosomal proteins (Figure $1 \mathrm{C}$ and D, highlighted in orange), including $36 \%$ of the small subunit and $39 \%$ of the large subunit proteins (respectively, 14 of 39 and 21 of 54) (Marygold et al., 2007). Overall, 92\% (66) of the RBPs and ribosomal proteins that co-purified with RIN did so in an RNA-dependent manner, including all of the 40S and 60S subunit proteins.

Previous studies have identified sets of RIN/G3BP-interacting proteins in other contexts

181 interactions are conserved in Drosophila embryos. In Drosophila ovaries, RIN has been shown

182 to be in an RNase-resistant complex with ORB (Costa et al., 2005); ORB is absent from embryos

183 (Hafer et al., 2011) and therefore did not co-IP in our experiments. Another mass-spectrometric 184 analysis, which used Dorsal (DL) as a negative control, identified additional RIN-interacting 185 proteins in ovaries (Costa et al., 2013). In that study, of the proteins that they found to IP with 186 RIN but not DL, eight were also present on our early embryo lists: three were RNA-independent 
(FMR1, Lingerer [LIG], Twenty-four [TYF]) and four were RNA-dependent (PABP, RpS24, RpL11, RpL13A). An additional nine proteins on our early embryo lists were found in both their RIN and their DL IPs: one (CAPR) was on our RNA-independent list, and eight were on our RNA-dependent list (Trailer-hitch [TRAL], Cup, Fibrillarin [FIB], RpL3, RpL15, RpLP0, RpLP2, RpS5).

Human G3BPs interact with many of the same proteins in both unstressed and stressed cells (Jain et al., 2016; Markmiller et al., 2018; Youn et al., 2018). We, therefore, compared our list of RIN interactors with G3BP-interactors as well as with SG components identified in recent global proteomic analyses in human cells (Jain et al., 2016; Markmiller et al., 2018; Solomon et al., 2007; Youn et al., 2018) and budding yeast (Jain et al., 2016) (Table S2). 24\% (5/21) of RIN's RNA-independent and 25\% (24/96) of the RNA-dependent interactors had been identified as G3BP interactors in the human datasets. Regarding RIN's RNA-independent interactors, all of the human datasets included CAPR, FMR1 and LIG and one study (Jain et al., 2016) found two additional proteins that were on our RNA-independent list (HSC70Cb, DCTN-p150). None of our RNA-independent interactors overlapped with budding yeast SG components while seven of the proteins on our RNA-dependent list overlapped (PABP, TRAL, LARP, RUMP, eIF3b, eIF4E1, RpS30). Finally, regarding our RNA-dependent list, 84\% of the proteins that overlapped with the human or yeast datasets are RBPs/translation factors (21/25).

G3BP interacts with the 40S (but not the 60S) ribosomal subunit in the context of SGs and their formation (Kedersha et al., 2016). Interestingly, our data showed that RIN interacts with multiple proteins from both the 40S and 60S subunits in early embryos, which lack SGs. Since these RIN interactions were RNase sensitive, one possibility is that, in early embryos, RIN binds to mRNAs that are actively translated, and thus the ribosomes transiting these mRNAs copurify with RIN. To assess whether RIN is associated with polysomes, we ran early embryo extracts on sucrose gradients treated with cycloheximide (which stabilizes the interaction of ribosomes with mRNAs) or puromycin (which disrupts mRNA-ribosome associations), followed by western blotting with an anti-RIN antibody (Aguilera-Gomez et al., 2017) (Figures 1E and S3). These experiments showed that a subset of RIN is polysome-associated.

Taken together, our data confirm that numerous RIN/G3BP-partner protein interactions occur under both non-stress and stress conditions, and are conserved in Drosophila, yeast and 
217 human cells. Furthermore, unlike in stressed cells, in early embryos RIN is found on polysomes.

218 A possible role for RIN in mRNA translation and stability is investigated below.

$\underline{\text { RIN associates with hundreds of mRNA species in the early embryo }}$

To identify mRNAs associated with RIN in 0-3 h embryos, we used the D072 anti-RIN synthetic antibody to carry out RNA co-immunoprecipitations followed by microarray analysis (RIP-Chip). Significance Analysis of Microarrays (SAM) (Tusher et al., 2001) identified the mRNAs encoded by 566 genes that were enriched at least two-fold and with an FDR $<5 \%$ in RIN IPs compared to control IPs performed with the C1 antibody. We defined these as RINassociated mRNAs (Figure S4; Table S3).

Given that no global analyses of endogenous mRNAs associated with Drosophila RIN

228 had been carried out previously, we validated our set of RIN-associated transcripts in two ways.

229 First, we performed two additional biological replicate RIPs using the anti-RIN antibody (D072)

230 and control antibody described above, after which reverse transcription followed by quantitative

231 polymerase chain reaction (RT-qPCR) was used to quantify five highly enriched RIN-associated

232 mRNAs and four mRNAs not associated with RIN according to our RIP-Chip experiments. The

233 five putative RIN-associated mRNAs were two- to seven-fold more enriched in the RIN versus

234 control RIP-RT-qPCR than were the non-target mRNAs (Figure S5). Second, we generated an

235 additional synthetic antibody, designated D074, against the NTF2-like domain of RIN (Figure

236 1A), which we used to perform RIP-Chip, and compared the average fold-enrichment of

237 transcripts in the initial anti-RIN D072 RIP-Chip to the fold-enrichments in the RIP-Chip

238 performed with D074. The results were consistent with the initial RIP-Chip data, with Spearman 239 correlation rho value for the comparison of fold enrichments of $0.79\left(P<10^{-15}\right)$ (Figure S6).

241 RIN-associated mRNAs are short and enriched for the RIN RRM's in vitro binding-motif

242 Next we assessed the properties of RIN-associated transcripts. Strikingly, we found that

243 RIN-associated mRNAs in early embryos are significantly shorter than co-expressed unbound

244 transcripts with the Area Under the Receiver Operating characteristic (AUROC) $=0.83\left(P<10^{-10}\right.$;

245 Figure 2A). The ROC graphs the diagnostic ability of a binary classifier by plotting the true-

246 positive rate versus the false-positive rate; no diagnostic ability gives an AUROC of 0.5 while 
perfect ability gives an AUROC of 1.0. For the Mann-Whitney $U$ test, the AUROC is equivalent to the $U$ statistic divided by the product of the numbers of targets and non-targets.

To assess whether enrichment of short mRNAs might be an artefact of our RIP-chip method, we reanalyzed our previously published data for three other RBPs - Brain tumor,

251 Pumilio, and Staufen (endogenous Staufen and transgenic GFP-Staufen) - for which we used the 252 same method and microarray platform (Laver et al., 2013; Laver et al., 2015a). For all four RIP253 Chip datasets (Table S4) - in contrast to the RIN RIP-Chip dataset - there was either enrichment for long mRNAs relative to co-expressed unbound transcripts (Figure S7A, B, D) or no length difference (Figure S7C). We conclude that short mRNAs do indeed co-purify with RIN.

To identify features other than transcript length that distinguish RIN-associated mRNAs,

257 we performed de novo motif discovery using \#ATS, a discriminative tool that searches for sequence motifs that are enriched in targets versus non-targets, in computationally predicted single-stranded regions ( $\mathrm{Li}$ et al., 2010). We failed to discover a consistent and significant motif in RIN targets compared to length-matched co-expressed non-targets (Table S5). and in vitro (Cook et al., 2011; Ray et al., 2013) studies. G3BP-family proteins are characterized 263 by a single RNA-recognition motif (RRM), which was used for the in vitro analyses (Cook et al., 264 2011; Ray et al., 2013). To assess whether any of these motifs were enriched in RIN-associated 265 mRNAs, we used position frequency matrices (PFMs) from those studies together with

266 RNAplfold, where the latter was used to define motif matches that were single-stranded and thus 267 available for RBP binding (Bernhart et al., 2006; Li et al., 2010). For each motif, we tested its 268 ability to distinguish RIN-associated (positive) transcripts from length-paired, co-expressed, non269 RIN-associated (negative) transcripts, by ranking transcripts with the maximum "hit score" 270 achieved for that motif, across all subsequences of a transcript (i.e., the best possible 271 subsequence resembling the motif sequence in a context that is predicted to be single-stranded).

272 We performed this test using three RIN fold-enrichment (FE) cut-offs $(>2,>2.5$ and $>3$ ) and four 273 transcript regions (5'UTR, CDS, 3'UTR, full mRNA), and repeated each FE and region pair 1000 274 times with length-matched negatives randomly selected each time. We assessed how well the 275 four motifs performed on samples from each FE cut-off and transcript region by the number of 276 Mann-Whitney $U$ tests that were significant (with $P<0.05$ ), and the mean and standard 277 deviation of the AUROC. We found that the in vitro RIN motif (Figure 2B) was significantly 
278 enriched in RIN-associated full mRNA sequences with the mean AUROC increasing with FE 279 from 0.54 at $\mathrm{FE}>2.0$ to 0.61 at $\mathrm{FE}>3.0$ (Figure 2C, Table S6). The motif was most enriched in

280 the open reading frame, with the mean AUROC increasing from 0.56 at FE $>2.0$ to 0.61 at FE $>$

2813.0 (Figure 2C), and 105 more motifs found in targets versus length-matched non-targets (Figure

282 2D). None of the motifs for the human G3BPs - defined either in vitro or in vivo-was enriched

283 (Table S6).

284 We conclude that the major feature of RIN-binding in vivo is short transcript length

285 (AUROC $=0.83$ ) with an additional, more minor, contribution from the motif (AUROC 0.55 to

286 0.61).

$\underline{\text { RIN-associated mRNAs are stable, translated, and depleted for Smaug recognition elements }}$

To gain insight into the effect RIN might have on the expression of its target mRNAs, we examined datasets that define the translational status (determined by ribosome occupancy) and abundance of the Drosophila transcriptome during late oogenesis and early embryogenesis, and asked whether RIN-association correlated with any particular patterns of post-transcriptional

293 outcome. We focused on the data from mature (Stage 14) oocytes and two embryonic stages that 294 overlap with the time window in which we carried out our RIP-chip: $0-1 \mathrm{~h}$ and $2-3 \mathrm{~h}$ postfertilization

First, we examined the abundance of RIN-bound mRNAs and of co-expressed, unbound mRNAs (Eichhorn et al., 2016). Whereas the median abundance of these two classes of transcripts was similar in mature oocytes and $0-1 \mathrm{~h}$ embryos, there was a striking change moving

299 from 0-1 h embryos to 2-3 h embryos: non-target mRNAs significantly decreased in abundance 300 (2.2-fold decrease in median RPKM, Wilcoxon rank-sum $\left.P<10^{-150}\right)$ whereas levels of RIN301 associated transcripts increased significantly (1.4-fold increase in median RPKM, Wilcoxon 302 rank-sum $P<10^{-3}$ ) (Figure 3A). This difference was maintained in 3-4 and 4-5 h embryos

303 (Figure S8). Since RIN-associated mRNAs are short, we also carried out abundance analyses 304 relative to length-matched non-targets and found that RIN-bound mRNAs are more stable at 2-3 305 hours even when length is taken into account (Figures 3B, S9).

306 The first three hours of embryogenesis encompass most of the Drosophila maternal-to307 zygotic transition, during which many maternally supplied mRNAs are degraded and the zygotic 308 genome becomes transcriptionally active (Tadros and Lipshitz, 2009; Vastenhouw et al., 2019). 
Transcripts present in the early embryo have been classified according to their maternal and/or zygotic origin, as well as their patterns of stability or decay (De Renzis et al., 2007; Tadros et al.,

311 2007; Thomsen et al., 2010). To understand how the abundance of RIN-associated transcripts

312 described above reflects changes in levels of maternal or zygotic mRNAs, we compared RIN313 associated mRNAs to these various classes. RIN-associated transcripts were enriched for two of

314 these classes: maternally supplied transcripts that remain stable through the MZT and are not 315 transcribed in the embryo (Class I in Thomsen et al., 2010); Fisher's exact test $P<10^{-11}$, odds ratio 2.0), and maternally supplied transcripts that remain stable and are also zygotically transcribed ('Stable + Transcription' in Thomsen et al., 2010) (Fisher's exact test $P<10^{-27}$, odds ratio 3.2). However, RIN-associated mRNAs were strongly depleted for maternally supplied transcripts that are degraded (Classes II-V in Thomsen et al., 2010) (Fisher's exact test $P<10^{-48}$, odds ratio 0.24 ) including those that are degraded and subsequently re-transcribed (Class III in Thomsen et al., 2010) (Fisher's exact test $P<10^{-7}$, odds ratio 0.20 ). Consistent with these results, examination of two additional datasets, which defined mRNAs that are maternally supplied and degraded, revealed depletion of RIN-associated mRNAs among transcripts that are 324 degraded in unfertilized eggs (Tadros et al., 2007) (Fisher's exact test $P<10^{-17}$, odds ratio 0.26) 325 or in early embryos (De Renzis et al., 2007) (Fisher's exact test $P<10^{-54}$, odds ratio 0.12 ). These comparisons therefore indicate that the dynamics of RIN-associated transcript levels in early embryos, described above, largely reflect RIN binding to stable, maternally supplied transcripts.

Next, to assess the translational efficiency of RIN-associated mRNAs we used a dataset that measured this parameter using ribosome 'footprinting' (Eichhorn et al., 2016) This revealed that RIN-associated mRNAs had significantly higher translational efficiency than co-expressed, 331 non-target mRNAs in both mature oocytes and early embryos, suggesting a possible role for RIN 332 in potentiating translation. The largest and most significant difference was in $0-1 \mathrm{~h}$ embryos 333 where the median translational efficiency of RIN-associated mRNAs was four-fold higher than 334 that of non-target mRNAs (dashed blue and red lines, respectively, in Figure 4A; Wilcoxon ranksum $P<10^{-100}$ ). Whereas the translational efficiency of RIN-associated mRNAs showed a

336 significant increase moving from mature oocytes to $0-1 \mathrm{~h}$ embryos (1.6-fold increase, Wilcoxon 337 rank-sum $P<10^{-17}$ ), the translational efficiency of co-expressed, non-target mRNAs decreased 338 over the same stages. At earlier stages of oogenesis (Stages 11-13) as well as at later embryonic 339 time points (3-4 and 4-5 h), RIN-bound transcripts also consistently exhibited higher 
translational efficiency than co-expressed unbound transcripts (Figure S8). The positive correlation between an mRNA's association with RIN and its translational activity was supported

342 by comparisons to an additional dataset that used ribosome footprinting to assess transcriptome-

343 wide mRNA translation in early embryos (Dunn et al., 2013) (Figure S10). Since RIN-associated mRNAs are short, we also carried out analyses of translational efficiency relative to lengthmatched non-targets and found that RIN-bound mRNAs have higher translational efficiency at all timepoints even when length is taken into account (Figure 4B, S11).

The Smaug RBP, which binds hairpin structures known as Smaug recognition elements (SREs), is a well-characterized negative regulator of both mRNA stability and translation (Chen et al., 2014; Pinder and Smibert, 2013; Semotok et al., 2005; Semotok et al., 2008; Smibert et al., 1996; Tadros et al., 2007). Since RIN-bound mRNAs are stable and translated in early embryos

351 it was of interest to assess whether they might be depleted for SREs. We therefore calculated an SRE 'score' (Chen et al., 2014) for RIN-associated mRNAs relative to length-matched, coexpressed mRNAs, and found that RIN-bound mRNAs were strikingly depleted of SREs (Table 354 S7).

A final feature that we examined was $\mathrm{N}^{6}$-methyladenosine $\left(\mathrm{m}^{6} \mathrm{~A}\right)$ modification of RIN's targets, since it has been reported that $\mathrm{m}^{6} \mathrm{~A}$ "repels" G3BP1 binding (Edupuganti et al., 2017). If so, then RIN-bound transcripts would be expected to be depleted for $\mathrm{m}^{6} \mathrm{~A}$. Recently, $\mathrm{m}^{6} \mathrm{~A}$ modifications have been mapped transcriptome-wide at several Drosophila embryonic stages (Kan et al., 2017). We, therefore, compared RIN-bound transcripts to this last study's $\mathrm{m}^{6} \mathrm{~A}$ transcriptome data from $0-45$ ', 45-90' and 1.5-6 h embryos. In all cases and for all transcript regions (5'UTR, ORF, 3'UTR), there was neither significant enrichment nor significant depletion

362 of $\mathrm{m}^{6} \mathrm{~A}$-modified transcripts among RIN's targets (Fisher's exact test $P$ values ranged from 0.15

363 to 1 ). We conclude that there is no evidence for a role - either positive or negative - of $m^{6} \mathrm{~A}$ in

364 determining RIN targets in early embryos.

Taken together, our data support a model in which RIN binds to maternally supplied transcripts, stabilizes them at the stage of the MZT when many other maternally supplied mRNAs are degraded and potentiates their translation. 
Human and yeast SG transcripts are long (Anderson and Kedersha, 2009a, b; Buchan and Parker, 2009; Kedersha and Anderson, 2009; Khong et al., 2017; Namkoong et al., 2018). As

373 described above, in contrast, RIN-associated mRNAs in early embryos are significantly shorter 374 than co-expressed unbound transcripts (Figure 2A). The high levels of translation of RINassociated transcripts in the early Drosophila embryo also contrasts with the translationally silent transcripts found together with G3BPs in SGs (Anderson and Kedersha, 2009a, b; Buchan and Parker, 2009; Kedersha and Anderson, 2009).

To ask whether the RIN-associated transcripts are likely to be recruited to SGs under different conditions or, instead, represent a separate pool of RIN-associated mRNAs, we took advantage of recent reports that define SG transcriptomes in yeast and human cells. We compared our list of RIN-associated mRNAs to the Drosophila homologues of transcripts found to be either enriched in or depleted from human U2OS SGs (Khong et al., 2017): RIN-associated Drosophila mRNAs were significantly depleted for homologous SG-enriched transcripts (Fisher's exact test $P<10^{-7}$, odds ratio 0.45$)$ but enriched for SG-depleted transcripts $\left(P<10^{-29}\right.$, odds ratio 3.2). Likewise, RIN-associated mRNAs were significantly depleted for transcripts homologous to those that undergo localization to RNA granules under ER stress (Fisher's exact test $P<10^{-4}$, odds ratio 0.49 ), heat shock (Fisher's exact test $P<10^{-7}$, odds ratio 0.55 ), or arsenite treatment (Fisher's exact test $P<10^{-8}$, odds ratio 0.49) in NIH3T3 cells (Namkoong et al., 2018). The observed enrichment or depletion of these classes in RIN-bound transcripts is consistent with the fact that the fly homologs of SG-enriched or -depleted transcripts show the same length distribution as the human transcripts (Figure S12).

In addition to these comparisons, we compared the length and translational efficiency of the Drosophila homologs of mammalian mRNAs that are either enriched in or depleted from

394 SGs. We found that, whereas there was no significant correlation of low translational efficiency

395 and length of the fly homologs of SG-enriched transcripts, there was a significant negative 396 correlation between length and translational efficiency of the fly homologs of SG-depleted 397 transcripts (Figure S13).

Taken together, these analyses are consistent with the hypothesis that the transcripts with which RIN associates in early embryos are a separate pool from those typically found in SGs. 
We next asked what biological and molecular functions RIN might control in early embryos, by searching for Gene Ontology (GO) terms enriched among the proteins encoded by

404 the RIN-associated mRNAs, using the DAVID functional annotation tool (Huang da et al., 405 2009a; Huang da et al., 2009b) (Table 1; Table S8). This revealed striking enrichment for roles in regulation of gene expression and in mitochondrial function.

With regard to the regulation of gene expression, RIN's targets included mRNAs encoding proteins involved in multiple levels of control, most notably transcription, pre-mRNA splicing, and translation. Among those involved in transcription were mRNAs encoding general transcription factors, including four subunits of the TFIID complex (Taf1, Taf10b, Taf12, Taf13),

411 both of the subunits of the TFIIA complex (TfIIA-S, TfIIA-L), six subunits of the 'mediator' 412 transcriptional co-activator complex (MED4, 7, 11, 21, 26, 28), histone modifiers, and

413 transcription factors with important roles in the activation of zygotic transcription, such as Zelda 414 and Stat92E. mRNAs associated with RIN that encode splicing-related factors included a number 415 of spliceosome subunits as well as regulators of pre-mRNA splicing, such as transformer and transformer 2. Finally, with regard to translation, RIN-associated mRNAs were enriched for

417 those encoding protein components of both the cytosolic ribosome (12 large subunit, 2 small 418 subunit) and the mitochondrial ribosome (15 large subunit, 8 small subunit). In addition, mRNAs 419 that encode all five subunits of the 'Ragulator' complex were found to be RIN-associated.

420 Ragulator regulates activation of the TOR pathway in response to amino acid availability (Bar421 Peled et al., 2012; Sancak et al., 2010).

422 With regard to mitochondria, in addition to the transcripts encoding 23 mitochondrial 423 ribosomal proteins, RIN-associated mRNAs were strongly enriched for transcripts encoding 424 proteins involved in the mitochondrial electron transport chain. Indeed, RIN was associated with 42530 nuclear-encoded mRNAs for proteins that are either components of the mitochondrial 426 respiratory chain Complexes I to V or involved in their assembly. Additional mRNAs associated 427 with RIN included those encoding components of the mitochondrial contact site and cristae428 organizing system (MICOS) complex, which acts to maintain mitochondrial cristae and 429 membrane architecture, and FIS1, which has a role in promoting mitochondrial fission.

430 We next examined each of the GO-term-enriched classes in detail. Strikingly, we found 431 that the vast majority of transcripts in each category tended to be enriched in the RIN IP, albeit 432 not to the level of statistical significance (i.e., tended to be to the right of ' 0 ' on the $x$-axis; in 
433 Figure 5 compare transcripts associated with RIN, highlighted in blue, and transcripts that fell

434 below the cut-off used to define RIN-associated mRNAs, highlighted in red). Notably, there was

435 also a clear negative correlation between transcript length and RIN-binding in each GO-term

436 class (i.e., the 'blue' transcripts tended to be shorter than the 'red' transcripts), indicating that the

437 correlation of RIN-association with shorter transcript length is independent of the function of the

438 bound mRNAs. Finally, the 'red' transcripts in each GO-term class tended to have similar

439 translational efficiency and stability to the RIN-bound ('blue') transcripts in that class, albeit

440 again not to as great an extent (Figure S14. These results suggest that RIN's role in binding and

441 regulating mRNAs that encode core components of transcription, splicing, translation and

442 mitochondria is more pervasive than predicted only from examination of its most highly bound

443 targets.

444 Together, these analyses lead to the hypothesis that RIN plays a global role in binding

445 and potentiating the stability and translation of mRNAs that encode core components of gene

446 expression and mitochondria in early embryos. Our analyses below of rin-mutant ovaries as well

447 as our tethering studies in S2 cells, suggest that RIN/G3BP may play a similarly positive post-

448 transcriptional role in additional cell types.

Levels of RIN's target transcripts are reduced in rin mutants

451 To assess the consequences of removal of endogenous RIN on the expression of RIN's

452 target mRNAs, we produced females trans-heterozygous for two previously identified rin alleles, $453 \operatorname{rin}^{2}$ (Pazman et al., 2000) and $\operatorname{rin}^{3}$ (Costa et al., 2013) (i.e., of genotype $\operatorname{rin}^{2} / \mathrm{rin}^{3}$ ) and used as

454 controls females that were either $\mathrm{rin}^{2} /+$ or $\mathrm{rin}^{3} /+$. We selected for analysis thirteen mRNAs that

455 were highly enriched in the RIP-chip experiments, five that were unchanged, and seven that were 456 depleted (Table S9). We used RT-qPCR to analyze transcript levels in at least three biological

457 replicates from ovaries rather than embryos in order to exclude secondary effects in embryos

458 from the mutant (Costa et al., 2013). Expression was normalized to the average of the transcripts

459 with no enrichment for RIN association and the change in expression of the depleted, non-

460 enriched, and enriched groups was compared pair-wise between $\mathrm{rin}^{2} / \mathrm{rin}^{3}$ mutant ovaries and

461 control ovaries using the two-tailed Wilcoxon signed-rank test. Transcripts depleted for RIN

462 binding and transcripts non-enriched for RIN binding did not show a significant change in

463 expression in mutant ovaries compared to control $(\mathrm{z}=0.82, P=0.41$ and $\mathrm{z}=0.12, P=0.90$, 
respectively). In contrast, transcripts enriched for RIN-binding showed a significant decrease in expression levels in mutant ovaries relative to control $\left(\mathrm{z}=3.63, P<3 \times 10^{-4}\right)$ (Table S9). These

466 data are consistent with the hypothesis that RIN acts as a potentiator of the stability of its 467 maternal mRNA targets.

$\underline{\text { RIN and G3BP potentiate mRNA stability and translation in } \mathrm{S} 2 \text { tissue culture cells }}$

Finally, to experimentally test the prediction that RIN is a potentiator of mRNA stability and translation, we tethered FLAG-tagged full-length RIN protein fused to BIV-Tat to a

472 luciferase reporter mRNA containing six tandem BIV-TAR elements in its 3'UTR (Wakiyama et al., 2012) in Drosophila S2 tissue culture cells (Figure 6A). BIV-Tat-FLAG-RIN behaved the same way as endogenous RIN (Aguilera-Gomez et al., 2017): under non-stress conditions it was ubiquitously distributed in the cytoplasm and co-localized with CAPR (Figure S15). The fact that BIV-Tat-FLAG-RIN was ubiquitously distributed in the cytoplasm of unstressed cells is consistent with a report that overexpression of RIN in Drosophila S2 cells does not induce SGs (Aguilera-Gomez et al., 2017), and permitted us to assess the role of RIN in regulating target mRNA expression outside SGs.

Tethering RIN resulted in a $\sim 2.4$-fold increase in luciferase protein levels compared to a negative control in which a BIV-Tat-FLAG-GFP fusion protein was tethered to the same reporter (Figure 6B). To determine whether this increase in luciferase levels might be a result of increased translation, increased mRNA levels, or both, we also assayed luciferase mRNA levels. This revealed that RIN tethering resulted in a 1.9-fold increase in mRNA levels compared to the control (Figure 6C). These data show that RIN stabilizes the reporter mRNA and, because the relative increase in luciferase protein levels was greater than the relative increase in luciferase mRNA levels, are also consistent with a role for RIN in stimulation of translation.

We next assayed the expression levels of Tat-tagged RIN and GFP via western blot and 489 found that GFP was expressed at significantly higher levels (Figure 6D). To assess whether the 490 differential behavior of the TAR reporter in the presence of tethered RIN versus GFP could be 491 explained by this difference in protein levels, we reduced the level of GFP plasmid transfected 492 into cells, while keeping the levels of the RIN plasmid constant. This reduced the expression of 493 GFP to levels equivalent to those seen for RIN (Figure 6E). When we compared luciferase 494 expression in this experiment, the fold enhancement in luciferase expression mediated by 
tethered RIN was 3.4-fold (Figure 6F), confirming that tethered RIN enhances reporter expression.

To determine whether this might represent a conserved function of RIN, we tested the effect of tethering human G3BP1 or G3BP2 to the reporter mRNA in S2 cells. As was the case for BIV-Tat-FLAG-RIN, BIV-Tat-FLAG-G3BPs were ubiquitously distributed in the cytoplasm

500 (Figure S15). Tethering either G3BP1 or G3BP2 led to increased levels of both luciferase protein 501 and luciferase mRNA similar to those observed for RIN (Figure 6B, C). Thus, potentiation of mRNA stability and translation represent conserved functions of the RIN/G3BP family of

503 proteins in unstressed cells.

\section{DISCUSSION}

We have used a combination of IP-MS, polysome gradients, RIP-chip, computational analyses, RT-qPCR in mutants, and tethering experiments in tissue culture cells, to define RIN's

508 protein partners and bound mRNAs, and to elucidate RIN's role as a post-transcriptional regulator in embryos and unstressed tissue-culture cells. Together our experiments have shown

510 that Drosophila RIN and human G3BPs function to potentiate the stability and translation of

511 bound mRNAs, contrasting with the repressive role of these RBPs in stressed cells.

\section{$513 \quad$ Features of RIN-bound transcripts}

514 Two features, short transcript length and the motif bound by the RIN RRM in vitro, are 515 predictive of RIN binding. That short transcripts in general might be more likely to contain the

516 motif, is excluded by the fact that RIN's target mRNAs are enriched for the motif when

517 compared to length-matched, co-expressed, unbound mRNAs. Thus, we propose that each

518 feature separately contributes to RIN target mRNA binding, with shortness playing a greater role 519 than the motif (AUROC $=0.83$ and $0.55-0.61$, respectively).

520 While it is unclear how RIN is able to measure transcript length, there is precedent for the 521 differential behaviour/regulation of short versus long mRNAs. For example, in general short 522 mRNAs are more highly translated than long mRNAs and this is thought to reflect the fact that 523 short mRNAs have a higher affinity for the cap-binding complex (Costello et al., 2015;

524 Thompson and Gilbert, 2017). It has been proposed that this higher affinity is related to the 525 possibility that short mRNAs are able to form a closed-loop structure more readily than longer 
mRNAs. We note that a recent study that calls the closed-loop model into question was unable to test short mRNAs because of technical limitations (Adivarahan et al., 2018). Thus, even if long mRNAs do not form a stable closed loop, it remains possible that short mRNAs do.

The ribosome-associated protein, RACK1, has been shown to be required for the efficient translation of short but not long mRNAs (Thompson et al., 2016). Although we have shown here

531 that RIN is associated with polysomes in early embryos, Drosophila RACK1 is not on our list of

532 RIN protein interactors, neither is there a significant overlap between our RIN protein interaction 533 network and a set of protein interactors previously identified for RACK1 (Kuhn et al., 2017).

534 Thus, the mechanisms by which RIN recognizes short mRNAs may differ from those that have 535 been identified previously.

Another striking feature of RIN-bound mRNAs is that they are depleted for SREs, the

537 binding sites of SMG. SMG destabilizes and translationally represses its target mRNAs. This

538 could suggest that the high translational efficiencies and stability of RIN-target mRNAs is

539 simply a result of a lack of SREs. However, we have provided evidence that RIN can exert its

540 effects in situations where SMG protein is not present (i.e., during oogenesis, in embryos older

541 than 3 hours, and in S2 cells). Thus we conclude that most RIN-bound mRNAs in the early

542 embryo are upregulated directly by RIN and indirectly through a lack of SREs.

$\underline{\mathrm{RIN}}$ as a direct and indirect potentiator of gene expression

Since the target mRNAs of RIN are enriched for GO terms related to multiple levels of

546 the core gene expression machinery - transcription, splicing, and translation — RIN may

547 directly potentiate expression of its bound target transcripts and, in so doing, also indirectly

548 upregulate gene expression globally. As an example of how RIN/G3BP's direct and indirect

549 effects might converge on the same cellular process, we consider the production of cytoplasmic

550 ribosomes. Metabolic labelling with radioactive amino acids has shown that cytoplasmic

551 ribosomal protein (cRP) synthesis increases after fertilization, peaks at 3-4 hours, and

552 subsequently decreases (Santon and Pellegrini, 1980, 1981). Recent ribosome footprinting-based

553 measurements have confirmed that the translational efficiency of cRP mRNAs increases in early

554 embryos relative to mature oocytes (Eichhorn et al., 2016). We have shown here that RIN

555 potentiates target mRNA stability and translation and that cRP mRNAs are highly enriched

556 among RIN's targets; thus, potentiation of cRP mRNAs is expected to be a direct effect of RIN. 
cRP mRNAs are also regulated by their conserved 5'-terminal oligopyrimidine (TOP) motifs (Meyuhas and Kahan, 2015). Two RBPs, La and Larp1, have been implicated in regulation of the stability and/or translation of 5'TOP mRNAs via this motif (Cardinali et al.,

560 2003; Crosio et al., 2000; Fonseca et al., 2018; Pellizzoni et al., 1996; Tcherkezian et al., 2014).

561 We have shown here that the Drosophila orthologs of both of these RBPs - LA and LARP-

562 associate with RIN in an RNA-dependent manner. This could reflect the fact that LA, LARP and

563 RIN co-bind cRP mRNAs and, thus, that this class of mRNAs is subject to multiple direct

564 mechanisms that potentiate its expression. Noteworthy is the fact that, of our RIN target mRNAs,

565 only the cRP transcripts carry 5'TOP motifs and, as such, these represent a distinct class of 566 mRNAs.

567 A possible indirect role of RIN in regulation of $\mathrm{cRP}$ mRNAs relates to their upregulation

568 by the Ragulator complex (Damgaard and Lykke-Andersen, 2011; Wilbertz et al., 2019). We

569 have shown here that RIN binds mRNAs encoding all five subunits of the Ragulator complex.

570 Thus, positive regulation by RIN of Ragulator subunit synthesis could indirectly promote cRP 571 mRNA translation.

572 Direct and indirect regulation of other aspects of gene expression by RIN are also likely.

573 Potentiation of production of core components of the transcription and splicing apparatus, as well

574 as of the translation machinery, might ensure that none of these becomes rate-limiting for gene

575 expression in rapidly developing early embryos. Likewise, adequate ATP production would be

576 ensured by potentiation of expression of mitochondrial ribosomal proteins and components of the 577 electron transport chain.

578 That said, our data suggest that the direct effects of RIN are much more pronounced than

579 its indirect effects. Specifically, we have shown that, in rin mutants, levels of several target

580 mRNAs are significantly reduced whereas co-expressed non-targets do not change significantly.

581 It should be noted however, that these analyses were of a small subset of targets; global analyses

582 - which fall outside the scope of the current study - might reveal that indirect targets also

583 change significantly.

$\underline{\text { A new function for RIN/G3BP sequestration into stress granules }}$

$586 \quad$ Our data have important implications for our understanding of how cells respond to stress

587 and the role of SGs in that response. A theme in the cellular stress response is a general 
588 downregulation of mRNA expression. For example, stress triggers eIF2 $\alpha$ phosphorylation, which

589 prevents translation initiation (reviewed in Panas et al., 2016). This in turn triggers polysome

590 disassembly, resulting in SG assembly. The storage of long mRNAs in SGs serves as a further

591 mechanism to downregulate their translation. Based on our results we propose that the

592 recruitment of RIN/G3BPs into SGs would sequester these proteins from their short target

593 mRNAs in the cytoplasm, serving to downregulate the expression of these transcripts. This could

594 indirectly downregulate global gene expression by limiting the production of proteins involved in

595 translation, transcription and splicing, Likewise, if RIN/G3BPs serve to upregulate mitochondrial

596 function and ATP production, sequestration could attenuate this aspect of cellular metabolism in

597 stressed cells.

\section{Acknowledgements}

600 We thank the three anonymous reviewers for helpful feedback regarding the manuscript, and the

601 following for providing antibodies: Liz Gavis (anti-RIN) (Aguilera-Gomez et al., 2017) and Paul

602 Macdonald (anti-CAPR) (Papoulas et al., 2010). The anti-FMR1antibody (5A11) developed by

603 H. Siomi was obtained from the Developmental Studies Hybridoma Bank, created by the

604 NICHD of the NIH and maintained at The University of Iowa, Department of Biology, Iowa

605 City, IA 52242. During the course of this research, we made extensive use of FlyBase and data

606 from the Berkeley Drosophila Genome Project. This research was supported by grants from the

607 Natural Sciences and Engineering Research Council Discovery Grants to H.D.L. (RGPIN-

608 06246) and to C.A.S. (RGPIN-435985), and from the Canadian Institutes for Health Research to

609 Q.M. (MOP-125894).

610

611 Author contributions

612 Conceptualization: J.D.L, C.A.S. and H.D.L.; Methodology: J.D.L., C.A.S., H.D.L., S.A., Q.M.,

613 S.S.S and J.T.W.; Investigation: J.D.L., J.L., A.K.W., S.L., A.K., G.B., W-X.C., N.J-L. and

614 A.K.; Software and Formal Analysis: K.L., J.D.L. and Q.M.; Writing — Original Draft: J.D.L.,

615 J.L.; Writing - Review and Editing: H.D.L. and C.A.S.; Funding Acquisition: H.D.L., C.A.S

616 and Q.M.; Resources: S.A., S.S.S. and J.T.W; Supervision: C.A.S., H.D.L., S.A. and Q.M.

617

618 Declaration of interests 
bioRxiv preprint doi: https://doi.org/10.1101/2020.01.21.913079; this version posted January 21, 2020. The copyright holder for this preprint (which was not certified by peer review) is the author/funder. All rights reserved. No reuse allowed without permission.

619 The authors declare no competing interests. 
621 Table 1. Representative GO terms enriched among proteins encoded by RIN-associated mRNAs.

623

\begin{tabular}{|l|l|l|l|}
\hline $\begin{array}{l}\text { Enriched function or } \\
\text { complex }\end{array}$ & Representative GO terms & $\begin{array}{l}\text { Fold- } \\
\text { enrichment }\end{array}$ & FDR (\%) \\
\hline \multirow{2}{*}{ Oxidative phosphorylation } & $\begin{array}{l}\text { oxidative phosphorylation } \\
\text { (GO:0006119) }\end{array}$ & 4.32 & $2.80 \times 10^{-5}$ \\
\cline { 2 - 4 } & $\begin{array}{l}\text { respiratory chain complex } \\
\text { (GO:0098803) }\end{array}$ & 4.21 & $2.92 \times 10^{-5}$ \\
\hline \multirow{2}{*}{ Ribosome } & $\begin{array}{l}\text { mitochondrial ribosome } \\
\text { (GO:0005761) }\end{array}$ & 3.43 & $3.63 \times 10^{-4}$ \\
\cline { 2 - 4 } & $\begin{array}{l}\text { cytosolic large ribosomal subunit } \\
\text { (GO:0022625) }\end{array}$ & 2.65 & 5.81 \\
\hline Ragulator complex & Ragulator complex (GO:0071986) & 11.02 & 0.44 \\
\hline \multirow{2}{*}{ Transcription } & $\begin{array}{l}\text { DNA-templated transcription, } \\
\text { initiation (GO:0006352) }\end{array}$ & 2.56 & 0.52 \\
\cline { 2 - 5 } & histone acetylation (GO:0016573) & 2.35 & 9.11 \\
\hline mRNA splicing & RNA splicing (GO:0008380) & 1.75 & 1.78 \\
\hline
\end{tabular}

624

625 


\section{FIGURE LEGENDS}

polysome associated. (A) The domain structure of Drosophila RIN and its human orthologs G3BP1 and G3BP2. Synthetic antibodies used in this study were generated against antigens

631 consisting of regions of RIN encompassing the NTF2 domain, as indicated. (B) Total RIN

632 peptide counts in IPs using the anti-RIN antibody D072, or the C1 control antibody,

633 demonstrating that RIN is efficiently and specifically immunoprecipitated from early embryos.

634 (C and D) RIN IP-MS results depicted as dotplots generated using the ProHits-viz web server

635 (Knight et al., 2017). Shown are proteins identified as RIN interactors by analysis of IP-MS data using SAINT, defined as those with a SAINT score $\geq 0.95$ and BFDR $\leq 0.01$. In (C) are proteins identified as RNA-independent interactors (scored as significant in IPs (+) RNase), and in (D) are proteins identified as RNA-dependent interactors (scored as significant in IPs (-) RNase but not (+) RNase). The shade of the dot fill represents protein abundance in the RIN IPs minus control IPs, based on total peptide counts, and the shade of the dot outline represents the SAINT score, as indicated in the legend at the bottom of panel (C). Protein names highlighted in

642 magenta indicate those that are known RBPs, mRNP complex components, or translation factors, and orange highlighting indicates ribosomal proteins. (E, F) Embryo extract treated with either cycloheximide (E) or puromycin (F) was fractionated on sucrose gradients, with the resulting fractions assayed for RIN via western blot.

648 binding-motif. (A) Plot showing the relationship between transcript length and association with 649 RIN, for all genes with transcripts represented on the microarray that were defined as expressed 650 in early embryos. Transcript length for each gene is taken to be the length of the longest 651 annotated transcript isoform, and RIN association is represented by the fold-enrichment in the 652 RIN RIP-Chip versus control RIP-Chip of the most highly enriched probe set on the microarray 653 for each gene. Genes encoding RIN-associated transcripts (defined as enriched $>2$-fold in RIN 654 RIP versus C1 RIP with FDR < 5\%) are highlighted in blue. Co-expressed RIN non-targets 655 (defined as $\log _{2}$ fold-enrichment in RIN versus C1 RIPs $<0$ ) are highlighted in red. Gene length 656 distributions of RIN targets and non-targets are shown in the density plots at the top. AUROC 
and $P$ value of Mann-Whitney $\mathrm{U}$ test on transcript lengths of RIN targets and non-targets is shown on the plot. (B-D) The in vitro RIN motif from RNAcompete (Ray et al., 2013) (B) is significantly enriched in the coding sequences of RIN-associated mRNAs (C, D). (C) Table showing the number, AUROC and range of nominal $P$ values of significant tests out of 1000 trials with randomly selected targets and length-paired non-targets. (D) Plot showing the difference in number of RIN motifs in the 3'UTR, CDS and 5'UTR of RIN-associated transcripts versus randomly selected co-expressed length-paired RIN non-targets for each region. The total number of RIN motifs (defined as sites with "hit score" > 0.001) in targets and non-targets for each region are grouped into 20 bins. The difference between the two Gaussian kernels fitting the motif distribution of targets and non-targets for each region is displayed on the plot. The

667 locations of motifs are represented by the relative location of the first nucleotide in the corresponding region.

Figure 3. RIN-associated transcripts are stable during the maternal-to-zygotic transition. (A) Plots showing the relationship between fold-enrichment in the RIN RIP-Chip and mRNA levels, measured by Eichhorn et al. (2016), during timepoints spanning the maternal-to-zygotic transition. RIN-associated transcripts as defined in this manuscript are highlighted in blue. Dashed blue horizontal lines indicate median value of mRNA levels for RIN-associated transcripts at each timepoint, and dashed red horizontal lines indicate median values for RIN non-targets (defined as $\log _{2}$ fold-enrichment in RIN versus C1 RIPs $<0$ ) at each timepoint. For all timepoints, solid dark-grey horizontal lines indicate the median values of mRNA levels in stage 14 oocytes, as a reference, and solid vertical lines indicate no enrichment in the RIN RIPChip. Points are shown for all genes measured in both this study and Eichhorn et al., with the RIP-Chip fold-enrichment value for each gene represented by the most highly enriched probe set on the microarray for that gene. (B) Boxplots comparing mRNA levels, measured by Eichhorn et al. (2016) as in (A), of RIN-associated transcripts ("Targets"; blue) and a set of randomly selected, length-matched, co-expressed non-RIN-targets (red), for each time point depicted in

684 (A). For comparisons with a statistically significant difference in mRNA levels between targets 685 and length-matched non-targets, Wilcoxon rank-sum $P$ values are indicated in the top right of the 686 plots. 

translational efficiency, measured by Eichhorn et al. (2016), during timepoints spanning the maternal-to-zygotic transition. Color code is as in Figure 3 but with respect to translational efficiency rather than RNA abundance. For all timepoints, solid dark-grey horizontal lines

693 indicate the median values of translational efficiency in stage 14 oocytes, as a reference, and

694 solid vertical lines indicate no enrichment in the RIN RIP-Chip. Points are shown for all genes measured in both this study and Eichhorn et al., with the RIP-Chip fold-enrichment value for each gene represented by the most highly enriched probe set on the microarray for that gene.

697 Boxplots comparing translational efficiency, measured by Eichhorn et al. (2016) as in (A), of 698 RIN-associated transcripts ("Targets"; blue) and a set of randomly selected, length-matched, coexpressed non-RIN-targets (red), for each time point depicted in (A). For comparisons with a statistically significant difference in translational efficiency between targets and length-matched non-targets, Wilcoxon rank-sum $P$ values are indicated in the top right of the plots.

702

Figure 5. RIN association with mRNAs is correlated with shorter transcript length for all of the enriched GO-term categories. Plots showing, for transcripts annotated with enriched GO terms, the relationship between length and association with RIN. Blue and red points represent genes annotated with the indicated GO term: genes we define as associated with RIN are highlighted in blue, and genes that fall below the cut-off used to define RIN-associated mRNAs are highlighted in red. Dashed purple horizontal lines indicate the median transcript length for all genes annotated with a given GO term. Solid vertical lines indicate no enrichment in the RIN RIP, and solid dark-grey horizontal lines indicate the median transcript length of all transcripts represented on the plot.

\section{Figure 6. Tethering RIN or its human homologues G3BP1 or G3BP2 potentiates reporter}

714 expression. (A) A schematic representation of the tethering assay used to assess an RNA-

715 binding protein's function. The trans-activator peptide (Tat) interacts with stem-loop structures

716 known as trans-activation response (TAR) elements. By co-expressing a luciferase reporter

717 mRNA carrying six TAR elements in the mRNA's 3'UTR, and RIN/G3BP-tagged Tat,

718 RIN/G3BP will be tethered to the luciferase mRNA, thus allowing one to assess RIN/G3BP's 
719 ability to control mRNA expression. (B) The Tat-tagged proteins indicated on the x-axis were 720 co-expressed in cells with TAR-tagged firefly luciferase mRNA. The y-axis indicates the firefly 721 luciferase enzyme activities normalized to a co-transfected unregulated Renilla luciferase. The 722 normalized firefly luciferase enzyme activities for tethered RIN, G3BP1, G3BP2 were compared 723 to tethered GFP, whose normalized luciferase activity was set to $1(n=3)$. (C) The relative firefly

724 luciferase mRNA levels were assessed by RT-qPCR, when the indicated protein on the x-axis 725 was tethered. Firefly luciferase mRNA levels were normalized to Renilla luciferase mRNA 726 levels and normalized GFP levels were set to $1(n=3)$. (D) Tethered proteins carry a triple 727 FLAG, allowing us to compare their levels using anti-FLAG western blots. GST carrying a 728 triple FLAG tag served as a loading/transfection control. (E, F) The same as (D) and (B), 729 respectively, with the exception that the levels of transfected Tat-GFP were reduced 10-fold. In 730 all graphs, error bars indicate standard deviation and results of Student's $t$-tests are indicated. 
STAR METHODS

\section{CONTACT FOR REAGENT AND RESOURCE SHARING}

735 Further information and requests for resources and reagents should be directed to and will be fulfilled by the Lead Contact, Howard Lipshitz (howard.lipshitz@,utoronto.ca).

\section{EXPERIMENTAL MODEL AND SUBJECT DETAILS}

Wild-type Drosophila stock was $w^{1118}$; mutant lines were $\operatorname{rin}^{2} / T M 6 B$, Sb (BDSC\# 9303)

740 (Pazman et al., 2000), and $\mathrm{rin}^{3} / T M 6 B$, Sb Tb (BDSC\# 57694) (Costa et al., 2013). The latter two

741 lines were crossed to produce $\mathrm{rin}^{2} / \mathrm{rin}^{3}$ mutants for RT-qPCR analysis. Drosophila S2 tissue

742 culture cells were maintained at $25^{\circ} \mathrm{C}$ in Express Five SFM (Fisher Scientific) containing

743 100units/mL penicillin, $100 \mu \mathrm{g} / \mathrm{mL}$ streptomycin and $16 \mathrm{mM}$ glutamine.

\section{METHOD DETAILS}

746 Western blots

747 Embryos were collected from cages containing $w^{1118}$ flies, dechorionated with 100\% bleach for 2 748 minutes, washed with $0.1 \%$ Triton X-100 and lysed by crushing in a minimal volume of lysis buffer: $150 \mathrm{mM} \mathrm{KCl,} 20 \mathrm{mM}$ HEPES-KOH pH 7.4, $1 \mathrm{mM} \mathrm{MgCl}_{2}$, supplemented with protease inhibitors ( $1 \mathrm{mM}$ AEBSF, $2 \mathrm{mM}$ benzamidine, $2 \mu \mathrm{g} / \mathrm{mL}$ pepstatin, $2 \mu \mathrm{g} / \mathrm{mL}$ leupeptin) and $1 \mathrm{mM}$ DTT. The lysate was cleared by centrifugation $\left(15\right.$ min at $\left.4^{\circ} \mathrm{C}, 13000 \mathrm{RPM}\right)$ and stored at $-80^{\circ} \mathrm{C}$. Protein concentration was determined using the Bio-Rad Protein Assay Dye Reagent (Cat\#5000006) and 15 $\mu \mathrm{g}$ total protein was resolved by SDS-PAGE. For S2 cell western blots, $1.2 \times 10^{6}$ cells were pelleted via centrifugation and lysed with 2 XSDS sample buffer supplemented with $1 \mathrm{mM}$ AEBSF and boiling for 3 minutes. Two to eight $\mu \mathrm{L}$ of the resulting extracts were resolved via SDS-PAGE. Proteins were transferred to PVDF membrane, blocked at room temperature for 1 hour with $0.5 \%$ milk in PBST (1x PBS $+0.1 \%$ Triton X-100). Blots were then incubated with the appropriate antibodies: anti-RIN (1:50000) (Aguilera-Gomez et al., 2017) and anti- $\alpha$ tubulin (1:10000, Sigma-Aldrich T5168), or anti-FLAG (1 $\mu \mathrm{g} / \mathrm{mL}$, Sigma-

760 Aldrich F3165) at $4^{\circ} \mathrm{C}$ overnight. After incubation with primary antibody, the blot was

761 incubated with HRP-conjugated secondary antibody (1:5000; either of Peroxidase-Affinipure 762 goat $\alpha$-mouse IgG $(\mathrm{H}+\mathrm{L})$ Cat\#115-035-003 or goat $\alpha$-rabbit $\operatorname{IgG}(\mathrm{H}+\mathrm{L}) \mathrm{Cat} \# 115-035-144$, 
763

764

765

766

767

768

769

770

771

772

773

774

775

776

777

778

779

780

781

782

783

784

785

786

787

788

789

790

791

792

793

Jackson Immunoresearch) at room temperature for 1 hour. Western blots were developed using the ECL detection system (Millipore Immobilon Luminata Crescendo Western HRP substrate Cat\#WBLUR0500). Relative levels of RIN and $\alpha$-tubulin were determined using a standard curve. Western blots were imaged and quantified using ImageLab (BioRad).

\section{Immunostaining of embryos}

Standard immunostaining procedures were followed (Ashburner, 1989). Embryos were collected after a 4 hour egg-lay from cages containing either $w^{1118}, \operatorname{rin}^{2} / \mathrm{rin}^{3}$ mutant females or females heterozygous for rin. Embryos were dechorionated with 50\% bleach and fixed in formaldehyde (4\%) and methanol. To visualize RIN and FMR1, fixed embryos were incubated with the following primary antibodies used at the concentrations indicated: rabbit anti-RIN (1:1000; provided by Liz Gavis) (Aguilera-Gomez et al., 2017) and mouse anti-FMR1 (1:10; \#5A11 from the Developmental Studies Hybridoma Bank) (Okamura et al., 2004). Conjugated secondary antibodies were purchased from Invitrogen-ThermoFisher and used at 1:300 (Alexa Fluor555 Goat Anti-Rabbit IgG, Catalog number A21429, and Alexa Fluor488 Goat Anti-Mouse IgG, Catalog number A11029). Embryos were also labeled for DNA using a $0.001 \mathrm{mg} / \mathrm{ml}$ DAPI (Sigma, Catalog number D9542) incubation for 10 min. Images were collected using a Nikon TiS inverted microscope with Nikon C2 confocal system, using NIS Elements AR software.

Images were then processed for figures using Fiji/ImageJ (Schindelin et al., 2012; Schneider et al., 2012), Adobe Photoshop and Adobe Illustrator.

\section{Generation of anti-RIN synthetic antibodies}

Synthetic antibodies were generated against antigens comprising RIN amino acids 12-131 (antibodies D072) or amino acids 12-170 (antibody D074; all amino acid numbering according to RIN-PB isoform), which were expressed and purified from E. coli as GST fusion proteins as described (Laver et al., 2012). Synthetic antibodies were obtained by performing five rounds of binding selection with synthetic antibody Library F (Persson et al., 2013) against each of the two RIN antigens, as described (Laver et al., 2015a). The three synthetic antibodies obtained against RIN were expressed and purified from E. coli as Fabs, tagged at the C-terminus of the light chain with a FLAG tag, as described (Laver et al., 2012). 
Immunoprecipitations and mass spectrometry

For RIN IP-MS experiments, 0-3 h old embryos were collected, and lysed by crushing in a minimal volume of lysis buffer $(150 \mathrm{mM} \mathrm{KCl}, 20 \mathrm{mM}$ HEPES-KOH pH 7.4, $1 \mathrm{mM} \mathrm{MgCl}$, supplemented with protease inhibitors and $1 \mathrm{mM}$ DTT), followed with clearing by centrifugation (15 min at $4^{\circ} \mathrm{C} ; 20,000 \mathrm{x} \mathrm{g}$ ), and stored at $-80^{\circ} \mathrm{C}$. Immediately prior to performing IPs, this cleared lysate was thawed and diluted $1 / 2$ with lysis buffer, and supplemented with Triton X-100 to a final concentration of $0.1 \%$. For IPs, $\sim 800 \mu \mathrm{L}$ of this diluted lysate, with or without 0.35 $\mu \mathrm{g} / \mu \mathrm{L}$ RNase A, was incubated with $40 \mu \mathrm{L}$ of anti-FLAG M2 beads (Sigma) that were preloaded with $20 \mu \mathrm{g}$ of either RIN Fab D072 or control C1 Fab, and blocked with BSA. IPs were incubated for $\sim 3$ hours at $4^{\circ} \mathrm{C}$ with end-over-end rotation. After incubation, beads were washed 4-5 times with lysis buffer supplemented with $0.1 \%$ Triton X-100, twice with lysis buffer (no Triton X-100), then transferred to new tubes and washed twice with lysis buffer (no Triton X100). Bound proteins were eluted by tryptic digest: beads were resuspended in $200 \mu \mathrm{L}$ of $50 \mathrm{mM}$ ammonium bicarbonate $\mathrm{pH} 8$, supplemented with $2 \mu \mathrm{g}$ of trypsin, and incubated overnight at room temperature with end-over-end rotation. The following day, the digested supernatant was recovered, and beads were washed once with an additional $200 \mu \mathrm{L}$ of $50 \mathrm{mM}$ ammonium

810 bicarbonate to collect any residual eluted material. The two supernatants were pooled and dried 811 by speed-vac. Liquid chromatography-tandem mass spectrometry (LC-MS/MS) was performed

812 using the Thermo Q-Exactive HF quadrupole-Orbitrap mass spectrometer (Thermo Scientific)

813 and the methods followed those previously described (Chiu et al., 2016; Jiang et al., 2015; Liu et 814 al., 2014).

815 Three biological replicates of RIN IPs and control IPs were performed, in both the

816 presence and absence of RNase A. Data analysis is described below.

818 Polysome gradients

819 Embryos were collected 0-3 hours post egg laying and lysed in a $2 \mathrm{mLs}$ of lysis buffer 820 per gram of embryos. Lysis buffer was $50 \mathrm{mM}$ Tris pH 7.5, 2mM MgCl $2,150 \mathrm{mM} \mathrm{KCl,} 100 \mu \mathrm{M}$

821 GTP, $1 \mathrm{mM}$ DTT, $50 \mathrm{U} / \mathrm{mL}$ RNase inhibitor, $1 \mathrm{mM}$ AEBSF, $2 \mu \mathrm{g} / \mathrm{mL}$ leupeptin, $2 \mathrm{mM}$ 822 benzamidine, $2 \mu \mathrm{g} / \mathrm{mL}$ pepstatin A that was supplemented with either $0.5 \mathrm{mg} / \mathrm{mL}$ cycloheximide 823 or $2 \mathrm{mM}$ puromycin. After lysis samples were left on ice for 20 minutes and then incubated at 30 $824{ }^{\circ} \mathrm{C}$ for 10 minutes. $30 \%$ Triton-X100 was added to a final concentration of $1 \%$ and samples 
825 were spun at $6000 \mathrm{x}$ g for 10 minutes. $400 \mu \mathrm{L}$ the resulting supernatant was layered onto a $5 \mathrm{~mL}$ $15 \%$ to $45 \%$ sucrose gradient in $7.5 \mathrm{mM} \mathrm{MgCl}_{2}, 500 \mathrm{mM} \mathrm{NaCl}$, and $50 \mathrm{mM}$ Tris $\mathrm{pH}$ 7.5. The gradient was created using a BioComp Model 117 Gradient Mate gradient maker (BioComp) using according to the manufacter's instructions. The gradients were chilled on ice for 1 hour before extract application after which they were spin at $36,000 \mathrm{rpm}$ for $2 \mathrm{~h} 30$ minutes at $4{ }^{\circ} \mathrm{C}$ in a Beckman SW50.1 rotor. The gradients were then hand fractionated into nine $600 \mu \mathrm{L}$ fractions which were analyzed via western blot.

$\underline{\text { RNA co-immunoprecipitations }}$

For RNA co-immunoprecipitations for RIP-Chip experiments, immunoprecipitations were carried out from $400 \mu \mathrm{L}$ of embryo lysate, prepared from embryos collected $0-3 \mathrm{~h}$ postegg-laying, using $20 \mu \mathrm{g}$ of FLAG-tagged Fab captured on $40 \mu \mathrm{L}$ of anti-FLAG M2 affinity gel (Sigma), as previously described (Laver et al., 2015a). RNA co-immunoprecipitations for RTqPCR experiments were performed similarly but at a reduced scale, using one-eighth the amount of material listed above.

Microarray analysis of RIN RIP samples RIN and control immunoprecipitated samples. Arrays were scanned, quantified, and normalized as previously described (Laver et al., 2015a), with all RIN and control IP samples normalized together. The data have been deposited in the Gene Expression Omnibus (GEO) under accession number GSE12900. Analysis is described below. [For reviewers: To review GEO accession GSE129900:

850 Go to https://www.ncbi.nlm.nih.gov/geo/query/acc.cgi?acc=GSE129900

851 Enter token otwtmoeqjhcztmv into the box]

\section{$853 \quad \underline{\text { RT-qPCR }}$}

854 For RT-qPCR from RIN RNA co-immunoprecipitations, single-stranded cDNA was 
transcriptase (Invitrogen) using a mixture of random hexamer and anchored oligo-dT primers, as described for cDNA synthesis for microarray sample preparation (Laver et al., 2015a). The single-stranded cDNA was used to perform quantitative real-time PCR with primers specific to the various transcripts assayed, using SensiFAST SYBR PCR mix (Bioline) and a CFX384 RealTime System (Bio-Rad). Sequences of the primers used for PCR are listed in Table S10.

$\underline{\text { S2 cell transient transfection, dual-luciferase assay and RT-qPCR. }}$

Drosophila S2 tissue culture cells were maintained at $25^{\circ} \mathrm{C}$ in Express Five SFM (Fisher

864 Scientific) containing $100 \mathrm{units} / \mathrm{mL}$ penicillin, $100 \mu \mathrm{g} / \mathrm{mL}$ streptomycin and $16 \mathrm{mM}$ glutamine. A 865 mixture of 1.5ng Firefly luciferase-6x TAR plasmid, 1.5ng Renilla luciferase plasmid, 3ng Tat866 FLAG-effector plasmid (carrying either the GFP, RIN, G3BP1 or G3BP2 open reading frame), $1.5 \mathrm{ng}$ of FLAG-GST and $192.5 \mathrm{ng}$ pSP72 was transfected into $0.4 \mathrm{~mL}$ of S2 cells at a density of $1.75 \times 10^{6}$ cells $/ \mathrm{mL}$ using $0.4 \mu \mathrm{L}$ TransIT-Insect transfection reagent (Mirus Bio), according to the manufacturer's instructions. Both luciferase reporters were cloned into pRmHa3 (Mohan et al., 2014) and, thus, were under the control of the metal-inducible metallothionein promoter. All FLAG-tagged constructs were derived from pAc5.1/V5-His (Thermo Fisher Scientific), which carries the Actin5C promoter. The expression of luciferase reporters was induced 24 hours post transfection through the addition of copper sulfate to a final concentration of $0.5 \mathrm{mM}$. 24 hours post induction, Firefly and Renilla luciferase activities were measured using the Dual-Luciferase Reporter Assay System (Promega). In indicated experiments, the amount of transfected Tat-GFP was reduced to $0.3 \mathrm{ng}$ and $2.7 \mathrm{ng}$ of a pAc5.1/V5-His derivative expressing only Tat-FLAG was included to maintain equal levels of actin promoter across all transfections.

To assay reporter transcript levels, 48 hours post-transfection $\mathrm{S} 2$ cells were harvested, resuspended in TRI reagent (MRC) and RNA was purified according to the manufacturer's protocol. 1ug of total RNA was treated with DNase I (Invitrogen) after which it was used to generate cDNA through reverse transcription with Superscript IV reverse transcriptase

882 (Invitrogen) and random hexamers (Thermo Fisher) following the manufacturer's instructions.

883 The cDNA was subjected to quantitative real-time PCR using the SensiFAST SYBR PCR mix 884 (Bioline) PCR mix and primers against the Firefly and Renilla luciferase ORFs. Relative levels 885 of the Firefly and Renilla transcripts were determined using a standard curve. Sequences of the 886 primers used for PCR are listed in Table S10. 
$\underline{\text { S2 cell immunofluorescence and microscopy }}$

Forty-eight hours post-transfection S2 cells were grown at $25^{\circ} \mathrm{C}$ on poly-D-lysine coated coverslips for 3 hours. Following any treatment, cells were immediately fixed with 4\% EM grade formaldehyde in PBS for 10 minutes. Cells were rinsed once with PBSTx (1X PBS $+0.1 \%$ Triton $\mathrm{X}-100)$, permeablized with PBSTx for 15 minutes then incubated with $5 \mu \mathrm{g} / \mathrm{mL} \alpha$-FLAG M2 (F3165, Sigma) and 1:200 rabbit $\alpha$-CAPR (Papoulas et al., 2010) overnight at 4C in a humidified chamber. Coverslips were washed 3 times for 5 minutes each time with PSBTx then incubated with $\alpha$-mouse Alexa Flour 555 and $\alpha$-rabbit Alexa Fluor 488 (Invitrogen-ThermoFisher Catalog numbers A21424 and A11034, respectively) for 2 hours at room temp in a humidified chamber.

897 Coverslips were washed 3 times for 5 minutes each with PSBTx and then mounted onto slides with Fluoromount g + DAPI (00-4959-52, Invitrogen) and incubated overnight at $4^{\circ} \mathrm{C}$. All images were collected using a Nikon Ti-S confocal microscope with NIS Elements AR software. Images were processed using ImageJ.

901

\section{QUANTIFICATION AND STATISTICAL ANALYSIS}

$903 \quad$ Mass spectrometry

To identify RIN-interacting proteins, we used the ProHits software package (Liu et al., 2010) to perform Significance Analysis of INTeractome (SAINT), comparing RNase-treated

906 RIN IP versus control IP samples, and non-RNase-treated RIN IP versus control IP samples.

907 Specifically, SAINT input files were generated using the "TPP iProphet" search engine option in

908 ProHits, filtering for iProphet probability $>0.95$ and number of unique peptides $<2$.

909 SAINTexpress (exp3.3) was run using the ProHits interface, including only detected Drosophila 910 proteins, with the following settings: number of compressed controls = 3; burn-in period, nburn

$911=2000 ;$ iterations, niter $=5000 ;$ lowMode $=1 ; \operatorname{minFold}=1 ;$ normalize $=1 ;$ nCompressBaits $=2$.

912 Identified proteins were defined as RNA-independent or RNA-dependent RIN-interacting

913 proteins, if, in the analyses of the respective samples, they achieved a SAINT score $\geq 0.95$ and a

914 Bayesian false discovery rate $(\mathrm{BFDR}) \leq 0.01$.

915

$916 \quad$ Microarrays 
To identify RIN-associated mRNAs, microarray data were analyzed using the Significance Analysis of Microarrays (SAM) (Tusher et al., 2001) function available in the

919 MultiExperiment Viewer software application (Saeed et al., 2006; Saeed et al., 2003), as

920 previously described (Laver et al., 2015a). Genes whose mRNAs were significantly enriched in 921 the anti-RIN IPs compared to the control IPs, with an FDR of less than 5\% and at least two-fold 922 enrichment, were defined as RIN-associated mRNAs.

923 For the purposes of all subsequent analyses, FBgn gene IDs listed in the array annotation 924 file were updated to FlyBase release 6.20 using the 'Upload/Convert IDs' tool available on 925 FlyBase, and mRNAs corresponding to gene models which have since been withdrawn were 926 excluded.

928 Extraction of length-matched target and non-target sets

929 Length-matched targets and non-targets were extracted as follows: first, we randomly 930 chose a target transcript from the target set, and then we looked for a transcript in the non-target 931 set that had the minimum length difference from that target, unless the length differences for the 932 remaining non-targets were all higher or equal to the length of the target transcript (we randomly 933 chose one if multiple non-targets with the same length difference were available). Non-targets 934 were removed from the candidate non-target set when they were selected as a match for a target, 935 and targets were removed from the candidate target set whether or not they had a match in the 936 non-target set. We repeated this process until we exhausted the target set. Because RIN targets 937 are generally shorter than non-targets, and the order of RIN targets being chosen from the target 938 set was different for each matching process, the composition of the length-matched target and 939 non-target sets was different in each iteration (five such iterations were carried out; see Figure 940 S7). We extracted multiple length-matched target and non-target sets for 5'UTR, CDS, 3'UTR 941 and full mRNA, using the sequence length of each transcriptomic region respectively.

943 Enrichment test of published RIN motifs

944 To test whether published RIN motifs are enriched in genes co-immunoprecipitated with 945 RIN in our analysis, we used in vitro-determined Drosophila RIN and human G3BP2 motifs 946 (Cook et al., 2011; Ray et al., 2013) (see http://cisbp-rna.ccbr.utoronto.ca/), and in vivo motifs of 947 human G3BP1 and G3BP2 (Edupuganti et al., 2017). Position frequency matrices (PFMs) of the 
948 in vivo motifs were estimated from the height of base logos and produced using ggseqlogo

949 (Wagih, 2017) and Logomaker (Tareen and Kinney, 2019). To eliminate the effect of sequence

950 length on motif enrichment, we randomly selected corresponding transcript regions from length-

951 paired co-expressed unbound genes as negative set for each transcript region of genes in the RIP-

952 enriched gene sets (positive set). The longest transcript isoform of each gene was used. For a

953 motif of length $\mathrm{K}$ and for all transcript subsequences of length K (i.e., K-mers), we calculated a

954 "hit score" by multiplying the probability of that K-mer under the PFM and the probability of the

955 entire subsequence being accessible at the given location within the transcript. The probability of

956 a K-mer under a PFM was calculated by multiplying the probability of each base of the K-mer at

957 its corresponding position in the PFM. Subsequence accessibility was estimated using

958 RNAplfold (Bernhart et al., 2006; Lorenz et al., 2011) with the parameters: -W 80 -L 40 -u

$959<$ motif_length>. For each motif, we tested its ability to distinguish positive genes from length-

960 paired negative genes by ranking genes according to the maximum "hit score" of all

961 subsequences of its corresponding transcript for that motif. We repeated the test 1000 times with

962 length-paired negatives randomly selected each time, and reported the number of significant

963 Mann-Whitney $U$ tests, and the mean and standard deviation of the AUROCs and $P$ values of

964 each motif's significant tests (Table S4). To show the distribution of motifs in RIN targets v.s.

965 non-targets, we grouped the number of RIN motifs (defined as sites with "hit score" >0.001) in a

966 length-paired positive and negative sample from each of the three transcript regions into 20 bins,

967 and used Gaussian kernels to fit the un-normalized positive and negative histogram for each

968 region. The differences between the two corresponding Gaussian kernels in each of the three

969 regions are displayed in Figure 2D.

970

Comparisons of RIN-associated mRNAs to published Drosophila datasets

972 For all comparisons of RIN-associated mRNAs to Drosophila transcripts reported in

973 previously published datasets, all gene IDs from the various datasets were first updated using the

974 FlyBase 'Upload/Convert IDs' tool to FBgn IDs from FlyBase release 6.20, to ensure

975 consistency of identifiers between datasets. The lengths of the longest and shortest mRNA

976 transcript isoforms for every gene were obtained from FlyBase release 6.20.

977 For comparisons of RIN-associated mRNAs to mRNA translation and abundance data

978 from Eichhorn et al. (Eichhorn et al., 2016), only genes measured in both datasets were included 
979 in the scatterplot comparisons. In cases where a single gene had more than a single fold-

980 enrichment value in our microarray data, due to the presence of multiple probe sets representing

981 the same gene, the higher fold-enrichment value was used.

982 For comparisons of RIN-associated mRNAs to lists of genes from other datasets,

983 including maternal decay classes, and $\mathrm{N}^{6}$-methyladenosine $\left(\mathrm{m}^{6} \mathrm{~A}\right)$ modification, significant

984 enrichment or depletion was assessed between the relevant lists with Fisher's exact test, using as

985 a background the intersection of the set of expressed genes for our RIP-Chip experiment and the

986 set of genes included in the dataset being compared, as previously described (Laver et al.,

987 2015a).

988

989 Comparisons of RIN-associated mRNAs and proteins to datasets in other species

990 To compare Drosophila RIN-associated mRNAs and proteins to reported lists of human

991 G3BP-associated proteins, and stress granule enriched or depleted proteins and mRNAs in yeast,

992 mouse, and human, the Drosophila homologs of genes in the non-Drosophila datasets were

993 obtained using the DRSC Integrative Ortholog Prediction Tool (DIOPT) web server

994 (http://www.flyrnai.org/cgi-bin/DRSC orthologs.pl) (Hu et al., 2011). Only Drosophila

995 homologs with a 'Rank' of 'moderate' or 'high' in the DIOPT output were considered, and

996 where more than one Drosophila homolog existed, only the best match was included. After

997 obtaining the lists of homologs, comparisons between the RIN-associated mRNAs and

998 Drosophila homologs of datasets from other species were carried out as for the intra-species comparisons described above.

$\underline{\text { Gene ontology annotation enrichment analysis }}$

GO annotation enrichment analysis was carried out using the DAVID 6.8 functional

1003 annotation tool web server (Huang da et al., 2009a; Huang da et al., 2009b), to search for

1004 enrichment of GO terms included in the GO FAT database. Genes identified by RIP-Chip as

1005 encoding RIN-associated mRNAs were analyzed for enrichment against the set of expressed

1006 genes defined for our RIP-Chip experiment, as previously described (Laver et al., 2015a). GO

1007 terms enriched at an FDR of less than 10\% were considered significant. 
1008 For GO terms highlighted in scatterplots that depict transcript length and transcript

1009 translational status or abundance, lists of all genes annotated with each GO term were obtained

1010 from FlyBase using the controlled vocabulary search tool.

1011

1012

1013 DATA AND SOFTWARE AVAILABILITY

1014 Microarray data have been deposited in the Gene Expression Omnibus (GEO) under

1015 accession number GSE12900. Reviewers, please go

1016 to https://www.ncbi.nlm.nih.gov/geo/query/acc.cgi?acc=GSE129900. 


\begin{tabular}{|c|c|c|}
\hline REAGENT or RESOURCE & SOURCE & IDENTIFIER \\
\hline \multicolumn{3}{|l|}{ Antibodies } \\
\hline a-RIN D072 synthetic antigen-binding fragment (Fab) & This paper & $\mathrm{N} / \mathrm{A}$ \\
\hline a-RIN D074 synthetic antigen-binding fragment (Fab) & This paper & $\mathrm{N} / \mathrm{A}$ \\
\hline a-CAPR rabbit polyclonal & Paul Macdonald & $\begin{array}{l}\text { Papoulas et al., } \\
2010\end{array}$ \\
\hline$\alpha-\mathrm{RIN}$ rabbit polyclonal & Liz Gavis & $\begin{array}{l}\text { Aguilera-Gomez et } \\
\text { al., } 2017\end{array}$ \\
\hline a-FMR1 mouse monoclonal 5A11 & $\begin{array}{l}\text { Developmental } \\
\text { Studies Hybridoma } \\
\text { Bank }\end{array}$ & Okamura et al., 2004 \\
\hline a-alpha-tubulin mouse monoclonal B-5-1-2 & Sigma-Aldrich & Cat\#T5168 \\
\hline a-FLAG mouse monoclonal M2 & Sigma-Aldrich & Cat\#F3165 \\
\hline a-FLAG M2 affinity agarose beads & Sigma-Aldrich & Cat\#A2220 \\
\hline a-mouse Alexa Flour 555 & Invitrogen & Cat\#A21424 \\
\hline a-rabbit Alexa Fluor 488 & Invitrogen & Cat\#A11034 \\
\hline a-mouse Alexa Fluor 488 & Invitrogen & Cat\#A21429 \\
\hline a-rabbit Alexa Fluor 555 & Invitrogen & Cat\#A11029 \\
\hline Peroxidase-AffiniPure Goat $\alpha-M o u s e \lg G(\mathrm{H}+\mathrm{L})$ & $\begin{array}{l}\text { Jackson } \\
\text { Immunoresearch Labs }\end{array}$ & Cat\#115-035-003 \\
\hline Peroxidase-AffiniPure Goat $\alpha-$ Rabbit lgG $(\mathrm{H}+\mathrm{L})$ & $\begin{array}{l}\text { Jackson } \\
\text { Immunoresearch Labs }\end{array}$ & Cat\#111-035-144 \\
\hline \multicolumn{3}{|l|}{ Chemicals, Peptides, and Recombinant Proteins } \\
\hline Fluoromount $\mathrm{g}+\mathrm{DAPI}$ & Invitrogen & Cat\#00-4959-52 \\
\hline Poly-D-lysine hydrobromide & Sigma-Aldrich & Cat\#P7886 \\
\hline DAPI & Sigma-Aldrich & Cat\#D9542 \\
\hline Trizol Reagent & Invitrogen & Cat\#15596018 \\
\hline Superscript IV Reverse Transcriptase & Invitrogen & Cat\#18090050 \\
\hline dNTP Mix & Thermo Scientific & Cat\#R0192 \\
\hline RNaseOUT Recombinant Ribonuclease Inhibitor & Invitrogen & Cat\#10777019 \\
\hline Ultrapure water & Invitrogen & Cat\#10977015 \\
\hline AEBSF & Bioshop & Cat\#AEB602 \\
\hline Benzamidine & Bioshop & Cat\#BEN666 \\
\hline Pepstatin & Bioshop & Cat\#PEP605 \\
\hline Leupeptin & Bioshop & Cat\#LEU001 \\
\hline DTT & Bioshop & Cat\#DDT001 \\
\hline Triton X-100 & BioShop & Cat\#TRX777 \\
\hline Bio-Rad Protein Assay Dye Reagent & Bio-Rad & Cat\#5000006 \\
\hline $30 \%$ Acrylamide/Bis-acrylamide solution (37.5:1) & Bio-Rad & Cat\#1610158 \\
\hline Skim Milk powder & BioShop & Cat\#SKI400 \\
\hline Immuno-Blot PVDF & Bio-Rad & Cat\#1620177 \\
\hline Puromycin & Bioshop & Cat\#PUR333 \\
\hline Cycloheximide & Bioshop & Cat\#CYC003 \\
\hline RiboLock RNase Inhibitor & Thermo Scientific & Cat\# EO0381 \\
\hline \multicolumn{3}{|l|}{ Critical Commercial Assays } \\
\hline SensiFAST SYBR No-ROX Kit & $\begin{array}{l}\text { BioLine Meridian } \\
\text { Bioscience }\end{array}$ & Cat\#BIO-98050 \\
\hline Dual Luciferase Kit & Promega & Cat\#E1910 \\
\hline
\end{tabular}




\begin{tabular}{|c|c|c|}
\hline $\begin{array}{l}\text { Millipore Immobilon Luminata Crescendo Western HRP } \\
\text { Substrate }\end{array}$ & Sigma-Aldrich & Cat\#WBLUR0500 \\
\hline \multicolumn{3}{|l|}{ Deposited Data } \\
\hline RIN (a-RIN D072) RIP-Chip raw and analyzed data & This paper & GEO: GSE12900 \\
\hline Flybase Drosophila melanogaster sequences v6.20 & FlyBase Consortium & $\begin{array}{l}\text { ftp://ftp.flybase.net/re } \\
\text { leases/FB2018 01/d } \\
\text { mel r6.20/fasta/ }\end{array}$ \\
\hline $\begin{array}{l}\text { Drosophila oogenesis and embryogenesis mRNA } \\
\text { abundance and mRNA translational efficiency data }\end{array}$ & Eichhorn et al., 2016 & N/A \\
\hline Drosophila embryo mRNA translational efficiency data & Dunn et al., 2013 & $\mathrm{~N} / \mathrm{A}$ \\
\hline $\begin{array}{l}\text { Drosophila embryo N6-methyladenosine mRNA } \\
\text { modification data }\end{array}$ & $\begin{array}{l}\text { Edupuganti et al., } \\
2017\end{array}$ & $\mathrm{~N} / \mathrm{A}$ \\
\hline $\begin{array}{l}\text { Drosophila early embryo mRNA stability, decay, and } \\
\text { transcription transcript classes }\end{array}$ & Thomsen et al., 2010 & $\mathrm{~N} / \mathrm{A}$ \\
\hline Drosophila unfertilized egg unstable mRNA dataset & Tadros et al., 2007 & $\mathrm{~N} / \mathrm{A}$ \\
\hline Drosophila early embryo unstable mRNA dataset & De Renzis et al., 2007 & $\mathrm{~N} / \mathrm{A}$ \\
\hline Drosophila ribosomal protein gene lists & Marygold et al., 2007 & $\mathrm{~N} / \mathrm{A}$ \\
\hline Drosophila ovary RIN protein interaction data & Costa et al., 2013 & $\mathrm{~N} / \mathrm{A}$ \\
\hline Yeast and human stress granule proteome datasets & Jain et al., 2016 & $\mathrm{~N} / \mathrm{A}$ \\
\hline $\begin{array}{l}\text { HEK293 and human neural progenitor cell stress } \\
\text { granule proteome datasets }\end{array}$ & Markmiller et al., 2018 & $\mathrm{~N} / \mathrm{A}$ \\
\hline $\begin{array}{l}\text { Human G3BP1-interacting proteins and human "core" } \\
\text { stress granule and P-body proteome datasets }\end{array}$ & Youn et al., 2018 & $\mathrm{~N} / \mathrm{A}$ \\
\hline $\begin{array}{l}\text { Human U2OS cell stress granule enrichment and } \\
\text { depletion datasets }\end{array}$ & Khong et al., 2017 & $\mathrm{~N} / \mathrm{A}$ \\
\hline $\begin{array}{l}\text { NIH3T3 cell stress-induced insoluble RNA granule } \\
\text { transcriptome datasets }\end{array}$ & Namkoong et al., 2018 & $\mathrm{~N} / \mathrm{A}$ \\
\hline \multicolumn{3}{|l|}{ Experimental Models: Cell Lines } \\
\hline D. melanogaster Cell line S2 & $\begin{array}{l}\text { Drosophila Genomics } \\
\text { Resource Center }\end{array}$ & Stock \#181 \\
\hline \multicolumn{3}{|l|}{ Experimental Models: Organisms/Strains } \\
\hline$w^{1118}$ & $\begin{array}{l}\text { Bloomington } \\
\text { Drosophila Stock } \\
\text { Centre }\end{array}$ & Stock \#3605 \\
\hline$w^{1118} ; \operatorname{rin}^{2} / T M 6 B, S b^{1}$ & $\begin{array}{l}\text { Bloomington } \\
\text { Drosophila Stock } \\
\text { Centre }\end{array}$ & Stock \#9303 \\
\hline$w^{1118} ; \operatorname{rin}^{3} / T M 6 B, S b^{1} T b^{1}$ & $\begin{array}{l}\text { Bloomington } \\
\text { Drosophila Stock } \\
\text { Centre }\end{array}$ & Stock \#57694 \\
\hline \multicolumn{3}{|l|}{ Oligonucleotides } \\
\hline Random Hexamer Primer & Thermo Scientific & Cat\#SO142 \\
\hline Anchored Oligo(dT) ${ }_{20}$ Primer & Invitrogen & Cat\#12577011 \\
\hline Primers used for RT-qPCR experiments: see Table S7 & This paper & $\mathrm{N} / \mathrm{A}$ \\
\hline \multicolumn{3}{|l|}{ Recombinant DNA } \\
\hline $\begin{array}{l}\text { Plasmid: pRm-Rluc - expresses the Renilla luciferase } \\
\text { ORF under the control of the metallothionein promoter }\end{array}$ & This paper & C2009 \\
\hline $\begin{array}{l}\text { Plasmid: pRm-Fluc6xTAR - expresses the Firefly } \\
\text { luciferase ORF under the control of the metallothionein } \\
\text { promoter with } 6 \text { TAR stem/loops in the reporters 3'UTR }\end{array}$ & This paper & NJ2 \\
\hline
\end{tabular}




\begin{tabular}{|c|c|c|}
\hline $\begin{array}{l}\text { Plasmid: pTat-FLAG-rin - the rin ORF under the control } \\
\text { of the Actin5C promoter carrying an amino terminal Tat } \\
\text { peptide and } 3 \text { FLAG tags }\end{array}$ & This paper & JY33 \\
\hline $\begin{array}{l}\text { Plasmid: pTat-FLAG-G3BP1 - the G3BP1 ORF under } \\
\text { the control of the Actin5C promoter carrying an amino } \\
\text { terminal Tat peptide and } 3 \text { FLAG tags }\end{array}$ & This paper & JY125 \\
\hline $\begin{array}{l}\text { Plasmid: pTat-FLAG-G3BP2 - the G3BP2 ORF under } \\
\text { the control of the Actin5C promoter carrying an amino } \\
\text { terminal Tat peptide and } 3 \text { FLAG tags }\end{array}$ & This paper & JY126 \\
\hline $\begin{array}{l}\text { Plasmid: pTat-FLAG-GFP - the GFP ORF under the } \\
\text { control of the Actin5C promoter carrying an amino } \\
\text { terminal Tat peptide and } 3 \text { FLAG tags }\end{array}$ & This paper & AW14 \\
\hline $\begin{array}{l}\text { Plasmid: } p F L A G-G S T \text { - the GST ORF under the control } \\
\text { of the Actin5C promoter carrying } 3 \text { amino terminal FLAG } \\
\text { tags }\end{array}$ & This paper & JY110 \\
\hline Plasmid: D072 - encodes anti-RIN FAB & This paper & D072 \\
\hline Plasmid: D074 - encodes anti-RIN FAB & This paper & D074 \\
\hline \multicolumn{3}{|l|}{ Software and Algorithms } \\
\hline ProHits software package & Liu et al., 2010 & http://prohitsms.com \\
\hline MultiExperiment Viewer & Saeed et al., 2006 & http://mev.tm4.org \\
\hline DAVID 6.8 functional annotation tool web server & Huang et al., 2009a,b & $\begin{array}{l}\text { http://david.ncifcrf.go } \\
\underline{\mathrm{v} /}\end{array}$ \\
\hline DRSC Integrative Ortholog Prediction Tool (DIOPT) & Hu et al., 2011 & $\begin{array}{l}\text { http://www.flyrnai.org } \\
\text { /diopt }\end{array}$ \\
\hline ImageJ & Schneider et al., 2012 & $\begin{array}{l}\text { https://imagej.nih.go } \\
\text { v/ij/ }\end{array}$ \\
\hline Fiji & Schindelin et al., 2011 & https://imagej.net/Fiij \\
\hline RNAplfold (v2.4.6) & Lorenz et al., 2011 & $\begin{array}{l}\text { https://www.tbi.univi } \\
\text { e.ac.at/RNA/ }\end{array}$ \\
\hline ggseqlogo & Wagih, 2017 & $\begin{array}{l}\text { https://github.com/o } \\
\text { marwagih/ggseglogo }\end{array}$ \\
\hline Logomaker & $\begin{array}{l}\text { Tareen and Kinney, } \\
2019\end{array}$ & $\begin{array}{l}\text { https://github.com/jb } \\
\text { kinney/logomaker }\end{array}$ \\
\hline \multicolumn{3}{|l|}{ Other } \\
\hline Human G3BP1, G3BP2 in vivo binding motifs & $\begin{array}{l}\text { Edupuganti et al., } \\
2017\end{array}$ & $\begin{array}{l}\underline{\text { https://www.nature.c }} \\
\underline{\text { om/articles/nsmb.34 }}\end{array}$ \\
\hline Human G3BP2, Drosophila RIN in vitro binding motifs & Ray et al., 2013 & 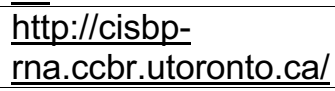 \\
\hline Synthetic antigen-binding fragment (Fab) Library $\mathrm{F}$ & Persson et al., 2013 & N/A \\
\hline SuperScript IV Reverse Transcriptase & Invitrogen & Cat\#18090050 \\
\hline Custom-designed Drosophila 4x72K microarray & Roche NimbleGen & GEO: GPL10539 \\
\hline
\end{tabular}




\section{REFERENCES}

1025

1026

1027

1028

1029

1030

1031

1032

1033

1034

1035

1036

1037

1038

1039

1040

1041

1042

1043

1044

1045

1046

1047

1048

1049

1050

1051

1052

1053

1054

1055

1056

1057

1058

1059

1060

1061

1062

1063

1064

1065

1066

1067

1068

1069

1070

Achsel, T., and Bagni, C. (2016). Cooperativity in RNA-protein interactions: the complex is more than the sum of its partners. Curr Opin Neurobiol 39, 146-151.

Adivarahan, S., Livingston, N., Nicholson, B., Rahman, S., Wu, B., Rissland, O.S., and Zenklusen, D. (2018). Spatial Organization of Single mRNPs at Different Stages of the Gene Expression Pathway. Mol Cell 72, 727-738 e725.

Aguilera-Gomez, A., Zacharogianni, M., van Oorschot, M.M., Genau, H., Grond, R., Veenendaal, T., Sinsimer, K.S., Gavis, E.A., Behrends, C., and Rabouille, C. (2017). Phospho-Rasputin Stabilization by Sec16 Is Required for Stress Granule Formation upon Amino Acid Starvation. Cell reports 20, 2277.

Alam, U., and Kennedy, D. (2019). Rasputin a decade on and more promiscuous than ever? A review of G3BPs. Biochim Biophys Acta Mol Cell Res 1866, 360-370.

Anderson, P., and Kedersha, N. (2009a). RNA granules: post-transcriptional and epigenetic modulators of gene expression. Nat Rev Mol Cell Biol 10, 430-436.

Anderson, P., and Kedersha, N. (2009b). Stress granules. Current biology : CB 19, R397-398.

Ashburner, M. (1989). Drosophila (Cold Spring Harbor, N.Y.: Cold Spring Harbor Laboratory).

Aviv, T., Lin, Z., Ben-Ari, G., Smibert, C.A., and Sicheri, F. (2006). Sequence-specific recognition of RNA hairpins by the SAM domain of Vts1p. Nature structural \& molecular biology 13, 168-176.

Aviv, T., Lin, Z., Lau, S., Rendl, L.M., Sicheri, F., and Smibert, C.A. (2003). The RNA-binding SAM domain of Smaug defines a new family of post-transcriptional regulators. Nature structural biology 10, 614-621.

Bar-Peled, L., Schweitzer, L.D., Zoncu, R., and Sabatini, D.M. (2012). Ragulator is a GEF for the rag GTPases that signal amino acid levels to mTORC1. Cell 150, 1196-1208.

Baumgartner, R., Stocker, H., and Hafen, E. (2013). The RNA-binding proteins FMR1, rasputin and caprin act together with the UBA protein lingerer to restrict tissue growth in Drosophila melanogaster. PLoS genetics 9, e1003598.

Benoit, B., He, C.H., Zhang, F., Votruba, S.M., Tadros, W., Westwood, J.T., Smibert, C.A., Lipshitz, H.D., and Theurkauf, W.E. (2009). An essential role for the RNA-binding protein Smaug during the Drosophila maternal-to-zygotic transition. Development 136, 923-932.

Bernhart, S.H., Hofacker, I.L., and Stadler, P.F. (2006). Local RNA base pairing probabilities in large sequences. Bioinformatics 22, 614-615.

Bovaird, S., Patel, D., Padilla, J.A., and Lecuyer, E. (2018). Biological functions, regulatory mechanisms, and disease relevance of RNA localization pathways. FEBS Lett 592, 2948-2972.

Buchan, J.R., and Parker, R. (2009). Eukaryotic stress granules: the ins and outs of translation. Mol Cell 36, 932-941.

Bushati, N., Stark, A., Brennecke, J., and Cohen, S.M. (2008). Temporal reciprocity of miRNAs and their targets during the maternal-to-zygotic transition in Drosophila. Current biology : CB 18, 501-506.

Cardinali, B., Carissimi, C., Gravina, P., and Pierandrei-Amaldi, P. (2003). La protein is associated with terminal oligopyrimidine mRNAs in actively translating polysomes. The Journal of biological chemistry 278, 35145-35151.

Chen, L., Dumelie, J.G., Li, X., Cheng, M.H., Yang, Z., Laver, J.D., Siddiqui, N.U., Westwood, J.T., Morris, Q., Lipshitz, H.D., et al. (2014). Global regulation of mRNA translation and stability in the early Drosophila embryo by the Smaug RNA-binding protein. Genome biology 15, R4.

Chiu, C.W.N., Monat, C., Robitaille, M., Lacomme, M., Daulat, A.M., Macleod, G., McNeill, H., Cayouette, M., and Angers, S. (2016). SAPCD2 Controls Spindle Orientation and Asymmetric Divisions by Negatively Regulating the Galphai-LGN-NuMA Ternary Complex. Developmental cell 36, 50-62.

Choi, H., Larsen, B., Lin, Z.Y., Breitkreutz, A., Mellacheruvu, D., Fermin, D., Qin, Z.S., Tyers, M., Gingras, A.C., and Nesvizhskii, A.I. (2011). SAINT: probabilistic scoring of affinity purification-mass spectrometry data. Nature methods $8,70-73$. 
Cook, K.B., Kazan, H., Zuberi, K., Morris, Q., and Hughes, T.R. (2011). RBPDB: a database of RNA-binding specificities. Nucleic acids research 39, D301-308.

Costa, A., Pazman, C., Sinsimer, K.S., Wong, L.C., McLeod, I., Yates, J., 3rd, Haynes, S., and Schedl, P. (2013). Rasputin functions as a positive regulator of orb in Drosophila oogenesis. PloS one 8, e72864.

1075

1076

1077

1078

1079

1080

1081

1082

1083

1084

1085

1086

1087

1088

1089

1090

1091

1092

1093

1094

1095

1096

1097

1098

1099

1100

1101

1102

1103

1104

1105

1106

1107

1108

1109

1110

1111

1112

1113

1114

1115

1116

1117

1118

Costa, A., Wang, Y., Dockendorff, T.C., Erdjument-Bromage, H., Tempst, P., Schedl, P., and Jongens, T.A. (2005). The Drosophila fragile $X$ protein functions as a negative regulator in the orb autoregulatory pathway. Developmental cell 8, 331-342.

Costello, J., Castelli, L.M., Rowe, W., Kershaw, C.J., Talavera, D., Mohammad-Qureshi, S.S., Sims, P.F., Grant, C.M., Pavitt, G.D., Hubbard, S.J., et al. (2015). Global mRNA selection mechanisms for translation initiation. Genome biology 16, 10.

Crosio, C., Boyl, P.P., Loreni, F., Pierandrei-Amaldi, P., and Amaldi, F. (2000). La protein has a positive effect on the translation of TOP mRNAs in vivo. Nucleic acids research 28, 2927-2934.

Damgaard, C.K., and Lykke-Andersen, J. (2011). Translational coregulation of 5'TOP mRNAs by TIA-1 and TIAR. Genes \& development 25, 2057-2068.

De Renzis, S., Elemento, O., Tavazoie, S., and Wieschaus, E.F. (2007). Unmasking activation of the zygotic genome using chromosomal deletions in the Drosophila embryo. PLoS Biol 5, e117.

Dunn, J.G., Foo, C.K., Belletier, N.G., Gavis, E.R., and Weissman, J.S. (2013). Ribosome profiling reveals pervasive and regulated stop codon readthrough in Drosophila melanogaster. Elife 2, e01179.

Edupuganti, R.R., Geiger, S., Lindeboom, R.G.H., Shi, H., Hsu, P.J., Lu, Z., Wang, S.Y., Baltissen, M.P.A., Jansen, P., Rossa, M., et al. (2017). N(6)-methyladenosine (m(6)A) recruits and repels proteins to regulate mRNA homeostasis. Nature structural \& molecular biology 24, 870-878.

Eichhorn, S.W., Subtelny, A.O., Kronja, I., Kwasnieski, J.C., Orr-Weaver, T.L., and Bartel, D.P. (2016). mRNA poly $(A)$-tail changes specified by deadenylation broadly reshape translation in Drosophila oocytes and early embryos. Elife 5 .

Fonseca, B.D., Lahr, R.M., Damgaard, C.K., Alain, T., and Berman, A.J. (2018). LARP1 on TOP of ribosome production. Wiley interdisciplinary reviews RNA, e1480.

Hafer, N., Xu, S., Bhat, K.M., and Schedl, P. (2011). The Drosophila CPEB protein Orb2 has a novel expression pattern and is important for asymmetric cell division and nervous system function. Genetics 189, 907-921.

Harvey, R., Dezi, V., Pizzinga, M., and Willis, A.E. (2017). Post-transcriptional control of gene expression following stress: the role of RNA-binding proteins. Biochem Soc Trans 45, 1007-1014.

Hu, Y., Flockhart, I., Vinayagam, A., Bergwitz, C., Berger, B., Perrimon, N., and Mohr, S.E. (2011). An integrative approach to ortholog prediction for disease-focused and other functional studies. BMC Bioinformatics 12, 357.

Huang da, W., Sherman, B.T., and Lempicki, R.A. (2009a). Bioinformatics enrichment tools: paths toward the comprehensive functional analysis of large gene lists. Nucleic acids research 37, 1-13.

Huang da, W., Sherman, B.T., Zheng, X., Yang, J., Imamichi, T., Stephens, R., and Lempicki, R.A. (2009b). Extracting biological meaning from large gene lists with DAVID. Curr Protoc Bioinformatics Chapter 13, Unit 1311.

ladevaia, V., and Gerber, A.P. (2015). Combinatorial Control of mRNA Fates by RNA-Binding Proteins and Non-Coding RNAs. Biomolecules 5, 2207-2222.

Jain, S., Wheeler, J.R., Walters, R.W., Agrawal, A., Barsic, A., and Parker, R. (2016). ATPase-Modulated Stress Granules Contain a Diverse Proteome and Substructure. Cell 164, 487-498.

Jiang, T., McKinley, R.F., McGill, M.A., Angers, S., and Harris, T.J. (2015). A Par-1-Par-3-Centrosome Cell Polarity Pathway and Its Tuning for Isotropic Cell Adhesion. Current biology : CB 25, 2701-2708.

Kan, L., Grozhik, A.V., Vedanayagam, J., Patil, D.P., Pang, N., Lim, K.S., Huang, Y.C., Joseph, B., Lin, C.J., Despic, V., et al. (2017). The m(6)A pathway facilitates sex determination in Drosophila. Nature communications 8, 15737. 
Kedersha, N., and Anderson, P. (2009). Regulation of translation by stress granules and processing bodies. Prog Mol Biol Transl Sci 90, 155-185.

Kedersha, N., Panas, M.D., Achorn, C.A., Lyons, S., Tisdale, S., Hickman, T., Thomas, M., Lieberman, J., Mclnerney, G.M., Ivanov, P., et al. (2016). G3BP-Caprin1-USP10 complexes mediate stress granule condensation and associate with $40 \mathrm{~S}$ subunits. The Journal of cell biology 212, 845-860. Transcriptome Reveals Principles of mRNA Accumulation in Stress Granules. Mol Cell 68, 808-820 e805.

Knight, J.D.R., Choi, H., Gupta, G.D., Pelletier, L., Raught, B., Nesvizhskii, A.I., and Gingras, A.C. (2017). ProHits-viz: a suite of web tools for visualizing interaction proteomics data. Nature methods $14,645-$ 646.

Kuhn, L., Majzoub, K., Einhorn, E., Chicher, J., Pompon, J., Imler, J.L., Hammann, P., and Meignin, C. (2017). Definition of a RACK1 Interaction Network in Drosophila melanogaster Using SWATH-MS. G3 (Bethesda) 7, 2249-2258.

Laver, J.D., Ancevicius, K., Sollazzo, P., Westwood, J.T., Sidhu, S.S., Lipshitz, H.D., and Smibert, C.A. (2012). Synthetic antibodies as tools to probe RNA-binding protein function. Molecular bioSystems 8 , 1650-1657.

Laver, J.D., Li, X., Ancevicius, K., Westwood, J.T., Smibert, C.A., Morris, Q.D., and Lipshitz, H.D. (2013). Genome-wide analysis of Staufen-associated mRNAs identifies secondary structures that confer target specificity. Nucleic acids research 41, 9438-9460.

Laver, J.D., Li, X., Ray, D., Cook, K.B., Hahn, N.A., Nabeel-Shah, S., Kekis, M., Luo, H., Marsolais, A.J., Fung, K.Y., et al. (2015a). Brain tumor is a sequence-specific RNA-binding protein that directs maternal mRNA clearance during the Drosophila maternal-to-zygotic transition. Genome biology 16, 94.

Laver, J.D., Marsolais, A.J., Smibert, C.A., and Lipshitz, H.D. (2015b). Regulation and Function of Maternal Gene Products During the Maternal-to-Zygotic Transition in Drosophila. Curr Top Dev Biol 113, 43-84.

Li, X., Quon, G., Lipshitz, H.D., and Morris, Q. (2010). Predicting in vivo binding sites of RNA-binding proteins using mRNA secondary structure. RNA 16, 1096-1107.

Liu, G., Zhang, J., Larsen, B., Stark, C., Breitkreutz, A., Lin, Z.Y., Breitkreutz, B.J., Ding, Y., Colwill, K., Pasculescu, A., et al. (2010). ProHits: integrated software for mass spectrometry-based interaction proteomics. Nature biotechnology 28, 1015-1017.

Liu, Y.C., Couzens, A.L., Deshwar, A.R., LD, B.M.-C., Zhang, X., Puviindran, V., Scott, I.C., Gingras, A.C., Hui, C.C., and Angers, S. (2014). The PPFIA1-PP2A protein complex promotes trafficking of Kif7 to the ciliary tip and Hedgehog signaling. Sci Signal 7, ra117.

Lorenz, R., Bernhart, S.H., Honer Zu Siederdissen, C., Tafer, H., Flamm, C., Stadler, P.F., and Hofacker, I.L. (2011). ViennaRNA Package 2.0. Algorithms for molecular biology : AMB 6, 26.

Luo, H., Li, X., Claycomb, J.M., and Lipshitz, H.D. (2016). The Smaug RNA-Binding Protein Is Essential for microRNA Synthesis During the Drosophila Maternal-to-zygotic Transition. G3 (Bethesda) 6, 35413551.

Markmiller, S., Soltanieh, S., Server, K.L., Mak, R., Jin, W., Fang, M.Y., Luo, E.C., Krach, F., Yang, D., Sen, A., et al. (2018). Context-Dependent and Disease-Specific Diversity in Protein Interactions within Stress Granules. Cell 172, 590-604 e513.

Marygold, S.J., Roote, J., Reuter, G., Lambertsson, A., Ashburner, M., Millburn, G.H., Harrison, P.M., Yu, Z., Kenmochi, N., Kaufman, T.C., et al. (2007). The ribosomal protein genes and Minute loci of Drosophila melanogaster. Genome biology 8, R216.

Meyuhas, O., and Kahan, T. (2015). The race to decipher the top secrets of TOP mRNAs. Biochim Biophys Acta 1849, 801-811. 
Mohan, R.D., Dialynas, G., Weake, V.M., Liu, J., Martin-Brown, S., Florens, L., Washburn, M.P., Workman, J.L., and Abmayr, S.M. (2014). Loss of Drosophila Ataxin-7, a SAGA subunit, reduces H2B ubiquitination and leads to neural and retinal degeneration. Genes \& development 28, 259-272.

Monzo, K., Papoulas, O., Cantin, G.T., Wang, Y., Yates, J.R., 3rd, and Sisson, J.C. (2006). Fragile X mental retardation protein controls trailer hitch expression and cleavage furrow formation in Drosophila embryos. Proceedings of the National Academy of Sciences of the United States of America 103, 18160-18165.

Na, H., Laver, J.D., Jeon, J., Singh, F., Ancevicius, K., Fan, Y., Cao, W.X., Nie, K., Yang, Z., Luo, H., et al. (2016). A high-throughput pipeline for the production of synthetic antibodies for analysis of ribonucleoprotein complexes. RNA 22, 636-655.

Namkoong, S., Ho, A., Woo, Y.M., Kwak, H., and Lee, J.H. (2018). Systematic Characterization of StressInduced RNA Granulation. Mol Cell 70, 175-187 e178.

Okamura, K., Ishizuka, A., Siomi, H., and Siomi, M.C. (2004). Distinct roles for Argonaute proteins in small RNA-directed RNA cleavage pathways. Genes \& development 18, 1655-1666.

Panas, M.D., Ivanov, P., and Anderson, P. (2016). Mechanistic insights into mammalian stress granule dynamics. The Journal of cell biology 215, 313-323.

Papoulas, O., Monzo, K.F., Cantin, G.T., Ruse, C., Yates, J.R., 3rd, Ryu, Y.H., and Sisson, J.C. (2010). dFMRP and Caprin, translational regulators of synaptic plasticity, control the cell cycle at the Drosophila midblastula transition. Development 137, 4201-4209.

Pazman, C., Mayes, C.A., Fanto, M., Haynes, S.R., and Mlodzik, M. (2000). Rasputin, the Drosophila homologue of the RasGAP SH3 binding protein, functions in ras- and Rho-mediated signaling. Development 127, 1715-1725.

Pellizzoni, L., Cardinali, B., Lin-Marq, N., Mercanti, D., and Pierandrei-Amaldi, P. (1996). A Xenopus laevis homologue of the La autoantigen binds the pyrimidine tract of the 5' UTR of ribosomal protein mRNAs in vitro: implication of a protein factor in complex formation. Journal of molecular biology 259, 904-915.

Persson, H., Ye, W., Wernimont, A., Adams, J.J., Koide, A., Koide, S., Lam, R., and Sidhu, S.S. (2013). CDR$\mathrm{H} 3$ diversity is not required for antigen recognition by synthetic antibodies. Journal of molecular biology 425, 803-811.

Pinder, B.D., and Smibert, C.A. (2013). microRNA-independent recruitment of Argonaute 1 to nanos mRNA through the Smaug RNA-binding protein. EMBO reports 14, 80-86.

Protter, D.S., and Parker, R. (2016). Principles and Properties of Stress Granules. Trends Cell Biol 26, 668679.

Ray, D., Kazan, H., Cook, K.B., Weirauch, M.T., Najafabadi, H.S., Li, X., Gueroussov, S., Albu, M., Zheng, H., Yang, A., et al. (2013). A compendium of RNA-binding motifs for decoding gene regulation. Nature 499, 172-177.

Saeed, A.I., Bhagabati, N.K., Braisted, J.C., Liang, W., Sharov, V., Howe, E.A., Li, J., Thiagarajan, M., White, J.A., and Quackenbush, J. (2006). TM4 microarray software suite. Methods Enzymol 411, 134-193.

Saeed, A.I., Sharov, V., White, J., Li, J., Liang, W., Bhagabati, N., Braisted, J., Klapa, M., Currier, T., Thiagarajan, M., et al. (2003). TM4: a free, open-source system for microarray data management and analysis. Biotechniques 34, 374-378.

Sancak, Y., Bar-Peled, L., Zoncu, R., Markhard, A.L., Nada, S., and Sabatini, D.M. (2010). Ragulator-Rag complex targets mTORC1 to the lysosomal surface and is necessary for its activation by amino acids. Cell 141, 290-303.

Santon, J.B., and Pellegrini, M. (1980). Expression of ribosomal proteins during Drosophila early development. Proceedings of the National Academy of Sciences of the United States of America 77, 5649-5653. 
Santon, J.B., and Pellegrini, M. (1981). Rates of ribosomal protein and total protein synthesis during Drosophila early embryogenesis. Dev Biol 85, 252-257.

1214

Schindelin, J., Arganda-Carreras, I., Frise, E., Kaynig, V., Longair, M., Pietzsch, T., Preibisch, S., Rueden, C., Saalfeld, S., Schmid, B., et al. (2012). Fiji: an open-source platform for biological-image analysis. Nature methods 9, 676-682.

Schneider, C.A., Rasband, W.S., and Eliceiri, K.W. (2012). NIH Image to ImageJ: 25 years of image analysis. Nature methods 9, 671-675.

Semotok, J.L., Cooperstock, R.L., Pinder, B.D., Vari, H.K., Lipshitz, H.D., and Smibert, C.A. (2005). Smaug recruits the CCR4/POP2/NOT deadenylase complex to trigger maternal transcript localization in the early Drosophila embryo. Current biology : CB 15, 284-294.

Semotok, J.L., Luo, H., Cooperstock, R.L., Karaiskakis, A., Vari, H.K., Smibert, C.A., and Lipshitz, H.D. (2008). Drosophila maternal Hsp83 mRNA destabilization is directed by multiple SMAUG recognition elements in the open reading frame. Molecular and cellular biology 28, 6757-6772.

Smibert, C.A., Lie, Y.S., Shillinglaw, W., Henzel, W.J., and Macdonald, P.M. (1999). Smaug, a novel and conserved protein, contributes to repression of nanos mRNA translation in vitro. Rna 5, 1535-1547.

Smibert, C.A., Wilson, J.E., Kerr, K., and Macdonald, P.M. (1996). Smaug protein represses translation of unlocalized nanos mRNA in the Drosophila embryo. Genes and Development 10, 2600-2609.

Solomon, S., Xu, Y., Wang, B., David, M.D., Schubert, P., Kennedy, D., and Schrader, J.W. (2007). Distinct structural features of caprin-1 mediate its interaction with G3BP-1 and its induction of phosphorylation of eukaryotic translation initiation factor 2alpha, entry to cytoplasmic stress granules, and selective interaction with a subset of mRNAs. Molecular and cellular biology 27, 23242342.

Tadros, W., Goldman, A.L., Babak, T., Menzies, F., Vardy, L., Orr-Weaver, T., Hughes, T.R., Westwood, J.T., Smibert, C.A., and Lipshitz, H.D. (2007). SMAUG is a major regulator of maternal mRNA destabilization in Drosophila and its translation is activated by the PAN GU kinase. Developmental cell 12, 143-155.

Tadros, W., and Lipshitz, H.D. (2009). The maternal-to-zygotic transition: a play in two acts. Development 136, 3033-3042.

Tareen, A., and Kinney, J.B. (2019). Logomaker: beautiful sequence logos in Python. Bioinformatics. Tcherkezian, J., Cargnello, M., Romeo, Y., Huttlin, E.L., Lavoie, G., Gygi, S.P., and Roux, P.P. (2014). Proteomic analysis of cap-dependent translation identifies LARP1 as a key regulator of 5'TOP mRNA translation. Genes \& development 28, 357-371.

Thompson, M.K., and Gilbert, W.V. (2017). mRNA length-sensing in eukaryotic translation: reconsidering the "closed loop" and its implications for translational control. Curr Genet 63, 613-620.

Thompson, M.K., Rojas-Duran, M.F., Gangaramani, P., and Gilbert, W.V. (2016). The ribosomal protein Asc1/RACK1 is required for efficient translation of short mRNAs. Elife 5.

Thomsen, S., Anders, S., Janga, S.C., Huber, W., and Alonso, C.R. (2010). Genome-wide analysis of mRNA decay patterns during early Drosophila development. Genome biology 11, R93.

Tourriere, H., Chebli, K., Zekri, L., Courselaud, B., Blanchard, J.M., Bertrand, E., and Tazi, J. (2003). The RasGAP-associated endoribonuclease G3BP assembles stress granules. The Journal of cell biology 160, 823-831.

Tusher, V.G., Tibshirani, R., and Chu, G. (2001). Significance analysis of microarrays applied to the ionizing radiation response. Proceedings of the National Academy of Sciences of the United States of America 98, 5116-5121.

Tutucci, E., Livingston, N.M., Singer, R.H., and Wu, B. (2018). Imaging mRNA In Vivo, from Birth to Death. Annu Rev Biophys 47, 85-106.

Van Treeck, B., and Parker, R. (2018). Emerging Roles for Intermolecular RNA-RNA Interactions in RNP Assemblies. Cell 174, 791-802. 
1260 Vastenhouw, N.L., Cao, W.X., and Lipshitz, H.D. (2019). The maternal-to-zygotic transition revisited. 1261 Development 146.

1262 Wagih, O. (2017). ggseqlogo: a versatile R package for drawing sequence logos. Bioinformatics 33, 3645-

1263

1264

1265 3647.

Wakiyama, M., Kaitsu, Y., Muramatsu, R., Takimoto, K., and Yokoyama, S. (2012). Tethering of proteins to RNAs using the bovine immunodeficiency virus-Tat peptide and BIV-TAR RNA. Anal Biochem 427, 130-132.

Wilbertz, J.H., Voigt, F., Horvathova, I., Roth, G., Zhan, Y., and Chao, J.A. (2019). Single-Molecule Imaging of mRNA Localization and Regulation during the Integrated Stress Response. Mol Cell 73, 946-958 e947.

Youn, J.Y., Dunham, W.H., Hong, S.J., Knight, J.D.R., Bashkurov, M., Chen, G.I., Bagci, H., Rathod, B., MacLeod, G., Eng, S.W.M., et al. (2018). High-Density Proximity Mapping Reveals the Subcellular Organization of mRNA-Associated Granules and Bodies. Mol Cell 69, 517-532 e511. 
A

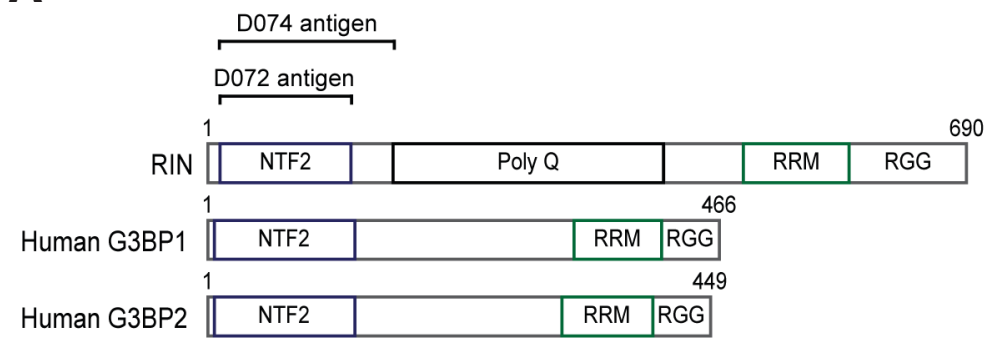

C

D

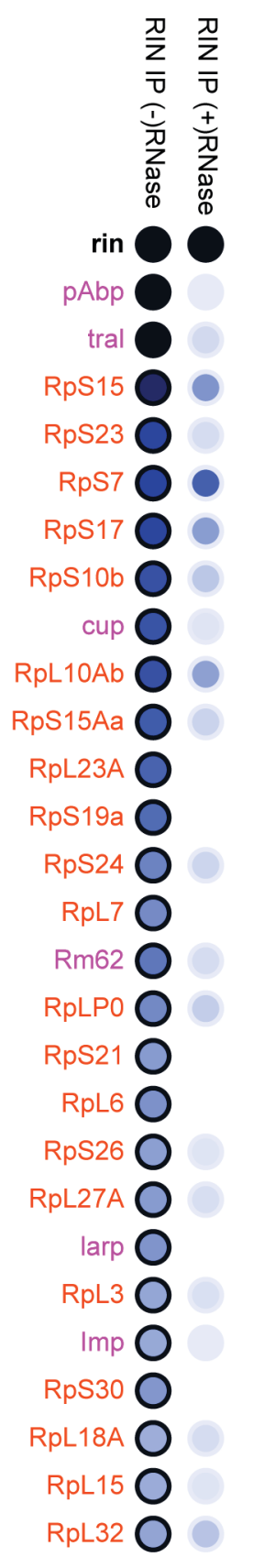

B

\begin{tabular}{|l|r|r|r|r|r|r|}
\cline { 2 - 5 } \multicolumn{1}{c|}{} & \multicolumn{4}{c}{ Total RIN peptide counts } \\
(3 replicates)
\end{tabular}

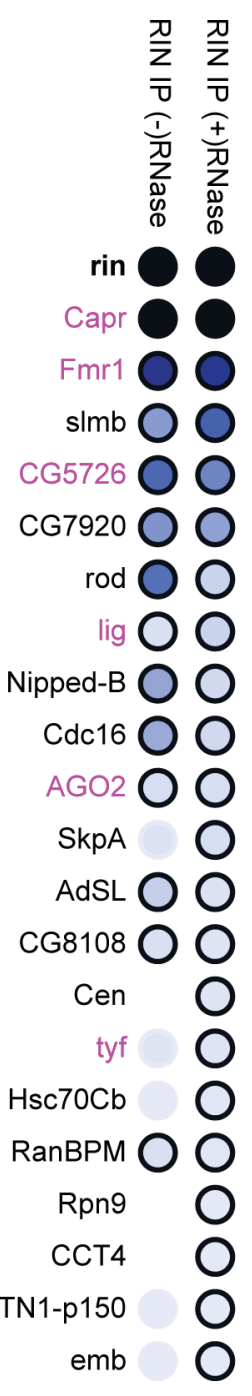

0 Average Spectral Counts 300

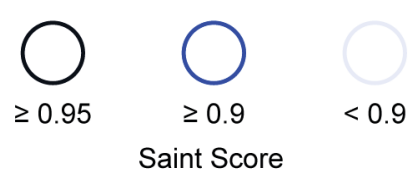

E

\section{F}


A

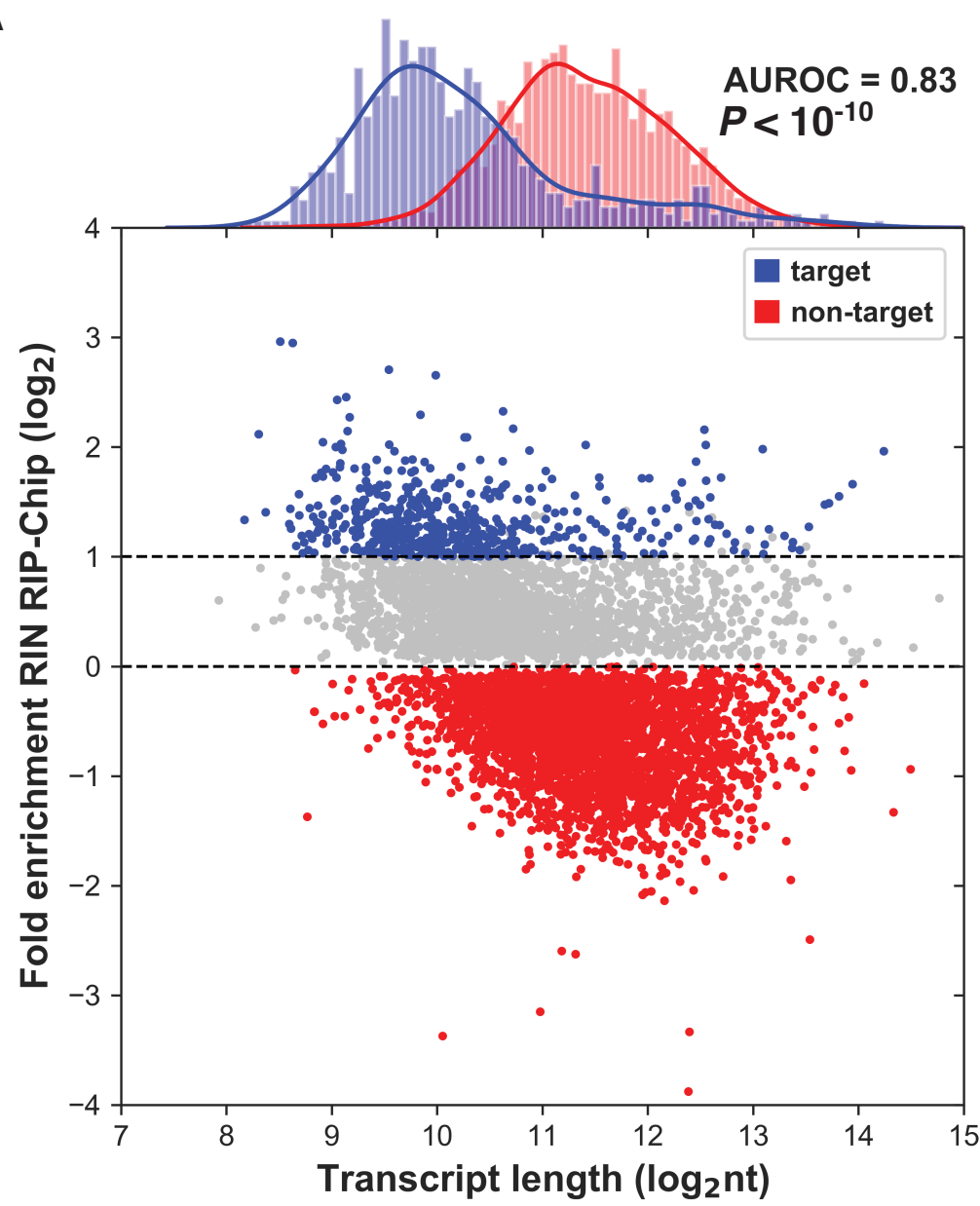

B

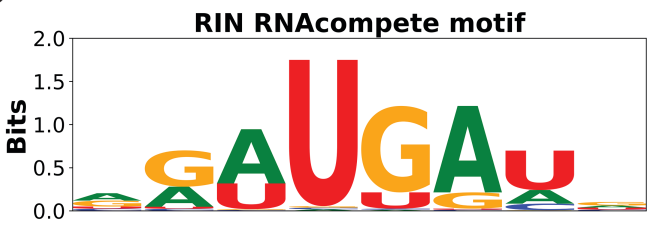

C

\begin{tabular}{|c|c|c|c|c|c|c|c|c|}
\hline \multirow{2}{*}{$\begin{array}{l}\text { Fold Enrichment } \\
\text { in RIN RIP-Chip }\end{array}$} & \multicolumn{4}{|c|}{ Significant Tests/1000 } & \multicolumn{4}{|c|}{ Mean AUROC \pm SD of Significant Tests } \\
\hline & 5'UTR & CDS & 3'UTR & Full & 5'UTR & CDS & 3'UTR & Full \\
\hline$>2.0$ & 0 & $1000^{* *}$ & 0 & $946^{*}$ & NA & $0.556 \pm 0.005$ & NA & $0.542 \pm 0.003$ \\
\hline$>2.5$ & 0 & $1000^{* \star \star}$ & 0 & $1000^{* \star}$ & NA & $0.596 \pm 0.005$ & NA & $0.597 \pm 0.005$ \\
\hline$>3.0$ & 0 & $1000^{*}$ & 0 & $1000^{*}$ & NA & $0.610 \pm 0.012$ & NA & $0.597 \pm 0.005$ \\
\hline
\end{tabular}

*: $0.01 \leq$ mean nominal $P<0.05$

$* *: 0.001 \leq$ mean nominal $P<0.01$

***: $0.0001 \leq$ mean nominal $P<0.001$

\section{D}

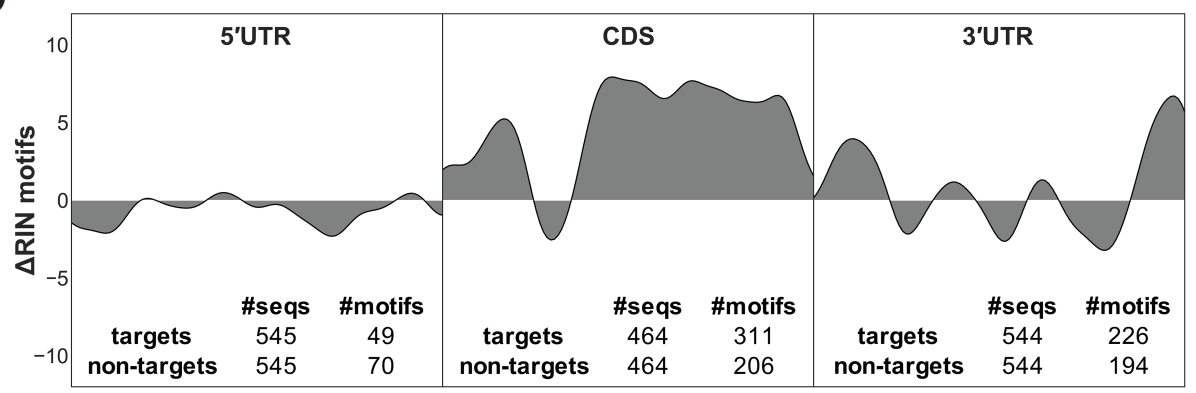


A

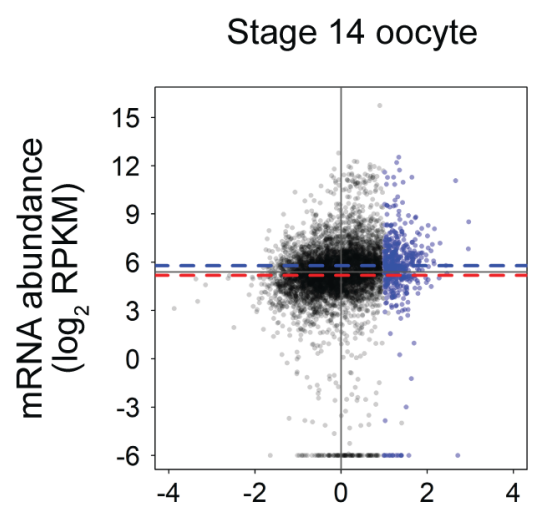

0-1 h embryo

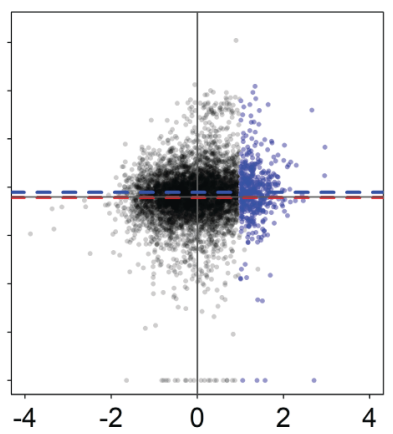

2-3 h embryo

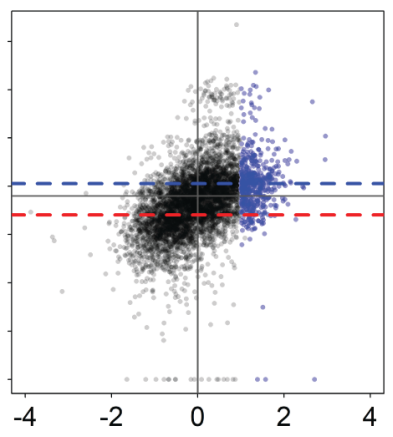

Fold enrichment RIN RIP-Chip $\left(\log _{2}\right)$

B

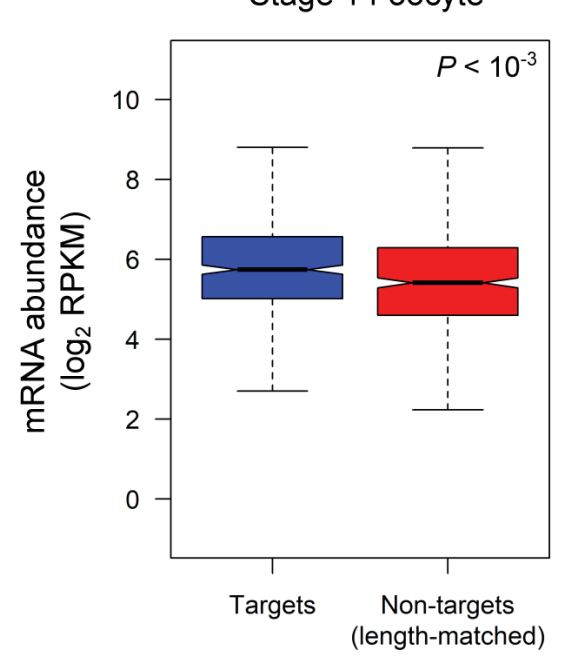

0-1 h embryo

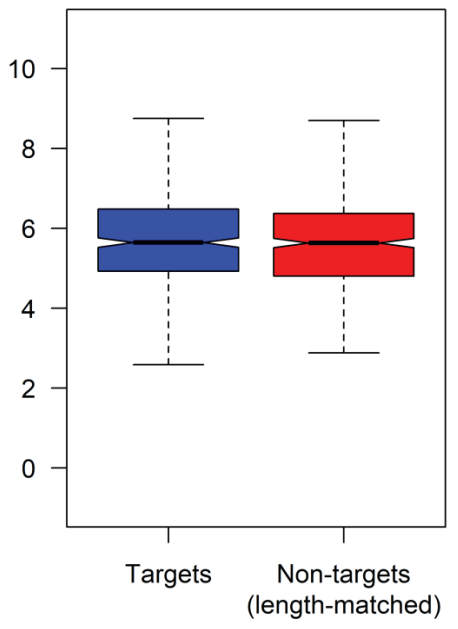

2-3 h embryo

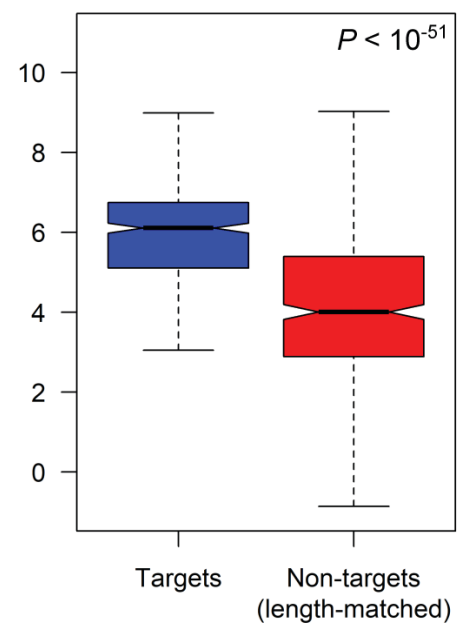


A

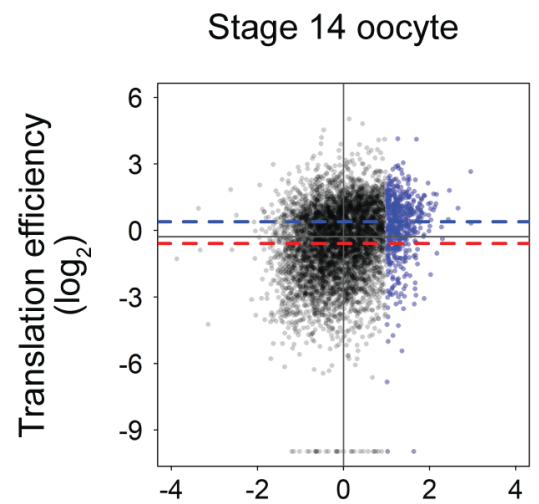

0-1 h embryo

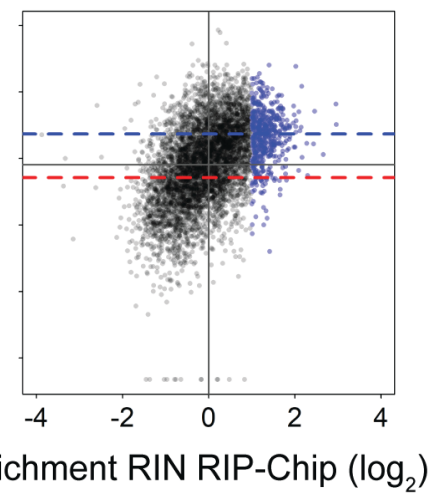

B

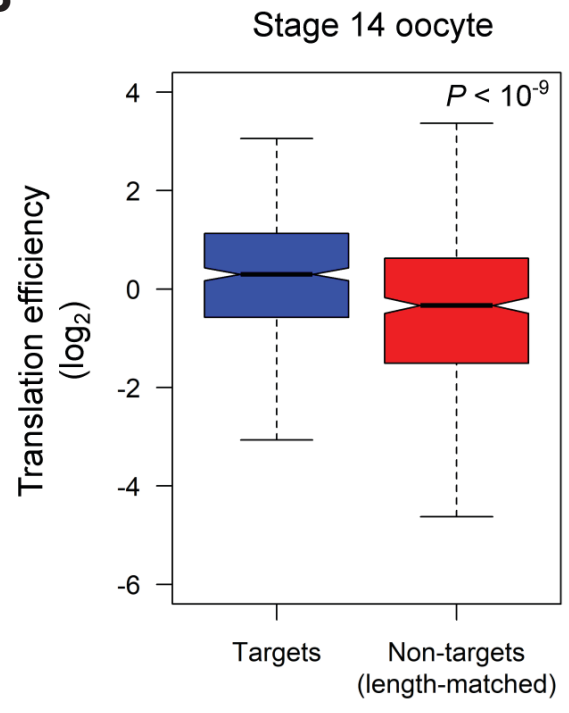

0-1 h embryo

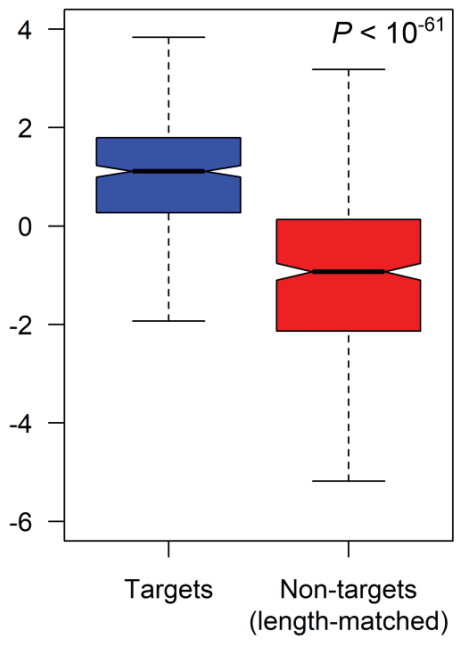

2-3 h embryo

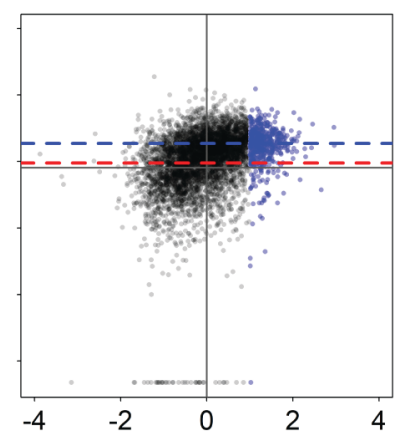

2-3 h embryo

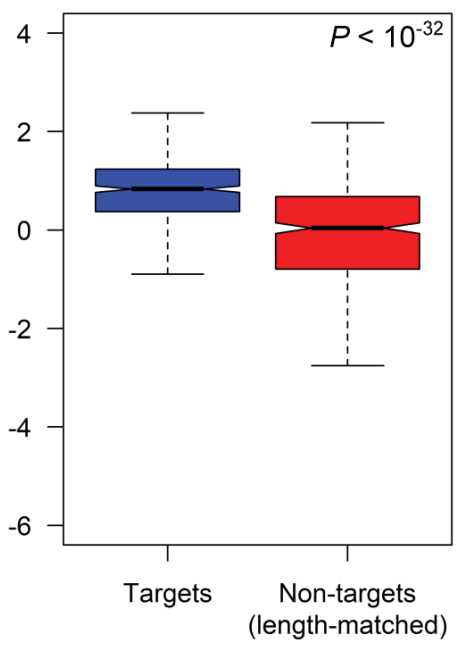


bioRxiv preprint doi: https://doi.org/10.1101/2020.01.21.913079; this version posted January 21, 2020. The copyright holder for this preprin (which was not certified by peer review) is the author/funder. All rights reserved. No reuse allowed without permission.
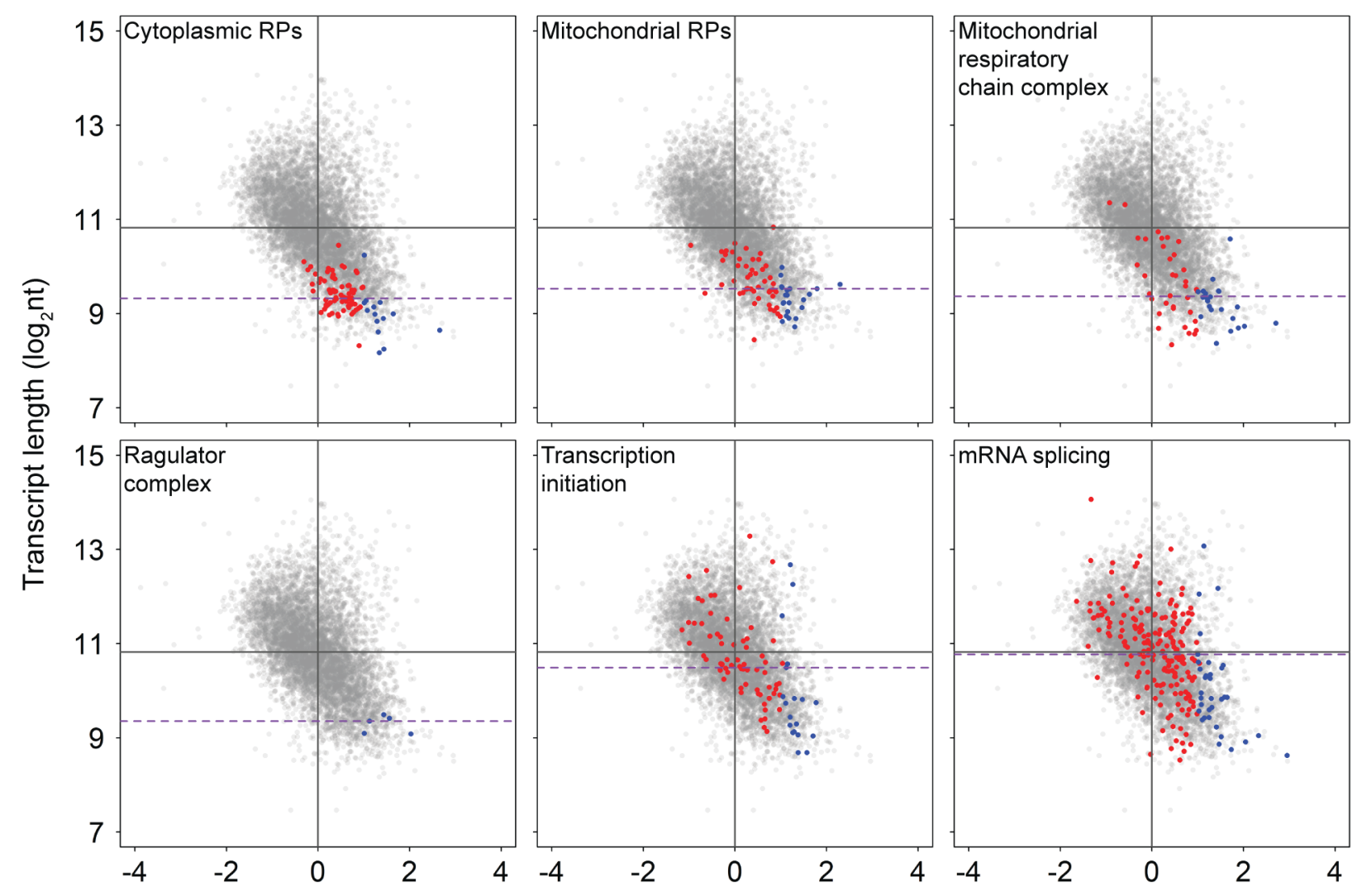

Fold enrichment RIN RIP-Chip $\left(\log _{2}\right)$ 


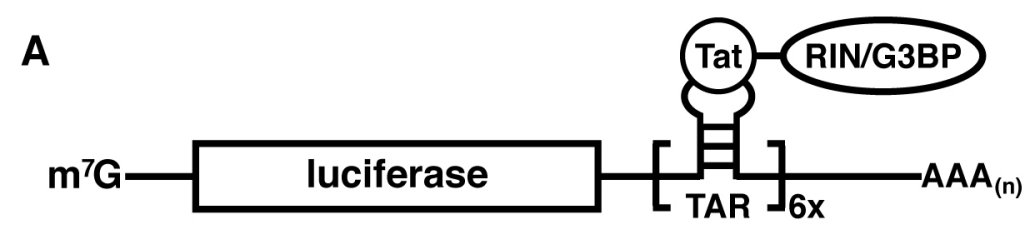

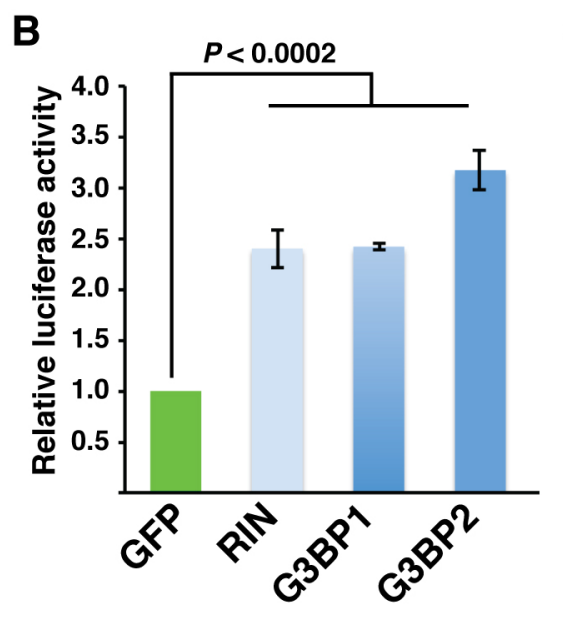

D

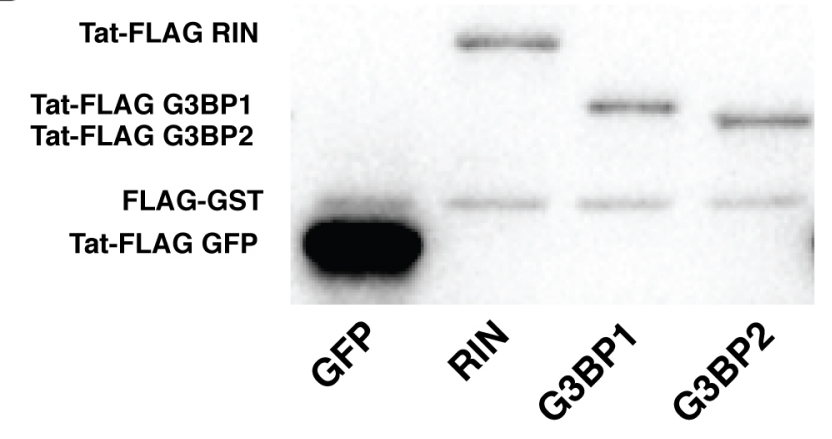

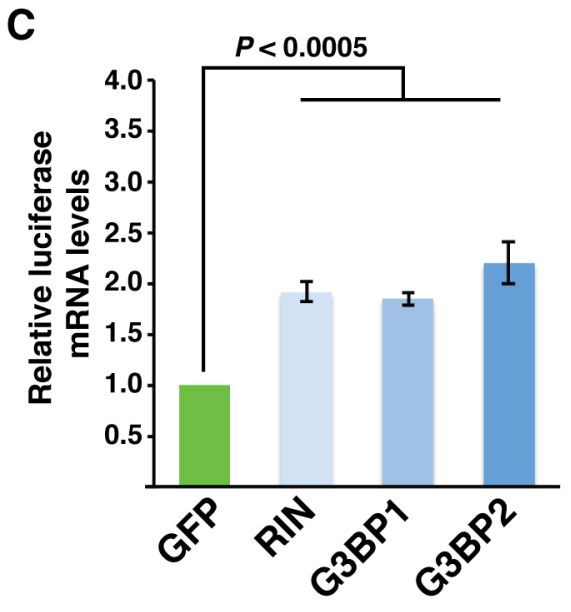

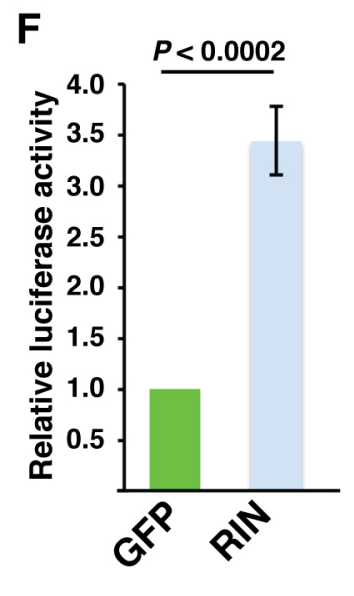

E

Tat-FLAG RIN

FLAG-GST Tat-FLAG GFP 


\section{List of Supplemental Figures and Tables with Legends}

Figure S1. RIN expression in early embryos. (A) Western blots showing a time course of RIN expression during the first four hours of embryogenesis in $w^{1118}$ embryos. $\alpha$-tubulin serves as the loading control. (B) RIN levels normalized to $\alpha$-tubulin, with the $0-1 \mathrm{hr}$ timepoint set to 100\%. There is a slight but not statistically significant decrease of RIN levels between 1-2 and 2-3 hr (Student's $t$ test; error bars indicate standard deviation of three biological replicates). (C)-(E) Confocal immunofluorescence z-axis projections of three mid-sagittal sections of early embryos which show RIN (magenta) and FMR1 (green) at nuclear cycle 2 (C), 6 (D) and 12 (E). Nuclei were visualized with DAPI (blue). The scale bar in the left panel in (C) also refers to the equivalent panels in (D) and (E); the scale bar in the second-from-left panel in (C) also refers to the equivalent panels in (D) and (E). Controls for the specificity of the anti-RIN antibody are shown in Figure S2.

Figure S2. Specificity of the anti-RIN antibody for immunofluorescence. Shown are early embryos from 'wild type' $w^{1118}$ (left) or $\mathrm{rin}^{2} / \mathrm{rin}^{3}$ mutant females. Confocal microscope z-axis projections of three mid-sagittal sections are presented. There is no RIN signal (magenta) in the mutants whereas control, FMR1, signal (green) is present in both genotypes.

Figure S3. RIN is polysome associated. Embryo extract treated with either cycloheximide or puromycin was fractionated on sucrose gradients. (A) A260 of each fraction showing a decrease of absorbance in the denser fractions upon puromycin treatment. (B) Western blots for RIN.

\section{Figure S4. RIN associates with hundreds of mRNAs in early Drosophila embryos. Plot} showing mRNA abundance, measured as the RMA-normalized microarray signal intensity, in anti-RIN (D072) RIPs versus C1 control RIPs, for all transcripts represented on the microarray that were defined as expressed in early embryos. Values represent the average of three biological replicates. mRNAs with an average enrichment $>2$-fold in RIN vs C1 IPs with an FDR $<5 \%$ are defined as RIN-associated mRNAs and are highlighted in blue (606 transcripts corresponding to 566 genes). The solid diagonal line represents no enrichment, and dashed diagonal lines represent 2-fold enrichment or depletion. See also Table S3; Figures S5 and S6. 
Figure S5. RT-qPCR validation of the enrichment of a subset of RIN-associated mRNAs identified by RIN (D072) RIP-Chip. Two biological replicates of RIN (D072) RIP and C1 RIP were performed, independent of the samples used for the RIP-Chip experiment, and RT-qPCR was used to quantify the levels of various mRNAs defined by RIP-Chip as RIN non-target mRNAs (timeout, slam, tsh, dob) or RIN-associated mRNAs (CG41128, CG7637, CG9548, gish, $N D-A G G G$ ). Shown are bar plots depicting the enrichment of mRNA levels in the RIN (D072) RIP vs C1 RIP. These enrichments observed by RT-qPCR are consistent with the RIP-Chip results. Error bars indicate standard deviation.

\section{Figure S6. Correlation of RIN (D072) RIP-Chip fold-enrichment data with RIN (D074)} RIP-Chip. To corroborate the RIN RIP-Chip data obtained using the anti-RIN D072 Fab, a single biological replicate of RIP-Chip was carried out using an additional anti-RIN Fab, D074, with the $\mathrm{C} 1 \mathrm{Fab}$ as a control. Shown are scatterplots depicting the relationship of foldenrichments (level in RIN IP / level in C1 IP) between the RIP-Chip performed with the antiRIN D072 Fab (average of three biological replicates) and the anti-RIN D074 Fab (single biological replicate), for all transcripts represented on the microarray that were defined as expressed in early embryos. There is a strong correlation between the fold enrichments obtained using the different anti-RIN Fabs. Transcripts defined in the anti-RIN D072 RIP-Chip as RINassociated are highlighted in blue.

Figure S7. BRAT, PUM, and STAU-associated transcripts are not short. Plots showing the relationship between transcript length and association with (A) BRAT, (B) PUM and (C, D) STAU, for all genes with transcripts represented on the microarray that were defined as expressed in early embryos in previous studies (Laver et al., 2013 and 2015a). Transcript length for each gene was taken to be the length of the longest annotated transcript isoform, and RBP association is represented by the fold-enrichment in the RBP RIP-Chip versus control RIP-Chip of the most highly enriched probe set on the microarray for each gene. Genes encoding RBPassociated transcripts (defined as enriched $>1.5$-fold for PUM and BRAT RIP and $>2$-fold for STAU and GFP-STAU, versus control RIP with FDR < 5\%) are highlighted in blue. Coexpressed non-targets (defined as $\log _{2}$ fold-enrichment in RBP versus C1 RIPs $<0$ in all cases) 
are highlighted in red. Gene length distributions of RBP targets and non-targets are shown in the density plots at the top. AUROC and $P$ value of Mann-Whitney $U$ test on transcript lengths of RIN targets and non-targets is shown on each plot.

Figure S8. Scatterplots showing the relationship between association with RIN and translational efficiency or mRNA abundance throughout late oogenesis and early embryogenesis. Scatterplots showing the relationship between (A) translational efficiency, or (B) mRNA abundance, as reported by Eichhorn et al., 2016, and association with RIN. Points are shown for all genes that were measured in both this study and Eichhorn et al., 2016. RINassociated transcripts as defined in this manuscript are highlighted as blue points, and solid vertical lines indicate no enrichment in RIN RIP (i.e. $\log _{2}$ fold enrichment $=0$ ). Dashed blue horizontal lines indicate median values of translational efficiency (A), or mRNA levels (B) for RIN-associated transcripts at each timepoint. Dashed red horizontal lines indicate median values of translational efficiency (A), or mRNA levels (B) for non-RIN targets (defined as foldenrichment in RIN/C1 RIPs $<1$, or $\log _{2}$ of fold-enrichment $<0$ ) at each timepoint. For (A) and (B), at all timepoints solid dark-grey horizontal lines indicate the median value of translational efficiency (A) or mRNA levels (B) in stage 14 oocytes as a reference.

Figure S9. Boxplots comparing mRNA levels of RIN-associated mRNAs to length-matched non-RIN-targets. mRNA levels, measured by Eichhorn et al. (2016), of RIN-associated transcripts ("Targets"; blue) and a five sets of randomly selected, length-matched, co-expressed non-RIN-targets (red), for each time point. Data for the first set is also shown in Figure 3B. For comparisons with a statistically significant difference in mRNA levels between targets and length-matched non-targets, Wilcoxon rank-sum $P$ values are indicated in the top right of the plots.

Figure S10. RIN-associated transcripts have higher levels of translation than RIN nontarget transcripts in 0-2 h embryos, based on genome-wide translation efficiencies reported by Dunn et al., 2013. Scatterplot showing relationship between fold-enrichment in RIN (D072) RIP-Chip, and translational efficiency in embryos collected 0-2 hours post-egg-laying as reported in Dunn et al., 2013. Points are shown for all genes that were measured in both this 
study and Dunn et al., 2013. RIN-associated transcripts as defined in this study are highlighted as blue points. Dashed blue horizontal line indicates median translational efficiency for RINassociated transcripts, and dashed red horizontal line indicates median translational efficiency for non-RIN targets (defined as fold-enrichment in RIN/C1 RIPs $<1$, or $\log _{2}$ of fold-enrichment $<$ $0)$. There is a significant correlation between enrichment in the RIN RIP and translational efficiency (Spearman rho $=0.47, P=1.22 \times 10^{-310}$ ), and RIN-associated transcripts have significantly higher translation efficiencies than RIN non-targets (Wilcoxon rank-sum $P=1.86 \mathrm{x}$ $\left.10^{-113}\right)$.

\section{Figure S11. Boxplots comparing translational efficiency of RIN-associated mRNAs to} length-matched non-RIN-targets. Translational efficiency, measured by Eichhorn et al. (2016), of RIN-associated transcripts ("Targets"; blue) and a five sets of randomly selected, lengthmatched, co-expressed non-RIN-targets (red), for each time point. Data for the first set is also shown in Figure 4B. For comparisons with a statistically significant difference in mRNA levels between targets and length-matched non-targets, Wilcoxon rank-sum $P$ values are indicated in the top right of the plots.

\section{Figure S12. The fly homologs of SG-enriched or -depleted transcripts show the same length distribution as the mammalian transcripts. The transcript lengths of Drosophila genes were} compared to published measurements of the degree to which their mammalian homologues are enriched in stress-granules, as defined for human homologues in Khong et al. (2017) (A, B), or mouse homologues in Namkoong et al., 2018 (C-H). In Khong et al., stress granule enrichment was measured as the amount of a given transcript present in isolated stress granule "cores" relative to total RNA, in response to arsenite stress. In Namkoong et al., stress granule enrichment was measured as the change in the percentage of a given transcript in the insoluble RNP granule fraction (“deltaRG”) in response to three different stresses: endoplasmic reticulum (ER) stress (panels C and D), heat shock stress ("HS"; panels E and F), and arsenite stress ("AS"; panels G and H). Transcript lengths of Drosophila genes were represented by the length of either the longest annotated transcript isoform (A, C, E, G) or the shortest annotated transcript isoform $(\mathrm{B}, \mathrm{D}, \mathrm{F}, \mathrm{H})$. Consistent with the relationship between transcript length and stress granule enrichment reported in Khong et al. and Namkoong et al., in all comparisons Drosophila 
genes with longer transcripts were more likely to have homologues enriched in stress granules, as indicated by the Spearman correlation rho values and associated $P$-values indicated on the plots.

\section{Figure S13. Relationship of transcript length and translational efficiency of Drosophila transcripts with stress granule-association status of their homologous mammalian}

transcripts. Plots of Drosophila transcript length (represented by length of the longest annotated isoform) versus translational efficiency (as measured in Eichhorn et al., 2016) are shown for translational efficiency values measured by Eichhorn et al. in Stage 14 oocytes, $0-1 \mathrm{~h}$ embryos, and 2-3 h embryos. Transcripts whose human homologues have been defined as enriched in stress granules, by Khong et al. (2017), are highlighted as green points, and transcripts whose human homologues have been defined as depleted in stress granules by Khong et al. are highlighted as magenta points. The plots only show transcripts that were considered in all three studies (i.e., defined in our study as expressed in early embryos, measured in Eichhorn et al., and with human homologues measured in Khong et al.).

\section{Figure S14. Relationship between RIN association, translational efficiency, transcript} levels, and GO term annotations. Plots showing the relationship between fold-enrichment in the RIN RIP-Chip and translational efficiency (left-hand panels) or mRNA levels (right-hand panels), measured by Eichhorn et al. (2016), during timepoints spanning the maternal-to-zygotic transition, as plotted in Figure 3. Blue and red points represent genes annotated with the following GO terms, which are enriched among RIN-associated mRNAs: (A) cytoplasmic ribosomal proteins, (B) mitochondrial ribosomal proteins, (C) mitochondrial respiratory chain complex, (D) Ragulator complex, (E) transcription initiation, and (F) mRNA splicing. mRNAs we define as associated with RIN are highlighted in blue, and genes that fall below the cut-off used to define RIN-associated mRNAs are highlighted in red. Dashed purple horizontal lines indicate the median translational efficiency (left-hand panels) or mRNA levels (right-hand panels) for all genes annotated with a given GO term at each timepoint. For all timepoints, solid dark-grey horizontal lines indicate the median values of translational efficiency (left-hand panels) or mRNA levels (right-hand panels) in stage 14 oocytes, as a reference, and solid vertical lines indicate no enrichment in the RIN RIP-Chip. See Tables 1 and S5. 
Figure S15. Distributions of RIN and CAPR in S2 tissue culture cells. Immunofluorescence visualization of (A) BIV-Tat-FLAG-RIN (B) BIV-Tat-FLAG-G3BP1, or (C) BIV-Tat-FLAGG3BP2 tethered onto the Firefly luciferase 6x TAR reporter using anti-FLAG M2 in S2 cells. Co-staining with anti-CAPR (Papoulas et al., 2010) revealed that under conditions used for the tethering assay, RIN/G3BPs are ubiquitously distributed throughout the cytoplasm and partially colocalize with CAPR. In each of (A)-(C) at least 20 transfected cells were imaged and representative z-axis projections of three sections images are shown. 


\section{Supplemental Tables:}

Table S1. Results of IP-MS SAINT analysis for IPs (+)RNase and (-)RNase.

(Excel spreadsheet)

Table S2. Comparison of RIN interactors with published datasets on human and yeast G3BP/SGs

(Excel spreadsheet)

Table S3. List of RIN2-associated mRNAs with fold-enrichment and q-values.

(Excel spreadsheet)

Table S4. Comparison of transcript length for RBP target transcripts versus co-expressed non-target transcripts defined by RIP-Chip in previous studies

(Excel spreadsheet)

\section{Table S5. Results of \#ATS de novo motif discovery}

Table showing de novo motif discovery results with the discriminative motif finder \#ATS (Li et al., 2010), which uses predicted sequence accessibility scores from RNAplfold (Bernhart et al., 2006) and identifies accessible sequence-specific RNA-binding protein motifs from in vivo binding data. Five samples comprised of the same number of length-paired targets and nontargets were extracted for each of the two different enrichment cut-offs ( $>2$-fold and $>3$-fold) and regions (CDS and full transcript). Some targets were discarded during sampling because we could not find length-paired non-targets for them. We then performed de novo motif discovery with five-fold cross validation on each sample, but we failed to discover a consistent and significant motif in RIN targets.

(Excel spreadsheet)

Table S6. Motif enrichment analysis

(Excel spreadsheet) 
Table S7. Wilcoxon rank sum test $P$ values for comparison of SRE scores of RIN targets vs non-targets

(Excel spreadsheet)

Table S8. Output from DAVID functional annotation enrichment analysis tool for RINassociated mRNAs.

(Excel spreadsheet) 
Table S9. RT-qPCR of mRNAs from ovaries.

A. RIN-enriched mRNAs $(n=13 \times 3$ biological replicates)

\begin{tabular}{|c|c|c|c|}
\hline Gene & $\begin{array}{c}\text { Rank } \\
\text { RIP-chip }\end{array}$ & $\begin{array}{c}\text { Fold enrichment } \\
\text { RIP-chip }\end{array}$ & $\begin{array}{c}\text { Fold change } \\
\operatorname{rin}^{2} / \operatorname{rin}^{3} \text { versus } \\
\operatorname{rin}^{2} \text { or } \operatorname{rin}^{3} /+ \\
\text { mean } \pm \mathrm{SD}\end{array}$ \\
\hline CG41128 & 1 & 7.79 & $0.58 \pm 0.21$ \\
\hline ubl & 2 & 7.74 & $0.85 \pm 0.33$ \\
\hline ND-AGGG & 3 & 6.52 & $0.80 \pm 0.36$ \\
\hline RpL38 & 4 & 6.31 & $0.68 \pm 0.23$ \\
\hline Pdrg1 & 5 & 5.49 & $0.98 \pm 0.34$ \\
\hline CG14057 & 6 & 5.40 & $0.64 \pm 0.28$ \\
\hline CG17768 & 7 & 5.02 & $0.70 \pm 0.18$ \\
\hline mRpS7 & 8 & 4.90 & $0.90 \pm 0.15$ \\
\hline CG40228 & 11 & 4.49 & $0.74 \pm 0.33$ \\
\hline PMCA & 12 & 4.47 & $1.24 \pm 0.19$ \\
\hline CG14210 & 13 & 4.43 & $0.80 \pm 0.18$ \\
\hline CG7637 & 14 & 4.34 & $0.82 \pm 0.02$ \\
\hline SamDC & 15 & 4.26 & $0.79 \pm 0.17$ \\
\hline
\end{tabular}

\section{B. Co-expressed mRNAs, not enriched $(n=5$ x 6 biological replicates or 3 biological} replicates for $\operatorname{chb}^{*}$ )

\begin{tabular}{|l|c|c|c|}
\hline Gene & $\begin{array}{c}\text { Rank } \\
\text { RIP-chip }\end{array}$ & $\begin{array}{c}\text { Fold enrichment } \\
\text { RIP-chip }\end{array}$ & $\begin{array}{c}\text { Fold change } \\
\boldsymbol{r i n}^{2} / \text { rin }^{3} \text { versus } \\
\boldsymbol{r i n}^{2} \text { or } \boldsymbol{r i n}^{3} /+ \\
\text { mean } \pm \text { SD }\end{array}$ \\
\hline 14-3-3-epsilon & 3175 & 1.04 & $1.04 \pm 0.12$ \\
\hline CG9346 & 3366 & 1.00 & $0.91 \pm 0.13$ \\
\hline chb* & 3369 & 1.00 & $1.21 \pm 0.39$ \\
\hline Dref & 3371 & 1.00 & $0.86 \pm 0.16$ \\
\hline mod(mdg4) & 3400 & 0.99 & $1.01 \pm 0.12$ \\
\hline C. Co-expressed
\end{tabular}

C. Co-expressed mRNAs, depleted ( $n=7 \times 3$ biological replicates)

\begin{tabular}{|l|c|c|c|}
\hline Gene & $\begin{array}{c}\text { Rank } \\
\text { RIP-chip }\end{array}$ & $\begin{array}{c}\text { Fold enrichment } \\
\text { RIP-chip }\end{array}$ & $\begin{array}{c}\text { Fold change } \\
\mathrm{rin}^{2} / \mathrm{rin}^{3} \text { versus }\end{array}$ \\
\hline
\end{tabular}




\begin{tabular}{|l|c|c|c|}
\hline & & & $\begin{array}{c}\operatorname{rin}^{2} \text { or } \operatorname{rin}^{3} /+ \\
\text { mean } \pm \text { SD }\end{array}$ \\
\hline CG10984 & 7178 & 0.17 & $1.30 \pm 0.33$ \\
\hline Spindly & 7179 & 0.16 & $0.98 \pm 0.34$ \\
\hline CG34449 & 7180 & 0.16 & $1.13 \pm 0.20$ \\
\hline CG2129 & 7182 & 0.10 & $0.86 \pm 0.08$ \\
\hline CG14562 & 7183 & 0.10 & $1.21 \pm 0.39$ \\
\hline CG31251 & 7184 & 0.10 & $1.05 \pm 0.26$ \\
\hline CG7692 & 7185 & 0.07 & $0.95 \pm 0.36$ \\
\hline
\end{tabular}

Table S10. RT-qPCR primer sequences

\section{A. Primers used in Figure 6}

\begin{tabular}{|l|l|l|}
\hline Gene & Forward primer & Reverse primer \\
\hline Firefly luc & AGCGAAGGTTGTGGATCTGG & GTGTTCGTCTTCGTCCCAGT \\
\hline Renilla luc & TGAACGTGCTGGACTCCTTC & CCGGACTTA CCCATTCC \\
\hline
\end{tabular}

\section{B. Primers used in Figure S5}

\begin{tabular}{|l|l|l|}
\hline Gene & Forward primer & Reverse primer \\
\hline timeout & AAAATGTTCGGGCTTGCAC & CAGCTTGGCCTGAAAAAGCA \\
\hline slam & TCCCCAAGATAACCAGCGAC & TGGCCTCGACAATGGAGTTC \\
\hline tsh & TGATTCCTGCCACGTTCAGT & GCGCTTTCTGATTTCTATCCTTG \\
\hline dob & TCCACAGGTCCGAGGAGTTC & CCGCAGAATGGACTTACGGT \\
\hline CG41128 & CCAGTGCGCGTTTGACTACT & GCAGATCCAATAATTACGCCTCC \\
\hline CG7637 & GATCGCGTTTACACCCTGAA & CCTCCGGTGAAAAACGTGC \\
\hline CG9548 & TTGATTTTCTGCCGCAAGCA & GGATCCGTAGTTGCACTCGT \\
\hline gish & GGGCAACACTGGGCAATCTA & TGTGATGGGCGTGTTTGAGT \\
\hline ND-AGGG & GTGGTGGGTAATCTGGCACT & ATGTAACTACATGCCTACATATCGC \\
\hline
\end{tabular}

\section{Primers used in Table S9}

\begin{tabular}{|l|l|l|}
\hline Gene & Forward primer & Reverse primer \\
\hline CG41128 & TTAAAGGATGTGGAGGCGTAA & CGTCCTATAAGCGATGCCCA \\
\hline ubl & CAAGAAGGTGCGCGTCAAGT & GCGAATCGGGTCCTTGAAGA \\
\hline ND-AGGG & ACCTGACCATATAACGGGGGA & ACTACATGCCTACATATCGCATT \\
\hline RpL38 & TGGATTAATATGCCACGGGAAA & TGATTTTTACAGCACGCGCA \\
\hline
\end{tabular}




\begin{tabular}{|l|l|l|}
\hline Pdrg 1 & GTTCGACGCTCTGAAAGCAA & TTTATATACCTCGCTAATGCGGA \\
\hline CG14057 & CGAGCAGGGATTTCGAGTGA & GCCCGTACATCTCCGATCAAA \\
\hline CG17768 & CAGAGCCATCCCATGTTGGT & ACCGATCGCCATCCTTTGAG \\
\hline mRpS7 & ACTTCAAGGCTCAGCTGCC & AGACGATTTGTTGACCGCCG \\
\hline CG40228 & AGAAAACCGCCTCCGAAGAG & TTTTATCCATTTTAACCTCACACGA \\
\hline PMCA & ATATTATCGTGGGGTCGCGG & ACTTGTGTTTGCAAGCGAGT \\
\hline CG14210 & AAATGAGTGAATCCGCACCG & CTTGCTAAATTTCTGCTTGGGCG \\
\hline CG7637 & CGTTTACACCCTGAAGAAACGC & CTCCGGTGAAAAACGTGCTG \\
\hline SamDC & GGCGCTACTGTGAAATCTGG & GAGTAGCCGCAAGGATCGAA \\
\hline 14-3-3-epsilon & GTGTACAAGGCAAAGCTGGC & GGCGTGCTCCAATCACATTC \\
\hline CG9346 & ACCCACAGAGAAGGCTGTTC & GCAGGACTCTCGTTGTCGAA \\
\hline chb & AAGGGGAACAACAACTAGCAG & CTTCGTTCTGCGGCAACTATT \\
\hline Dref & TTCCCCTGGACACTGTACGA & CGTGTCCAAAGCAATCACCAG \\
\hline mod(mdg4) & GTCCTGCTTCACGTTGACCT & CACCCACGCTATCGTATTCC \\
\hline CG10984 & AGGAGCTACCCAACCCAGAT & TGGTGCGGGATGAATCTGTC \\
\hline Spindly & CCTCCAGGTCAAATCAGCTTCA & CGATGGTTTTCTCTTTTTCAGCC \\
\hline CG34449 & GGGAAAACAGCCGCTTCAAA & AGATTCGCGGGAAACGGAAA \\
\hline CG2129 & CAAGTGGCAGGACCATCAGT & GGAATCTTGGCAGAGTGCCT \\
\hline CG14562 & ACTTGGACAAACTCTCTCCCG & TGCGTCTCGTGGACTTTGAA \\
\hline CG31251 & CGACGCAACACCGACTTTTAT & AAGCAATCCGGATCGTAGCG \\
\hline CG7692 & GCATCAGGAGAAGAAGTTGCT & TTCGTGTGCTTTCACCCAAG \\
\hline
\end{tabular}


bioRxiv preprint doi: https://doi org/10.1101/2020.01.21.913079; this version posted January 21, 2020. The copyright holder for this preprint

A

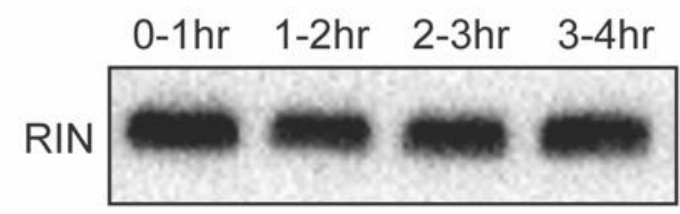

$\alpha-T U B$

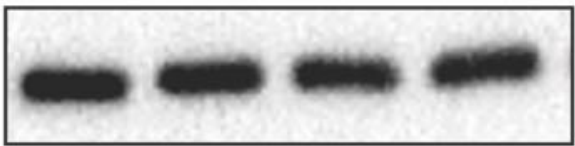

B

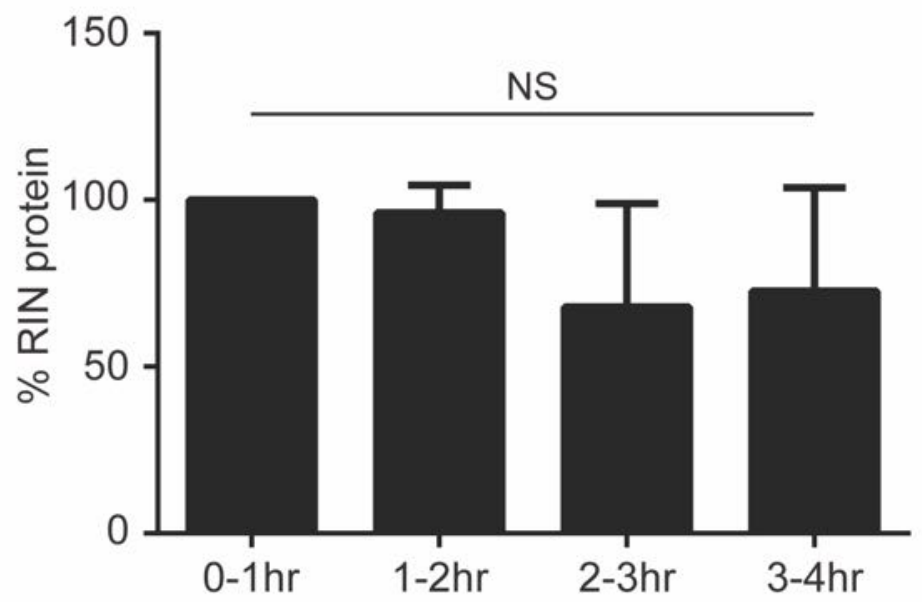

C

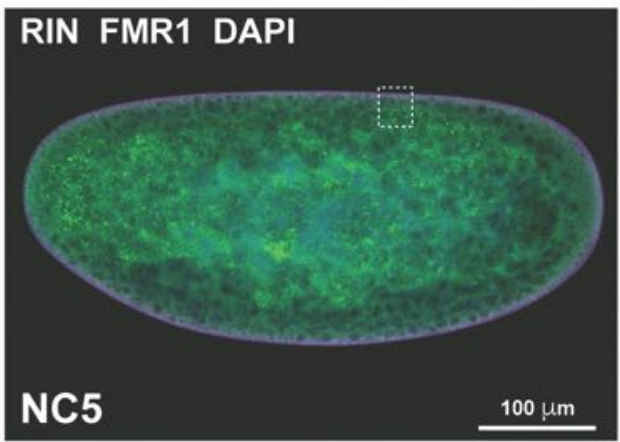

D

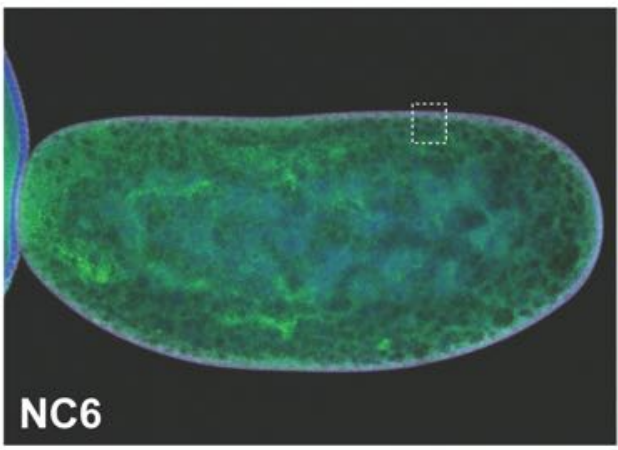

E

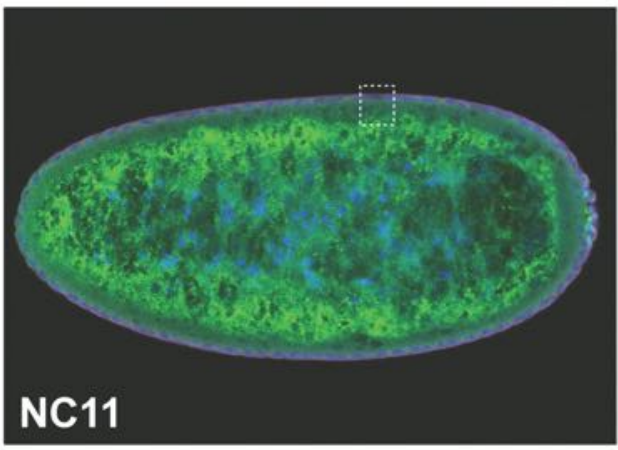

\section{RIN}
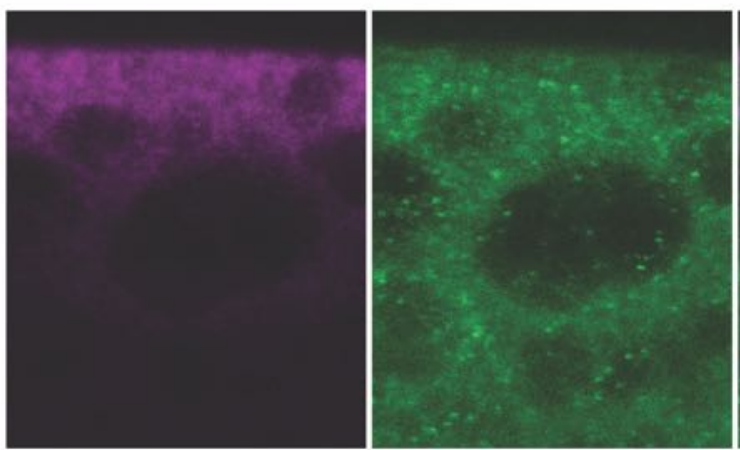

$5 \mu \mathrm{m}$
RIN FMR1 DAPI
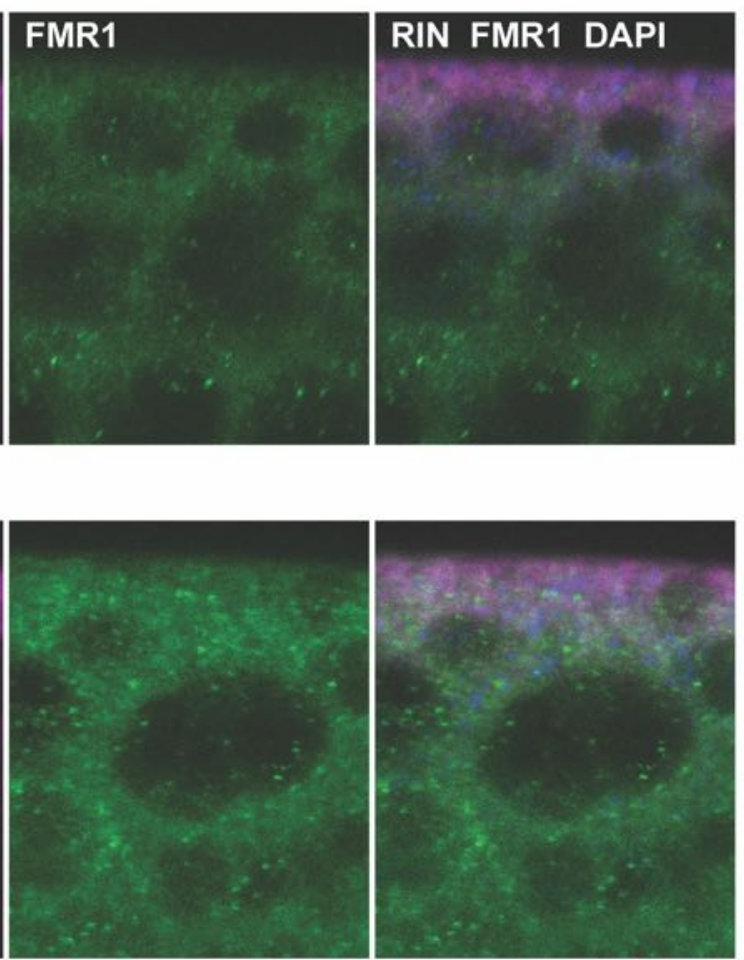
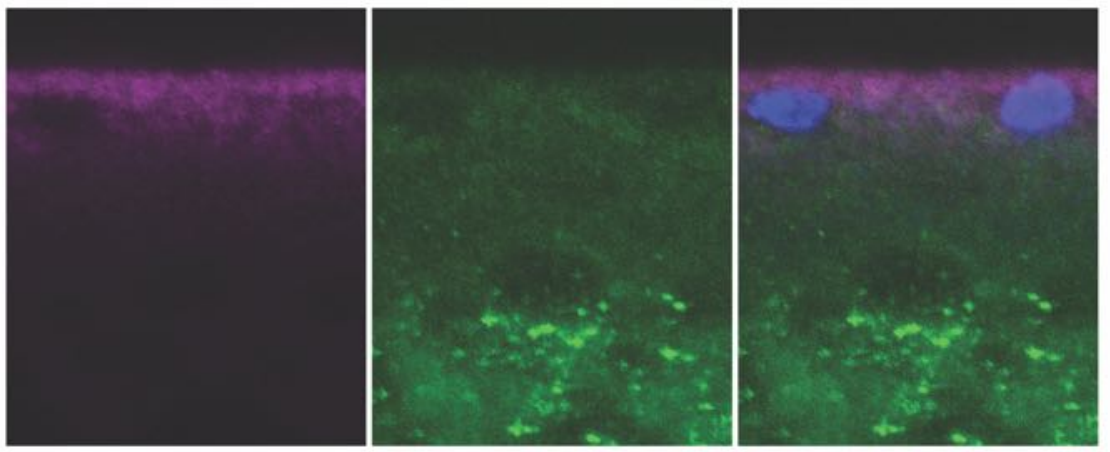
bioRxiv preprint doi: https://doi.org/10.1101/2020.01.21.913079; this version posted January 21, 2020. The copyright holder for this preprint

(which was not certified by peer review) is the author/funder. All rights reserved. No reuse allowed without permission.

$W^{1118}$
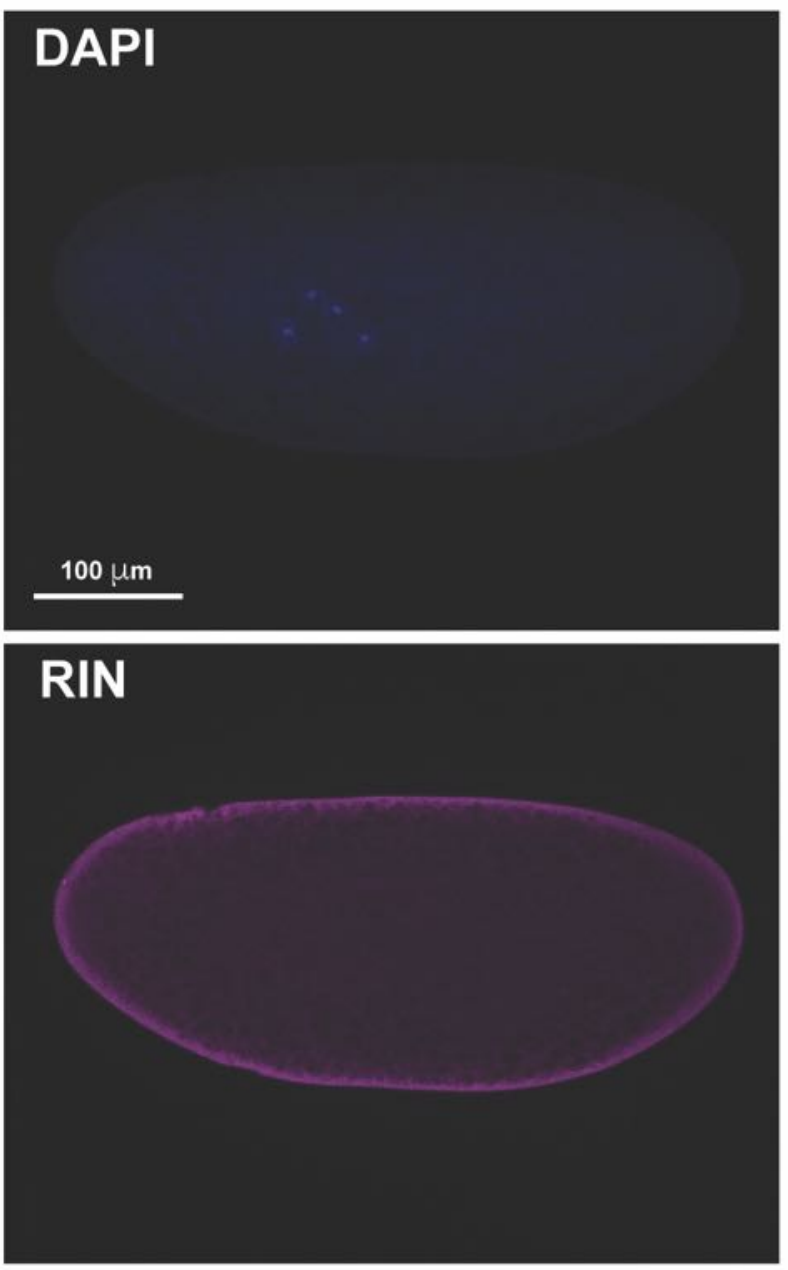

\section{FMR1}

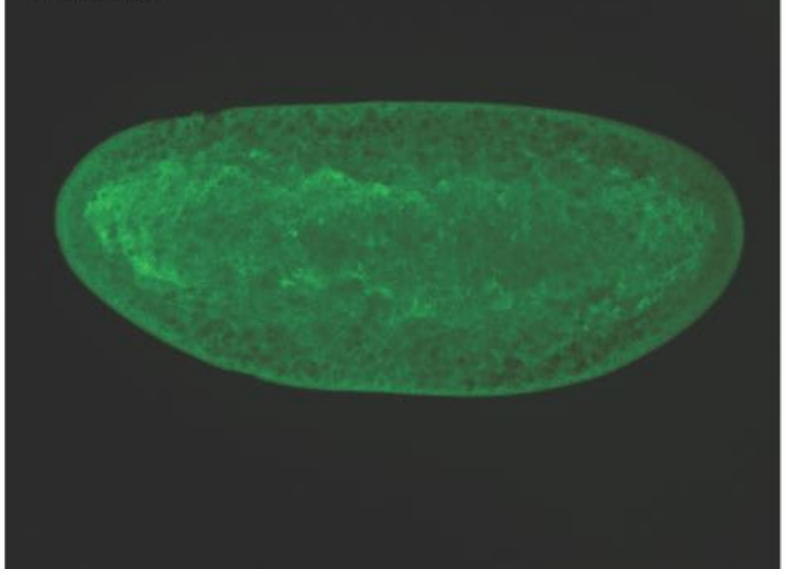

$\operatorname{rin}^{2} / \operatorname{rin}^{3}$
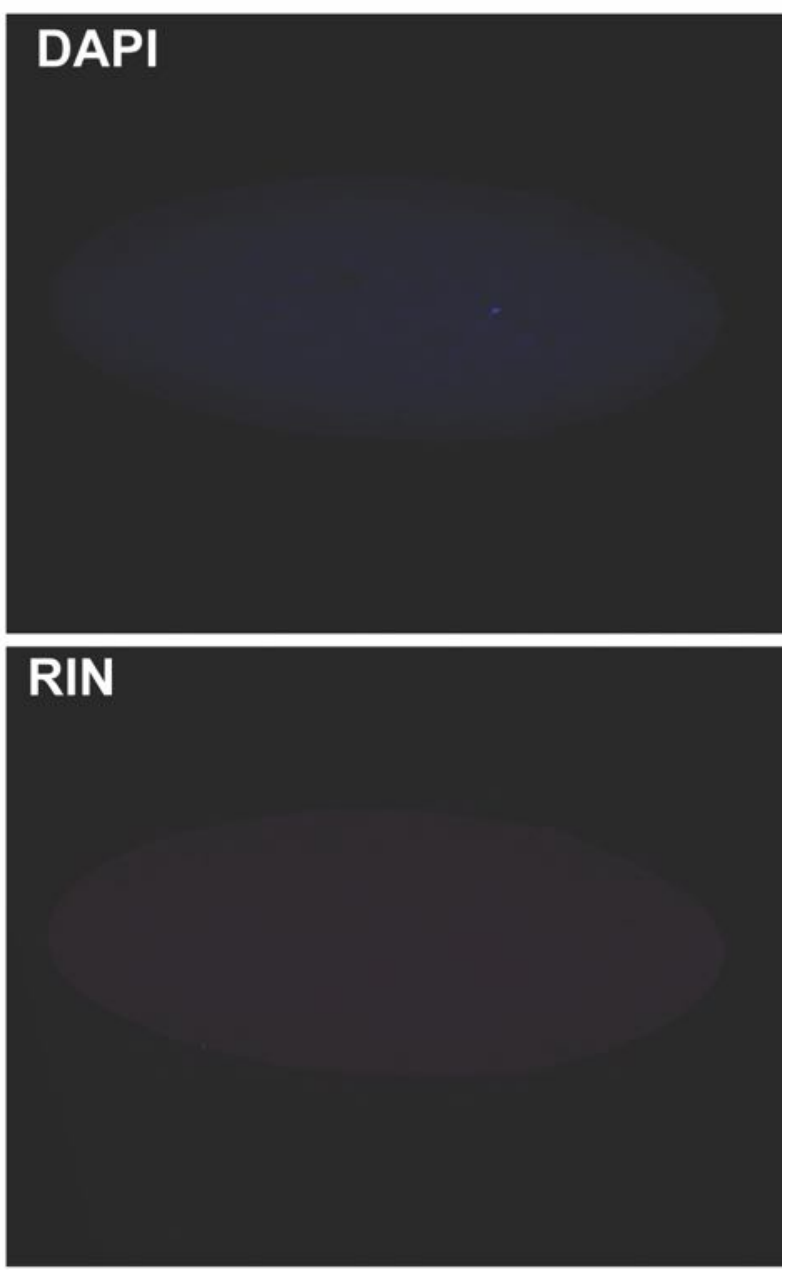

FMR1 
A
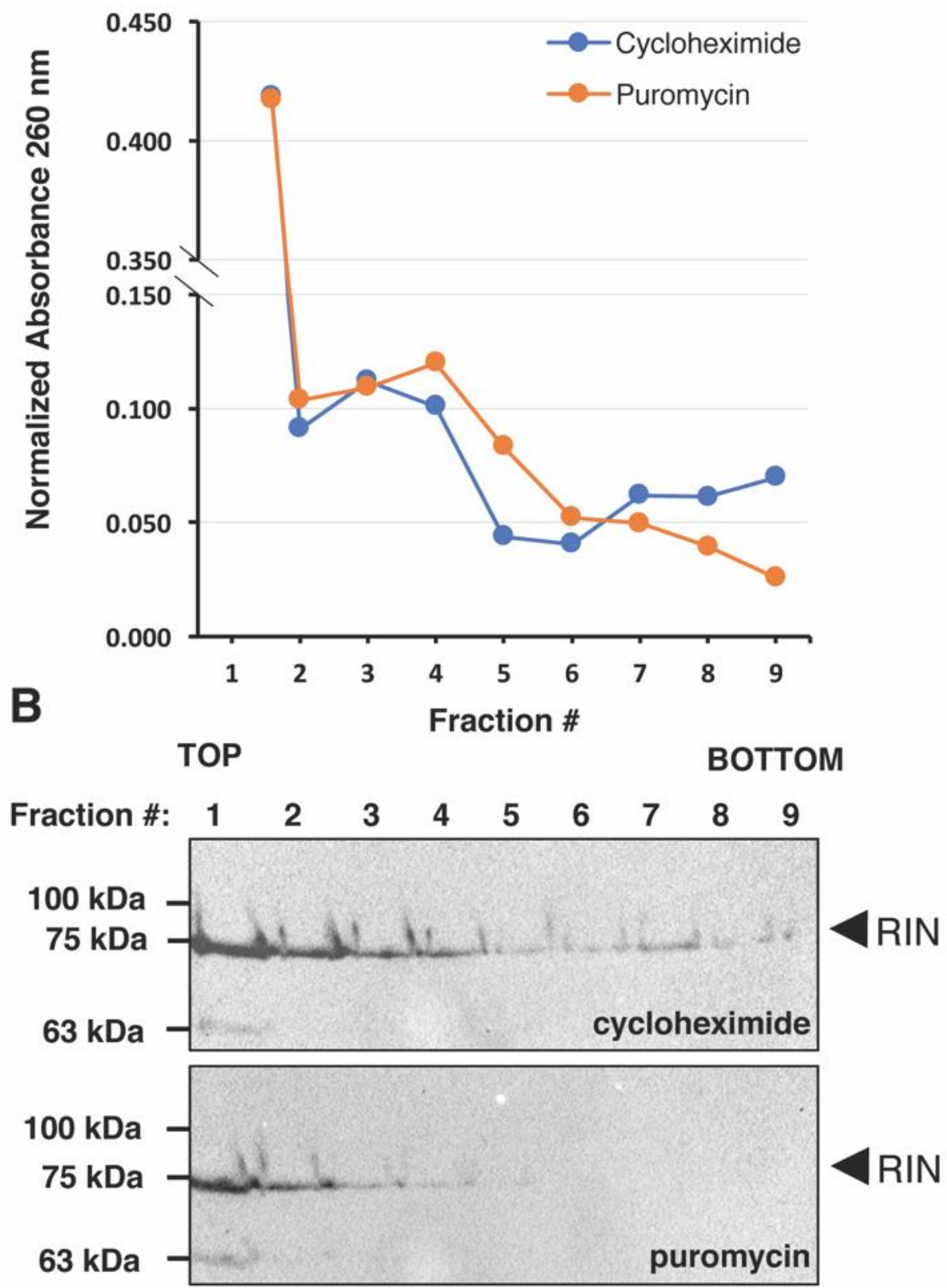


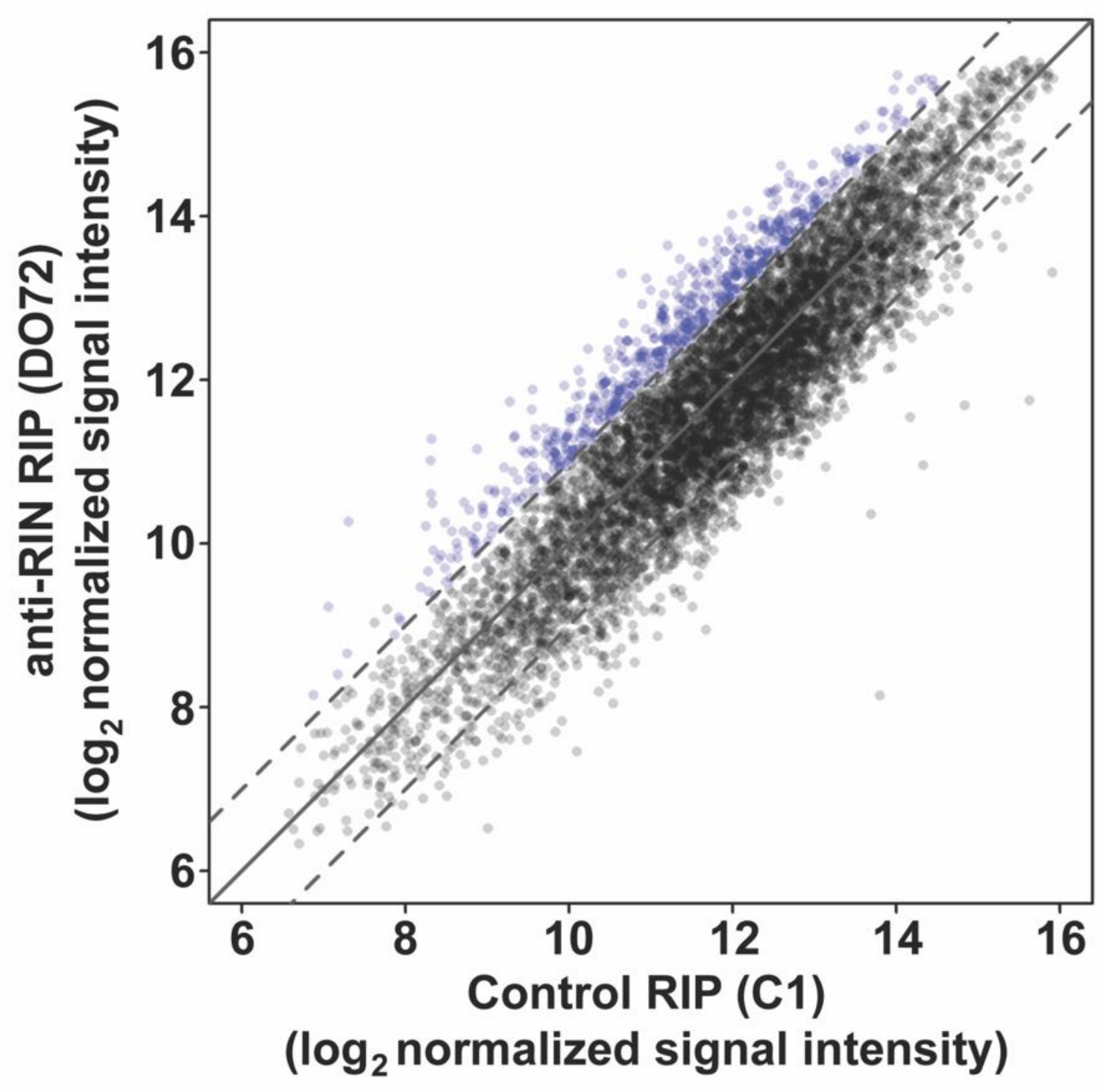




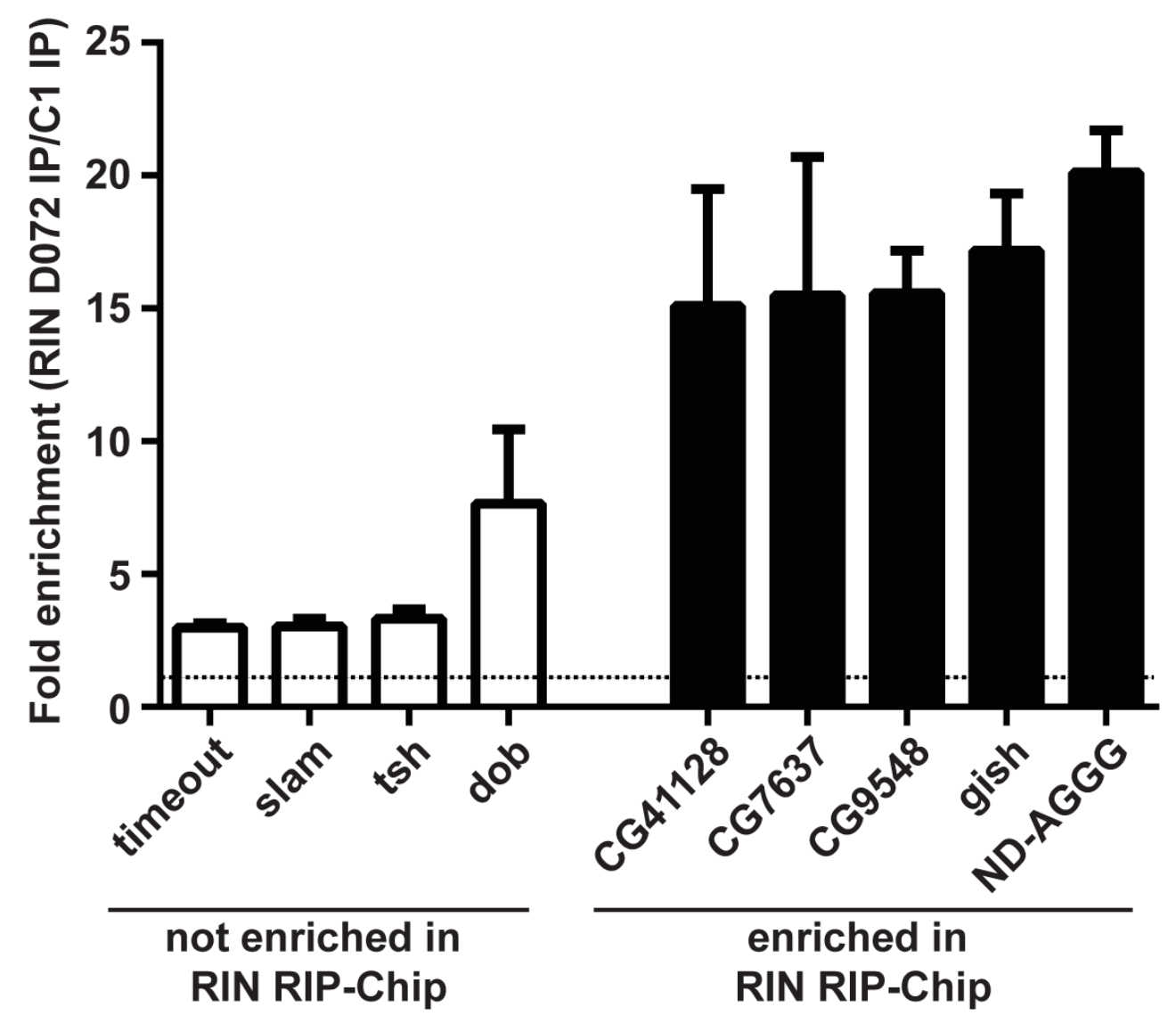




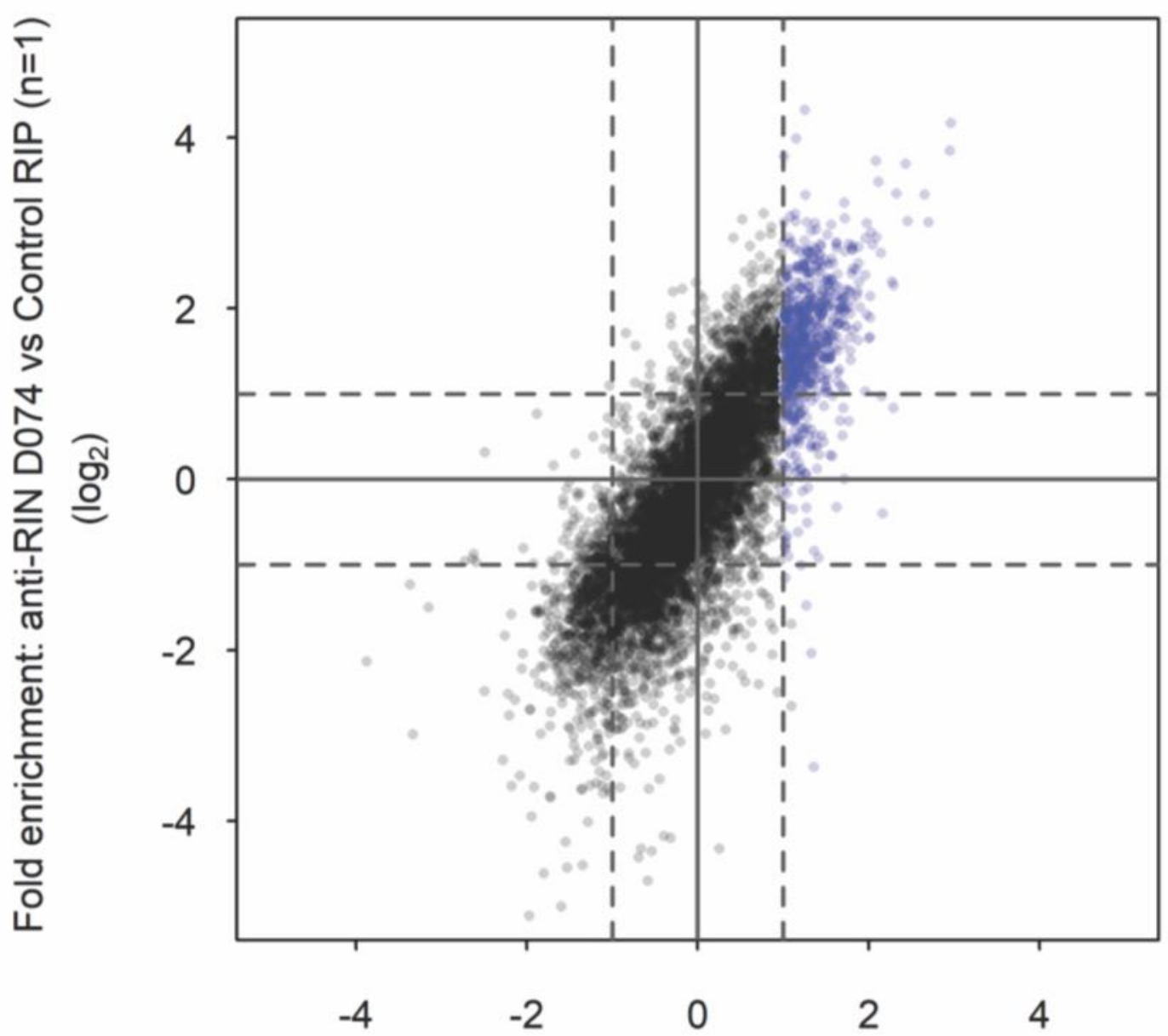

Fold enrichment: anti-RIN D072 vs Control RIP $\left(\log _{2}\right)$ 
Figure S7

A

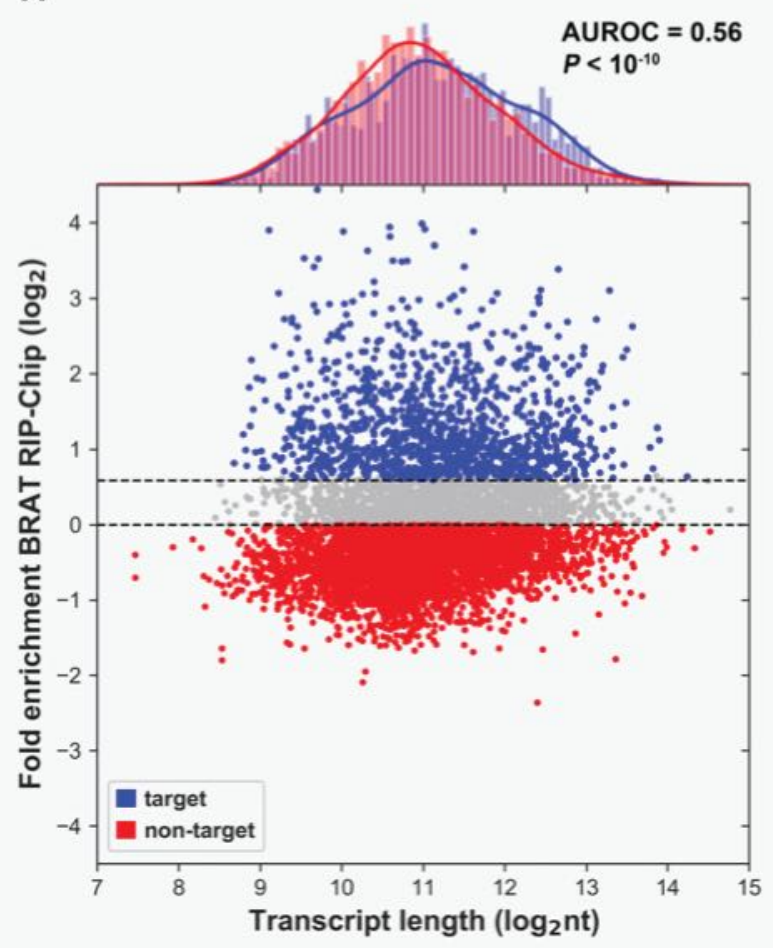

C

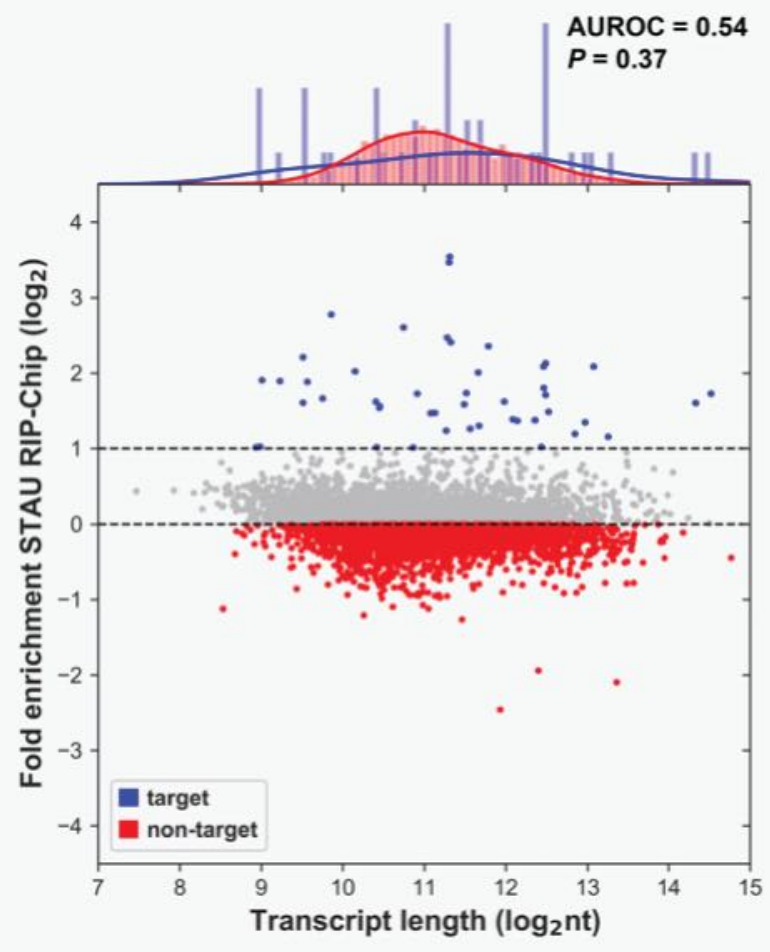

B

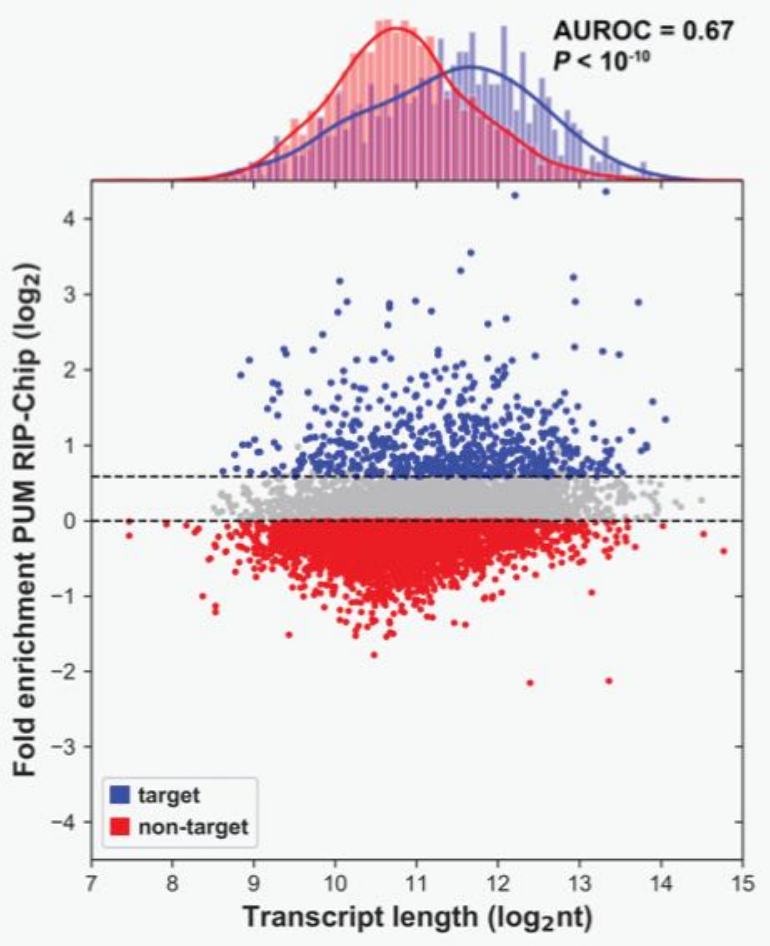

D

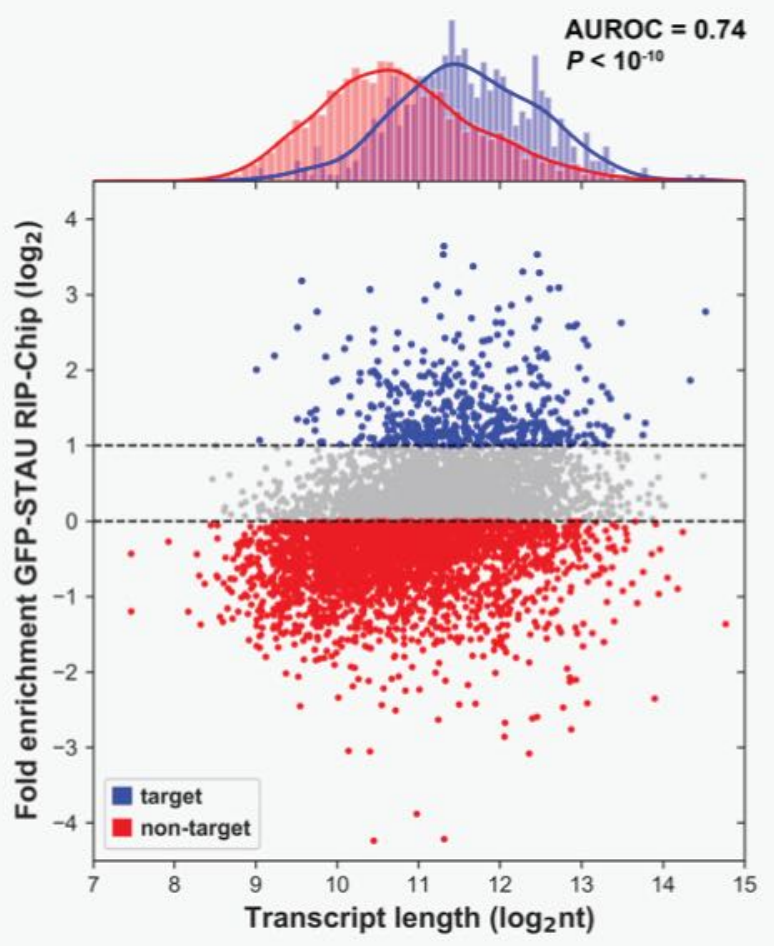


bioRxiv preprint dol: https://doi.org/10.1101/2020.01.21.913079; this version posted January 21, 2020. The copyright holder for this preprint (which was not certified by peer review) is the author/funder. All rights reserved. No reuse allowed without permission

Figure S8

A

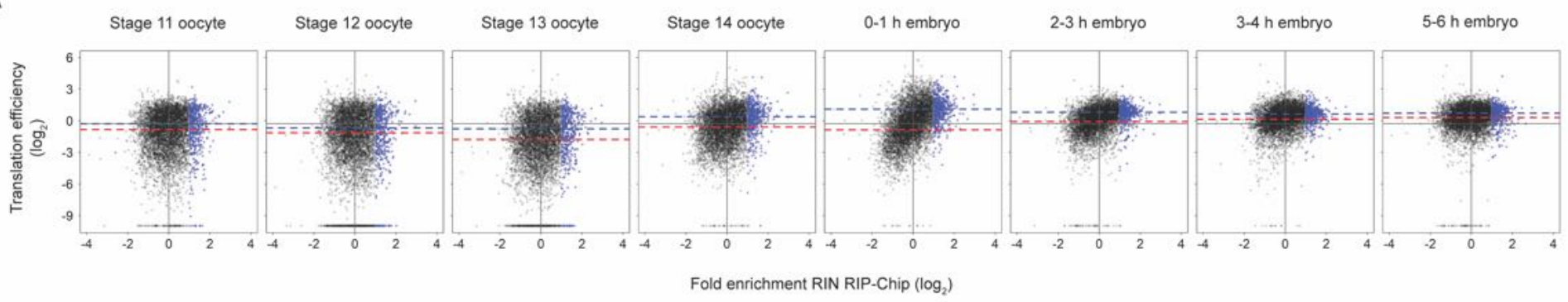

B

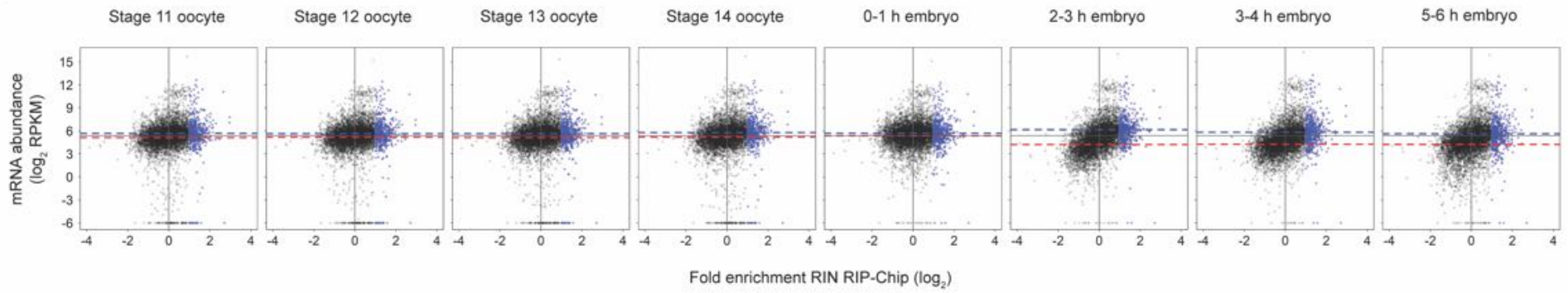


Length-matched non-target set 1

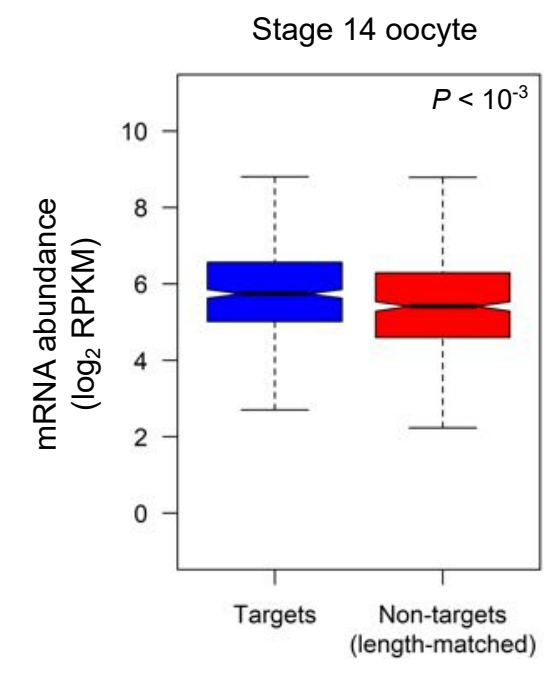

0-1 h embryo

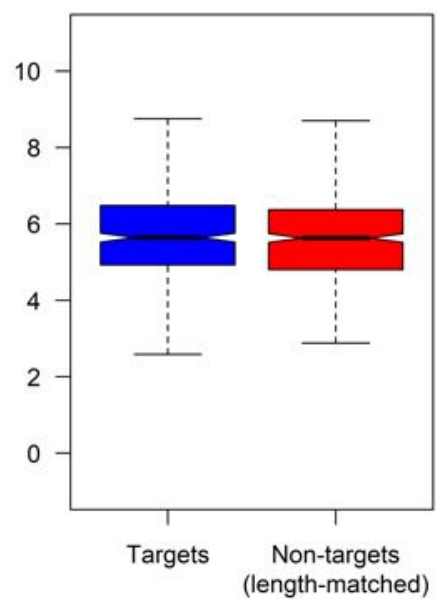

2-3 h embryo

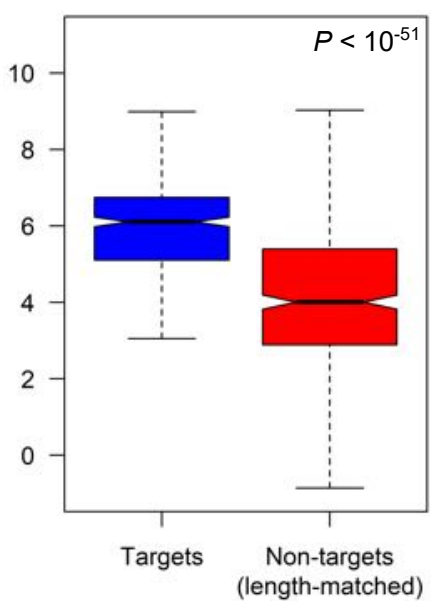

Length-matched non-target set 2

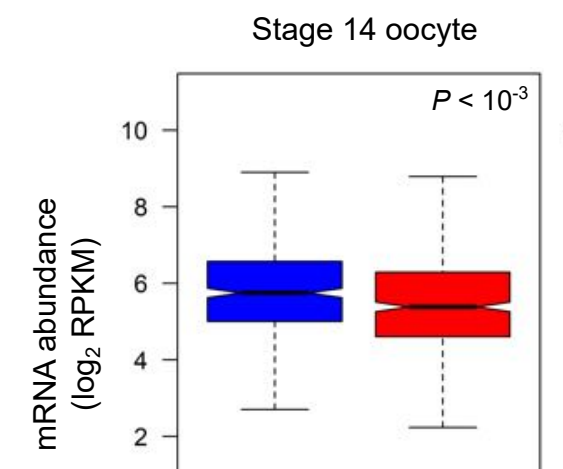

$0-1$ h embryo

2-3 h embryo
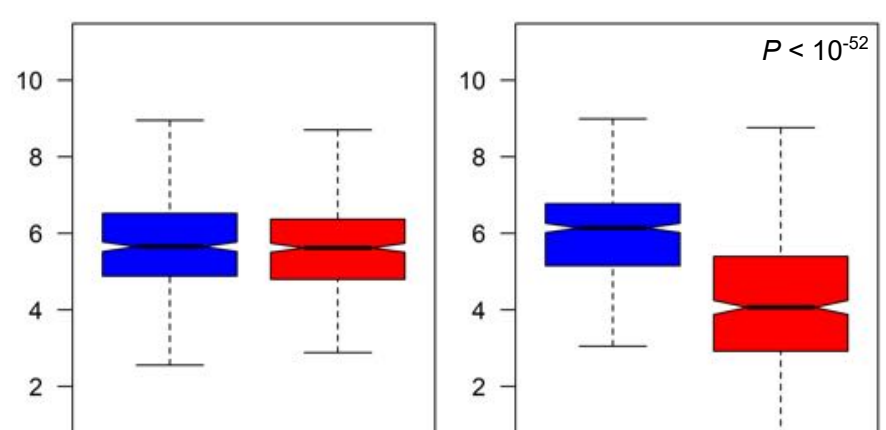

bioRxiv preprint doi: https://doi.org/10.1101/2020.01.21.913079; this version posted January 21, 2020. The copyright holder for this preprint (which was not certified by peer review) is the author/funder. All rights reserved. No reuse allowed without permission.

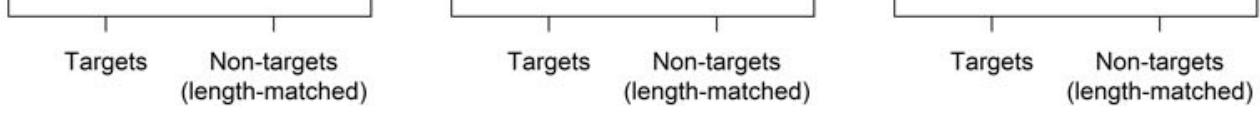

\section{Length-matched non-target set 3}
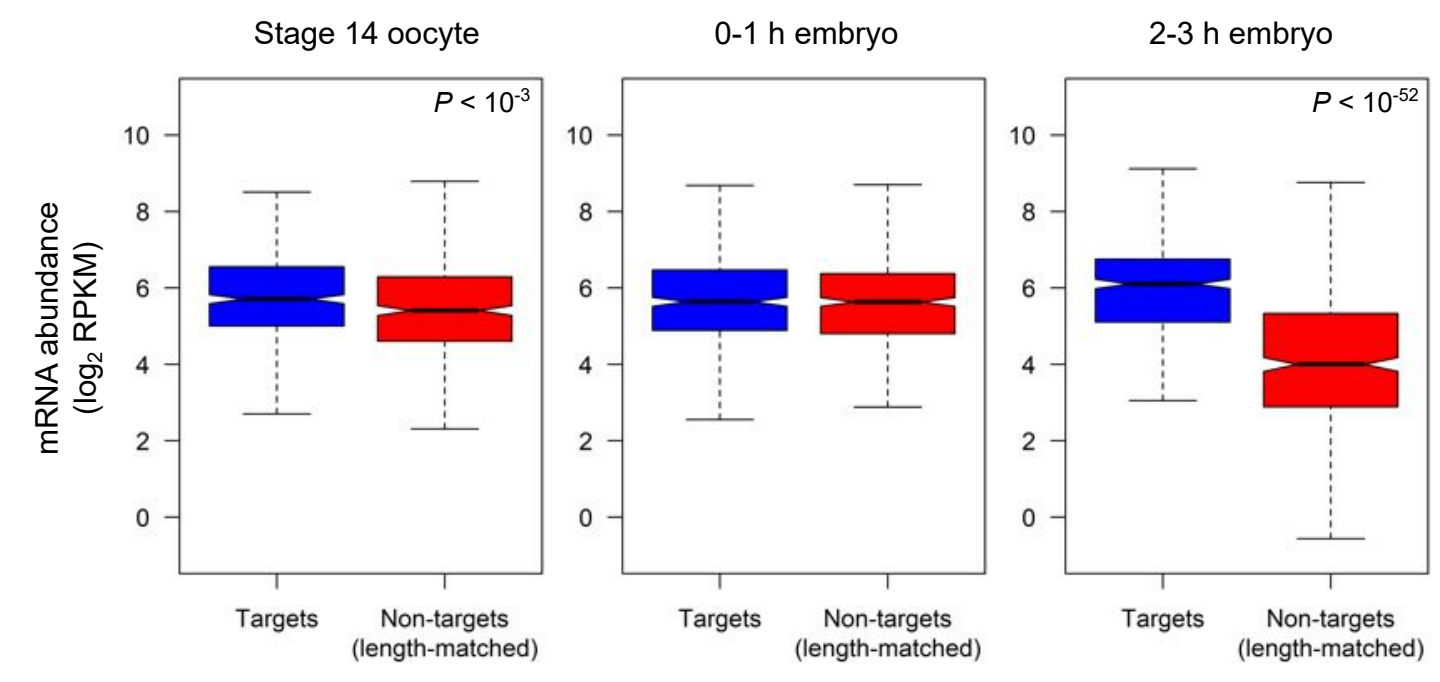

\section{Length-matched non-target set 4}
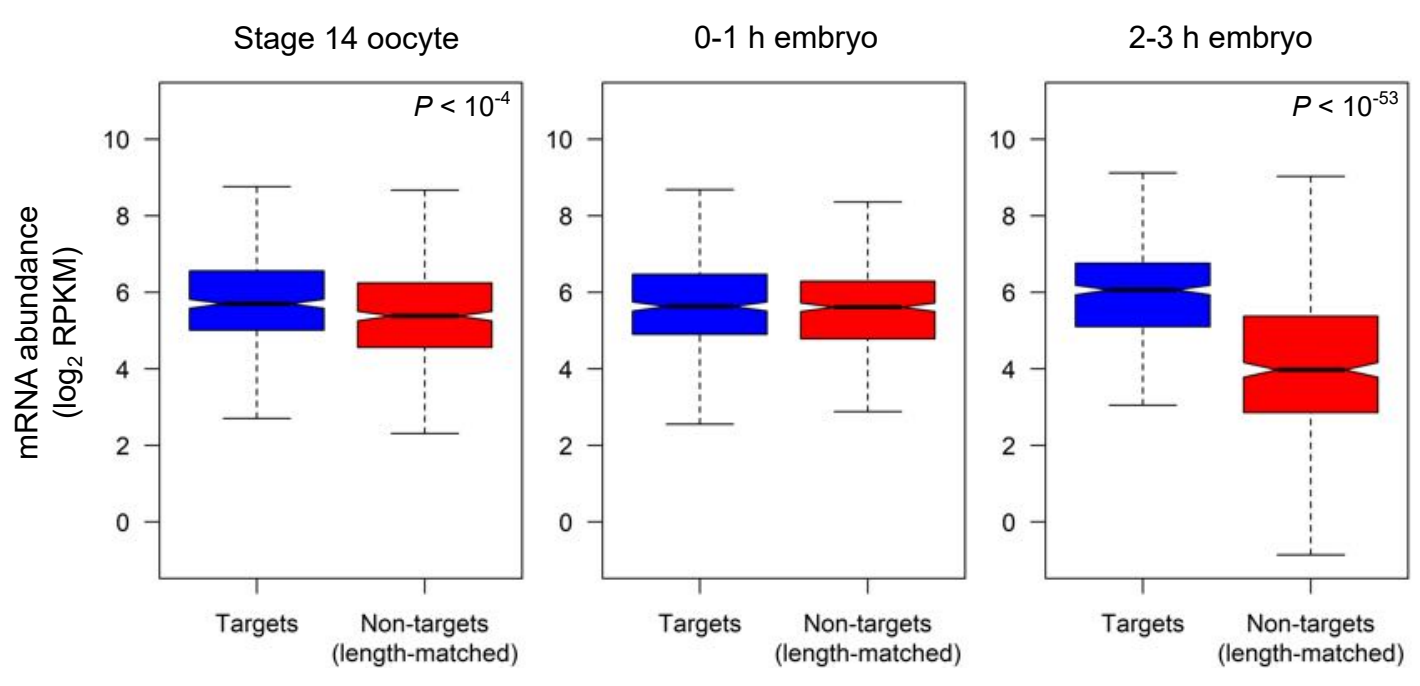

\section{Length-matched non-target set 5}
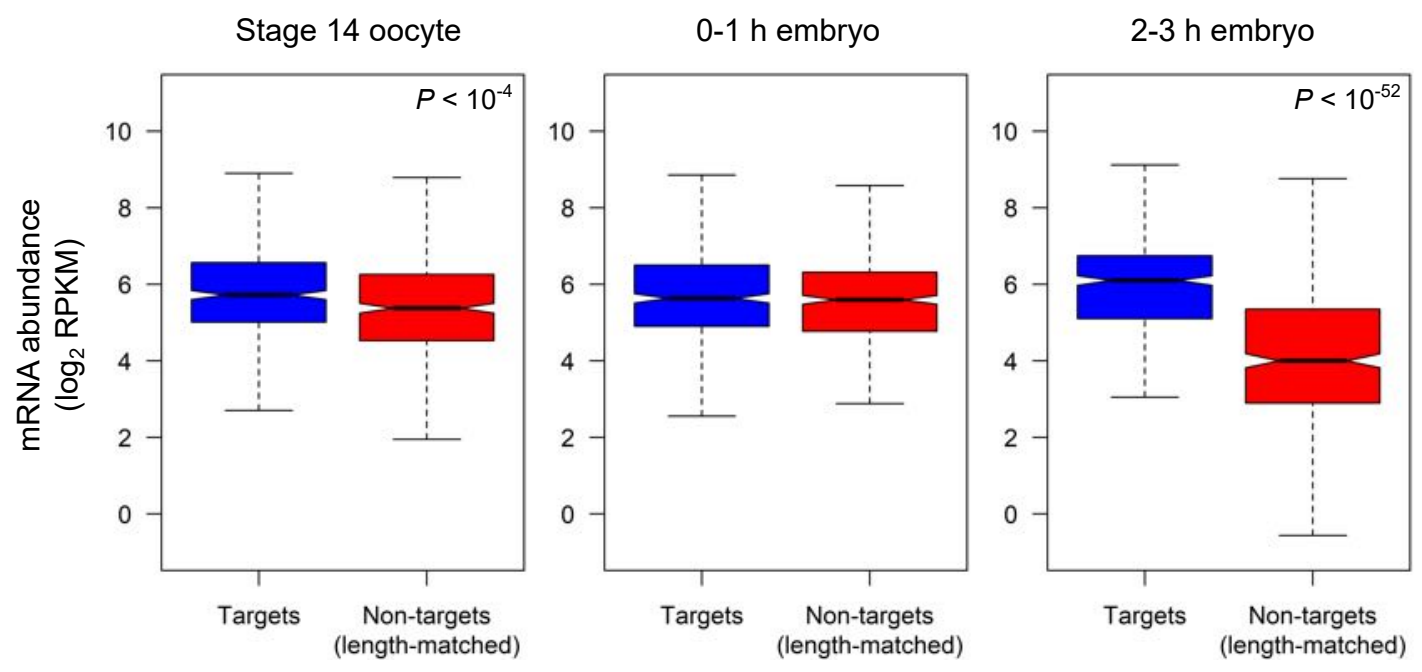


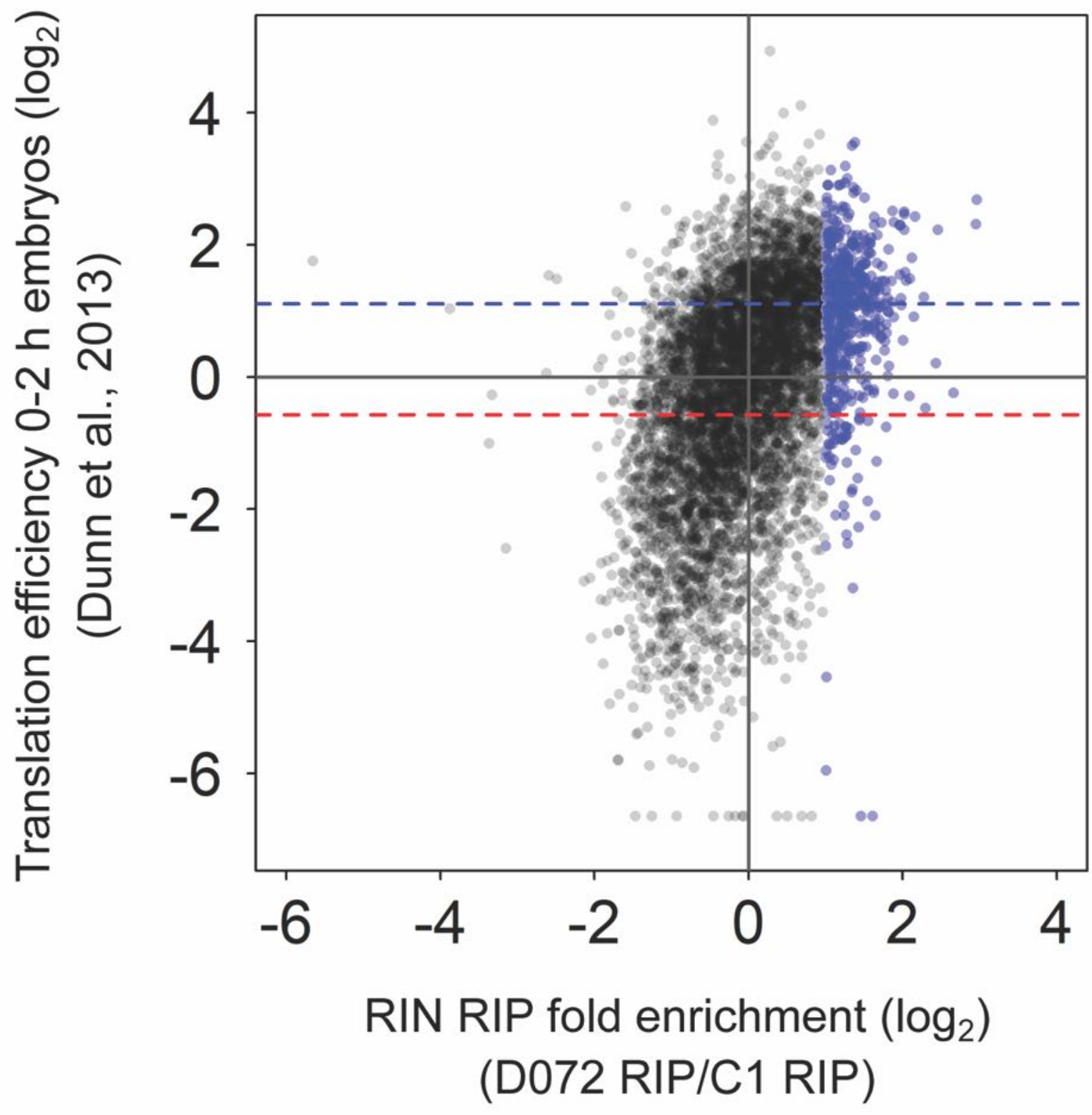



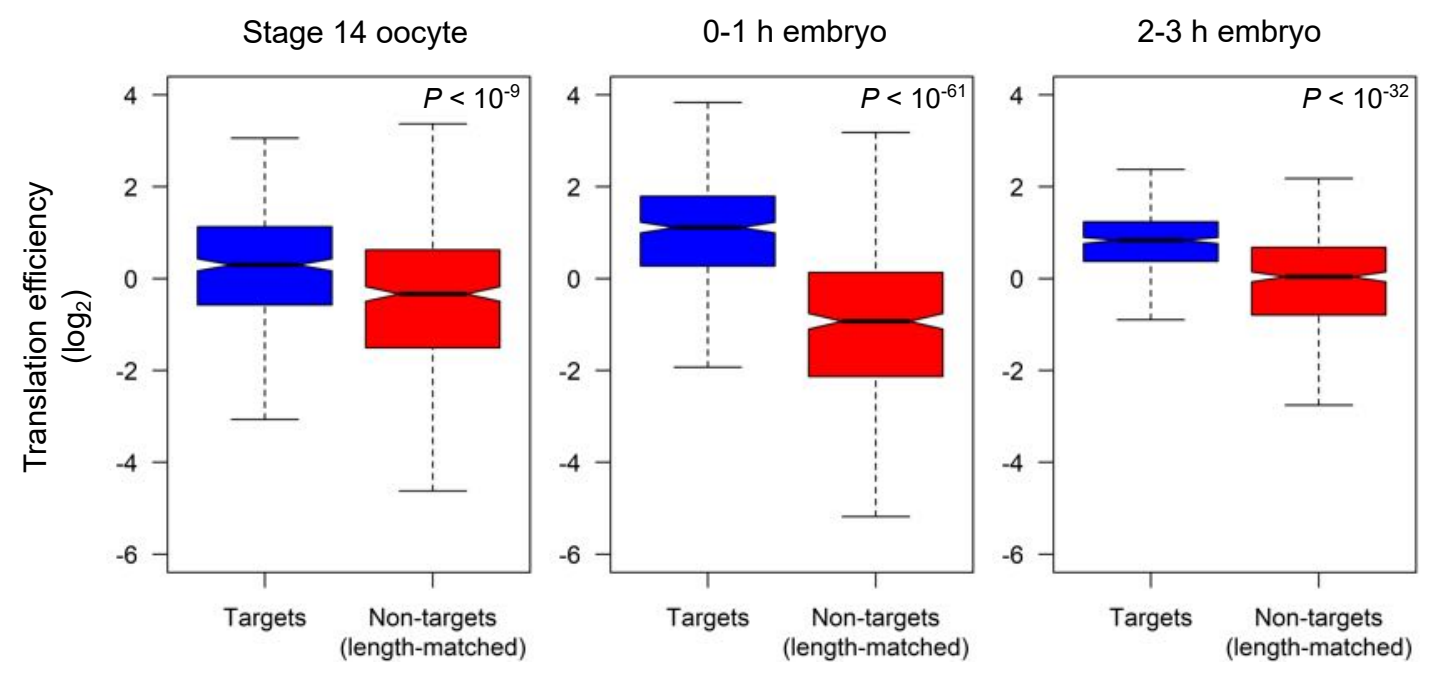

Length-matched non-target set 2

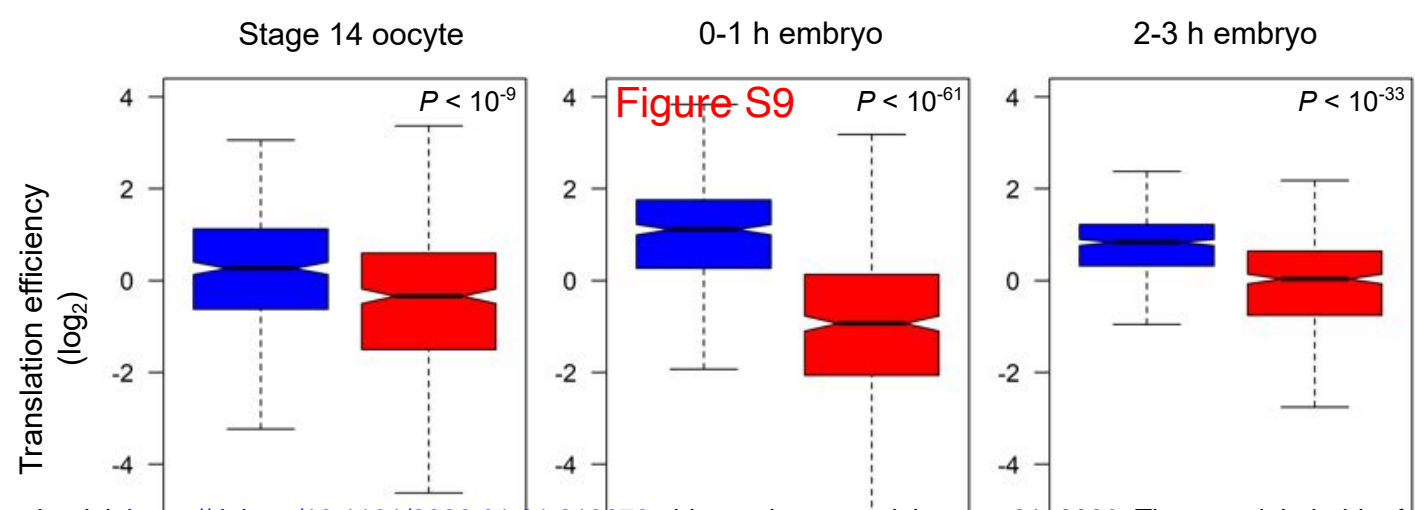

bioRxiv preprint doi: https://doi.org/10.1101/2020.01.21.913079; this version posted-January 21, 2020. The copyright holder for this preprint (which was not certified by peer review) is the_author/funder. All rights reserved. N\& reuse allowed without permission.

$$
\text { Targets } \begin{gathered}
\text { Non-targets } \\
\text { (length-matched) }
\end{gathered} \quad \text { Targets } \begin{gathered}
\text { Non-targets } \\
\text { (length-matched) }
\end{gathered} \quad \text { Targets } \begin{gathered}
\text { Non-targets } \\
\text { (length-matched) }
\end{gathered}
$$

Length-matched non-target set 3
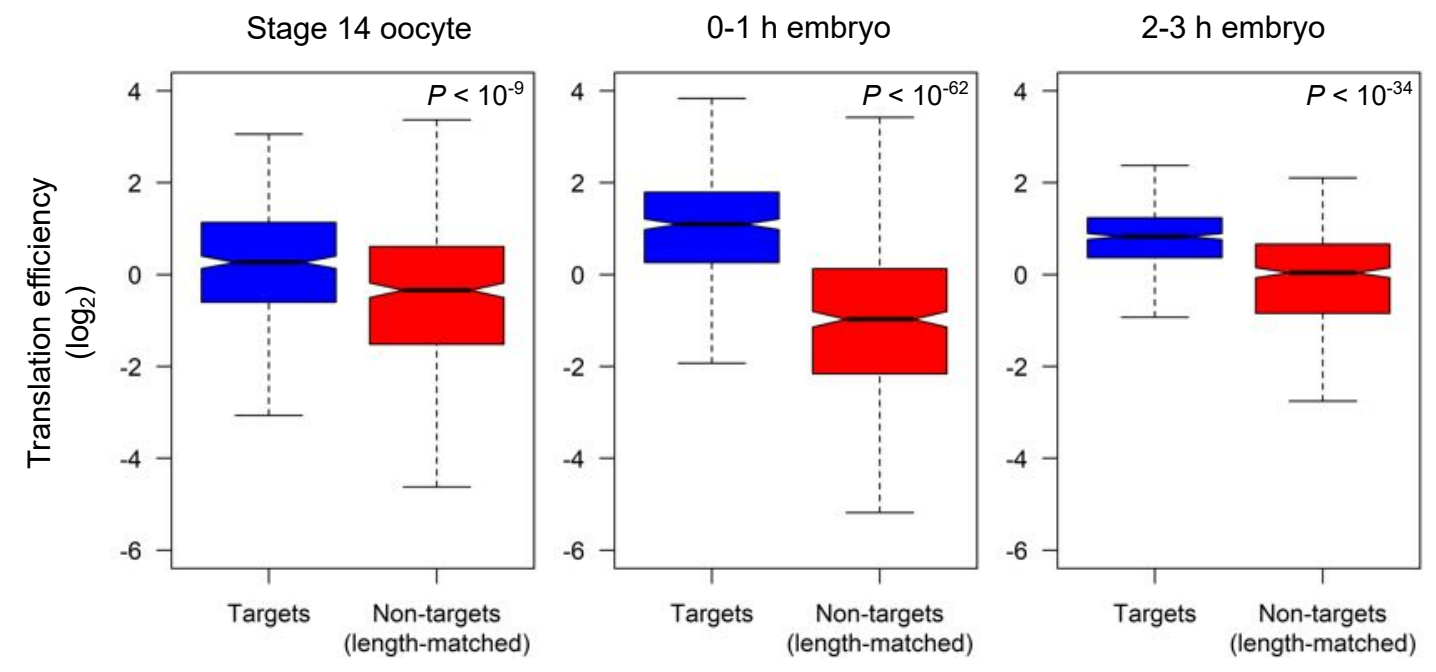

Length-matched non-target set 4
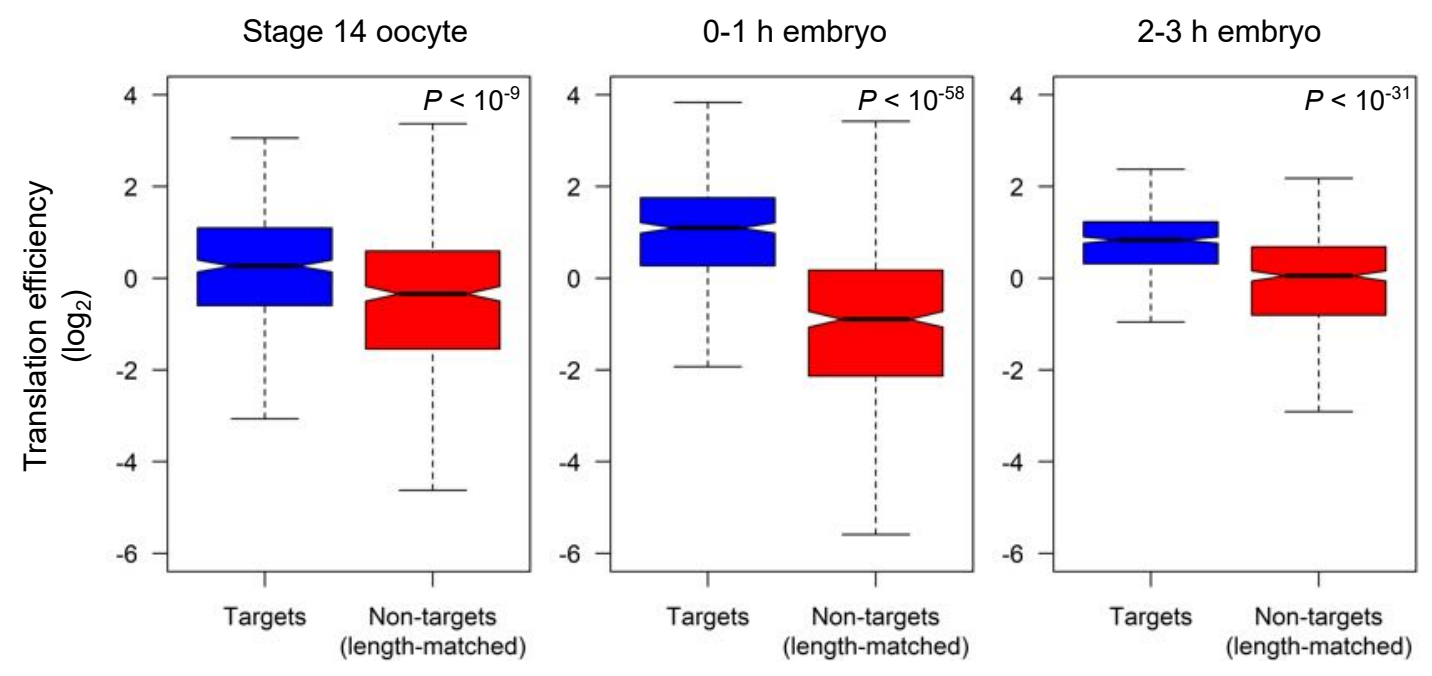

Length-matched non-target set 5
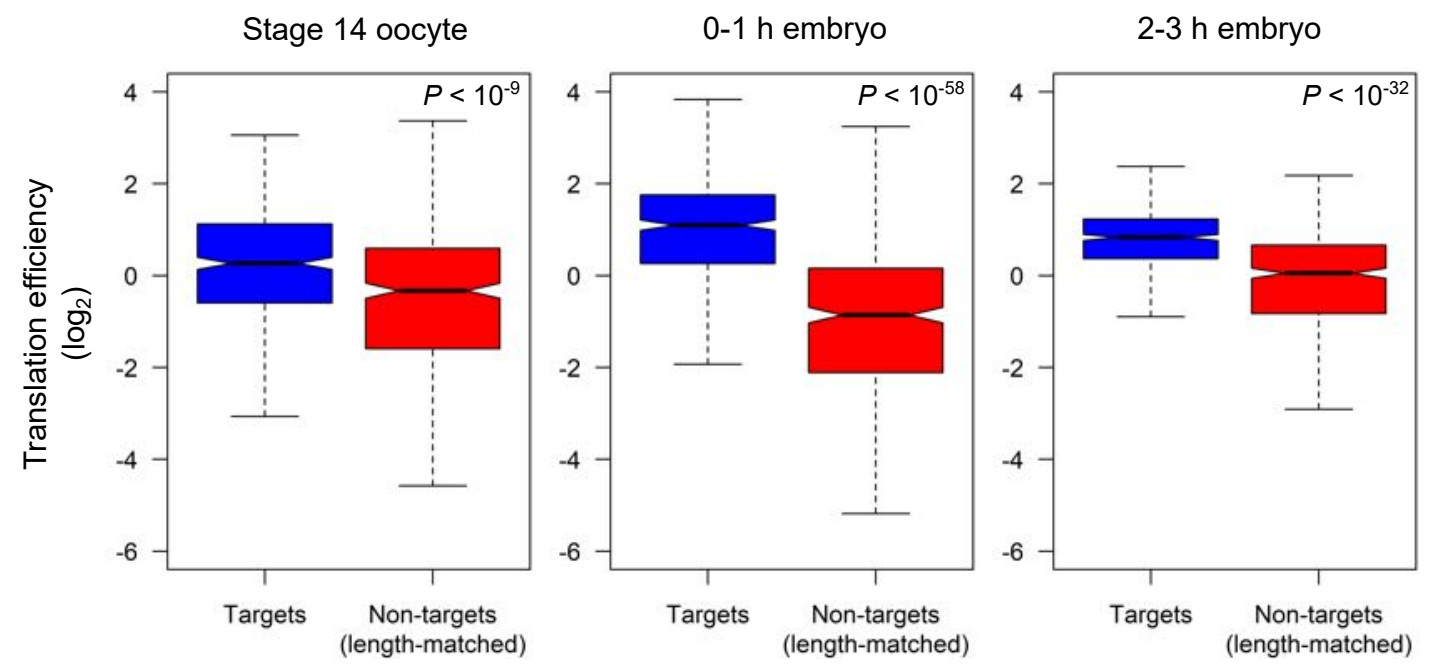
bioRxiv preprint doi: https://doi.org/10.1101/2020.01.21.913079; this version posted January 21, 2020. The copyright holder for this preprint (1) author/funder. All rights reserved. No reuse allowed without permiss

A

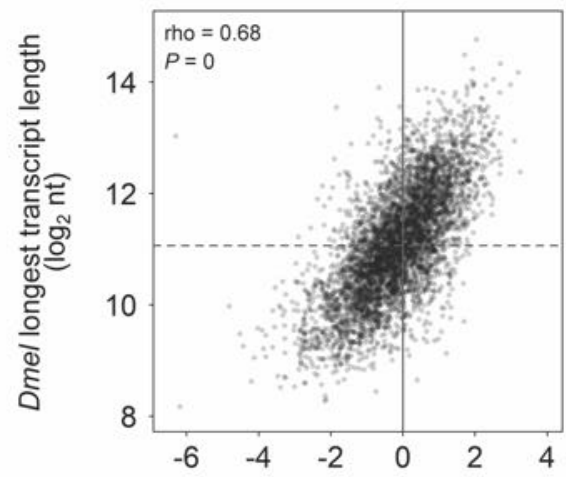

Human homolog fold enrichment in SG $\left(\log _{2}\right)$ (Khong et al 2017)

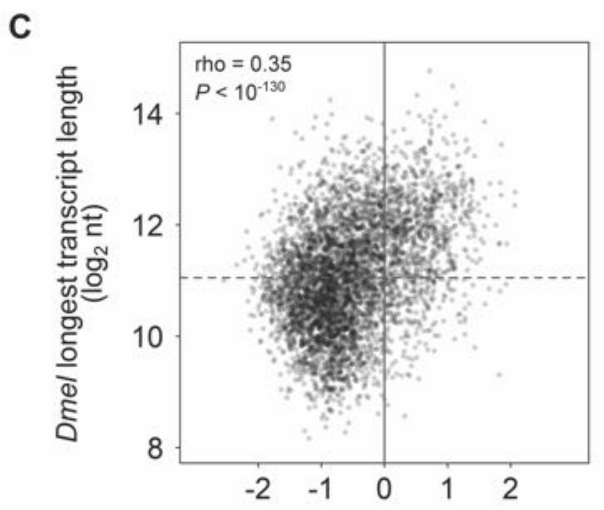

Mouse homolog ER stress deltaRG $\left(\log _{2}\right)$ (Namkoong et al 2018)

\section{E}

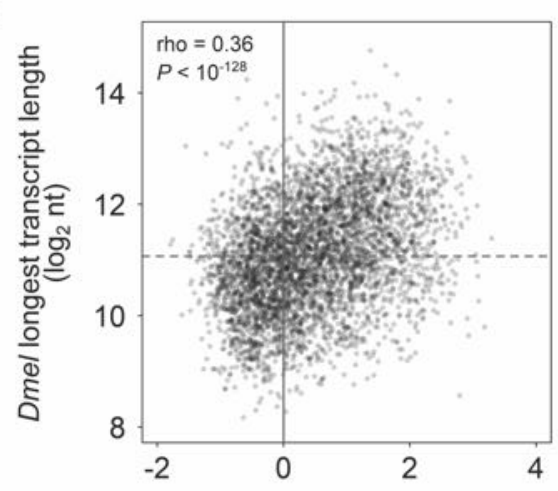

Mouse homolog HS stress deltaRG $\left(\log _{2}\right)$ (Namkoong et al 2018)

\section{G}

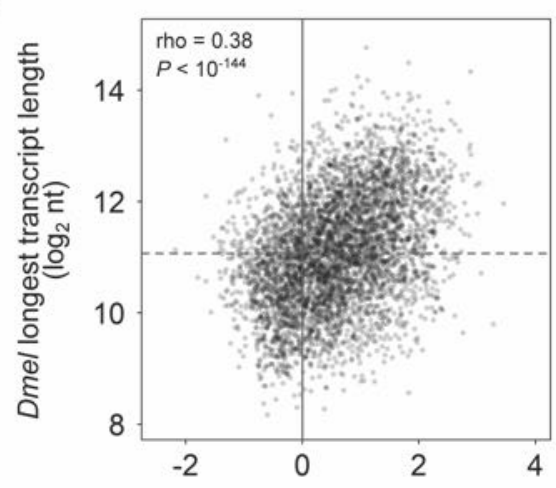

Mouse homolog AS stress deltaRG $\left(\log _{2}\right)$ (Namkoong et al 2018)
B

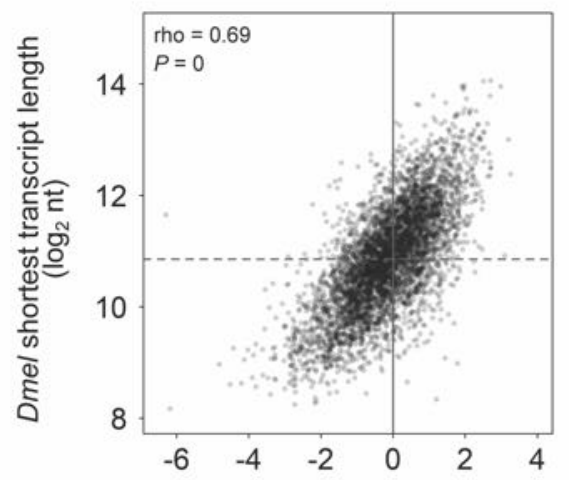

Human homolog fold enrichment in SG $\left(\log _{2}\right)$ (Khong et al 2017)

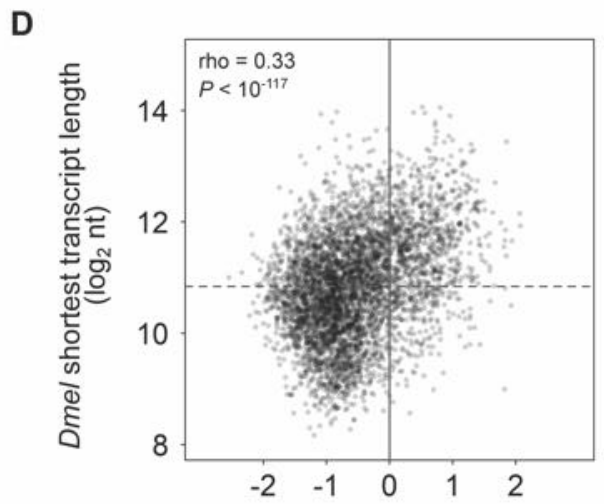

Mouse homolog ER stress deltaRG $\left(\log _{2}\right)$ (Namkoong et al 2018)

$\mathbf{F}$

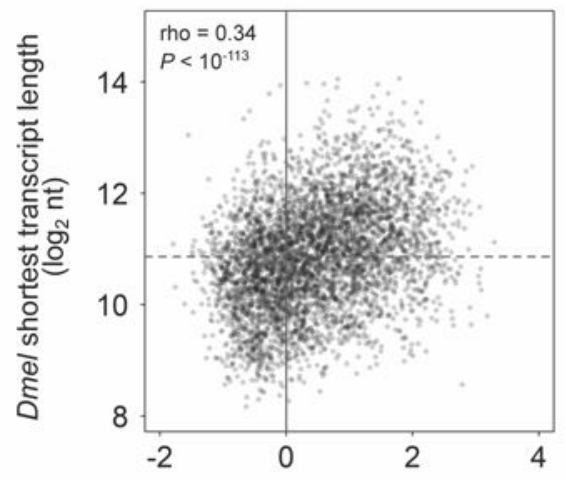

Mouse homolog HS stress deltaRG ( $\left.\log _{2}\right)$ (Namkoong et al 2018)

H

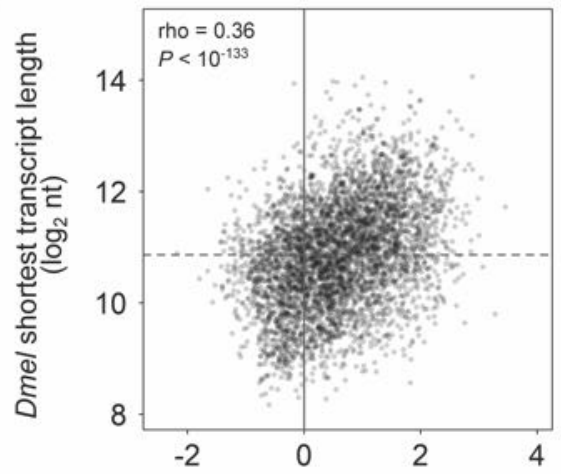

Mouse homolog AS stress deltaRG $\left(\log _{2}\right)$ (Namkoong et al 2018) 

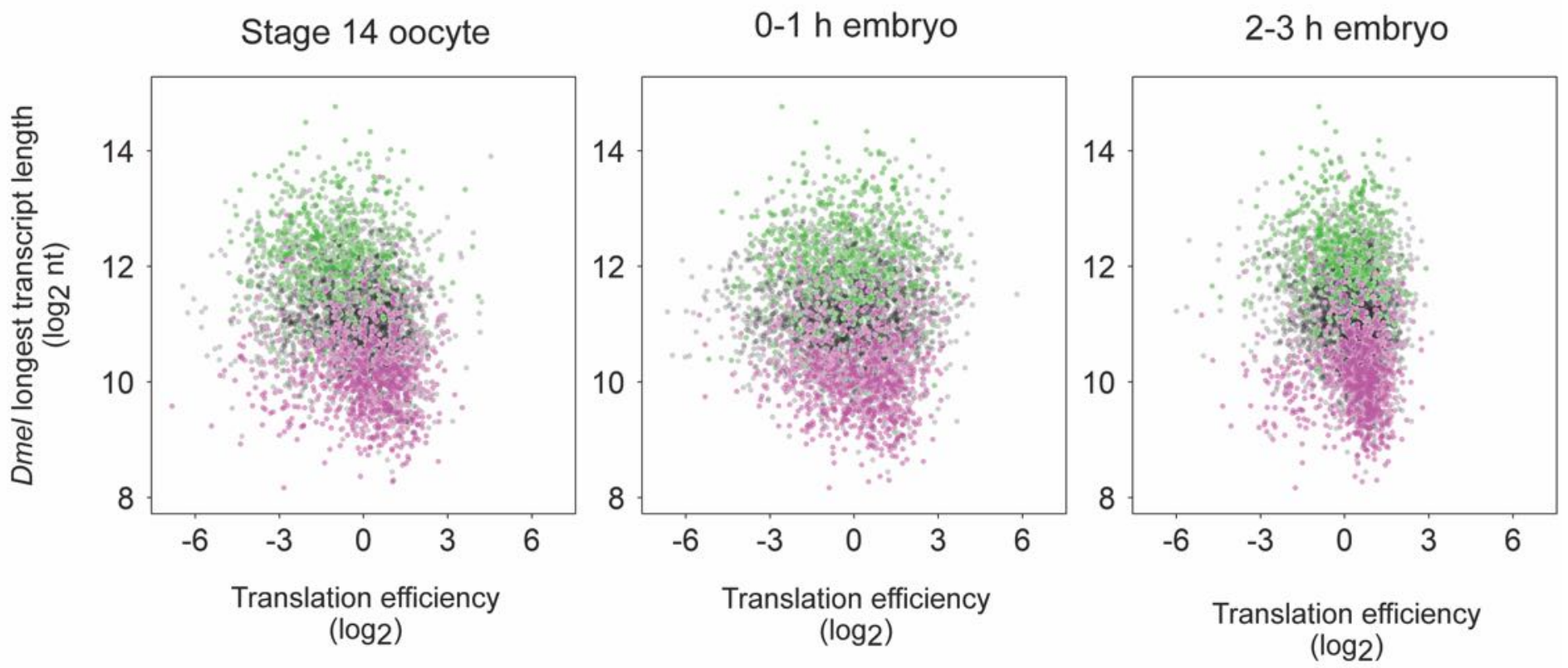
bioRxiv preprint doi: https://doi.org/10.1101/2020.01.21.913079; this version posted January $21,2020$. The copyright holder for this preprint (which was not certified by peer review) is the author/funder. All rights reserved. No reuse allowed without permission.

\section{A. Cytoplasmic RPs}

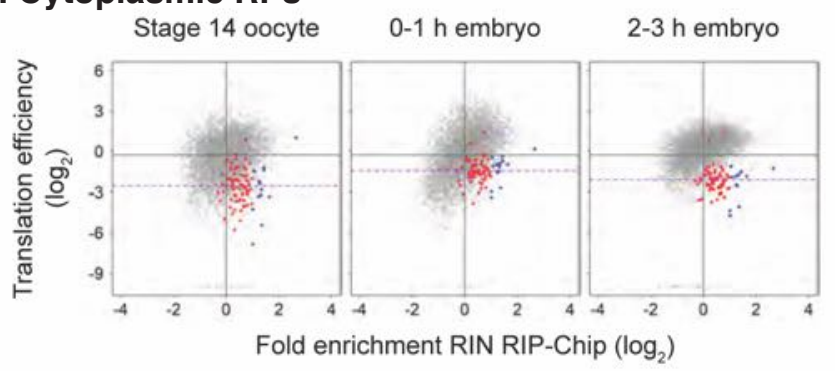

\section{B. Mitochondrial RPs}

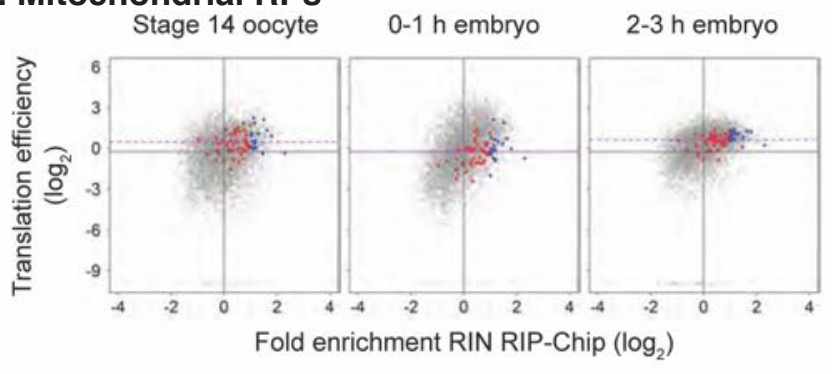

\section{Mitochondrial respiratory chain complex}

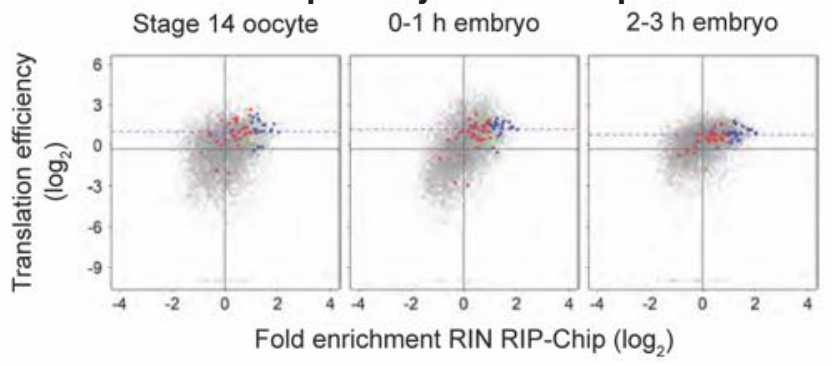

\section{Ragulator complex}

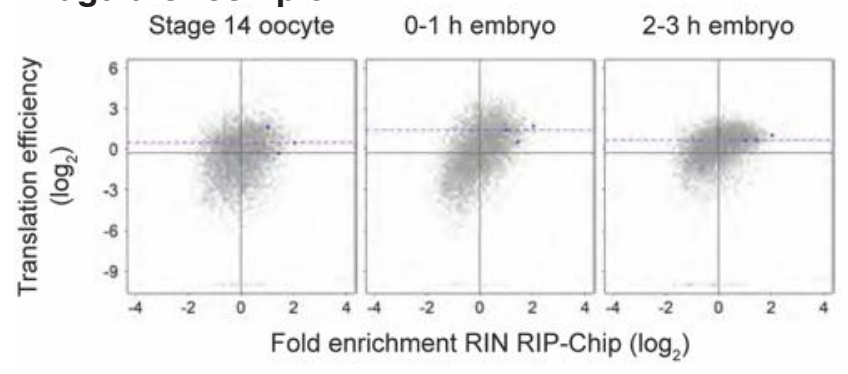

\section{E. Transcription initiation}

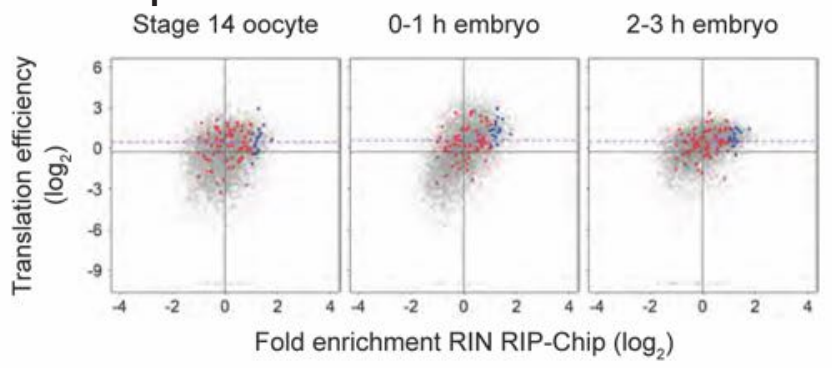

\section{F. mRNA splicing}

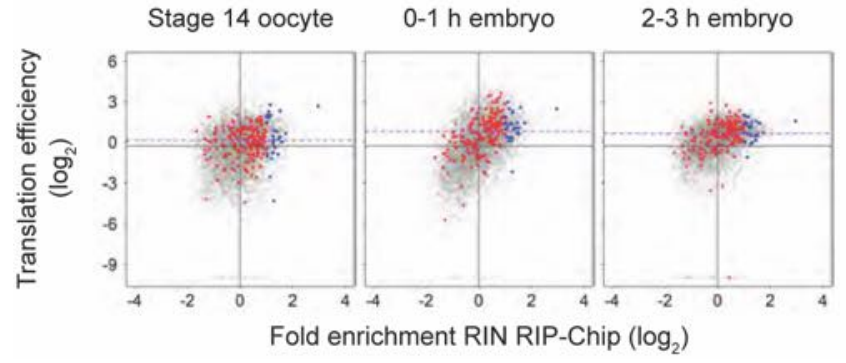

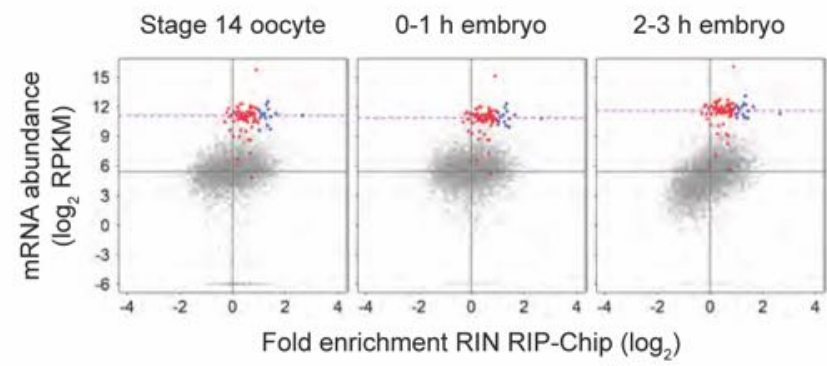
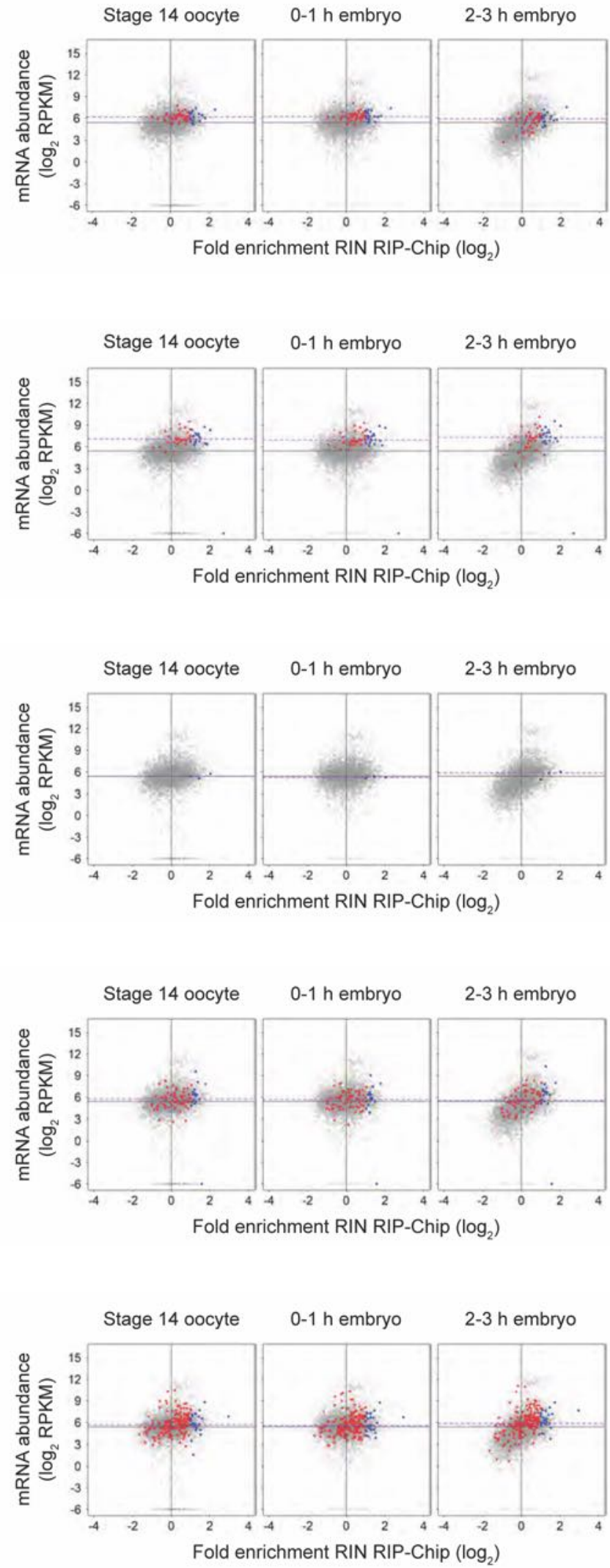

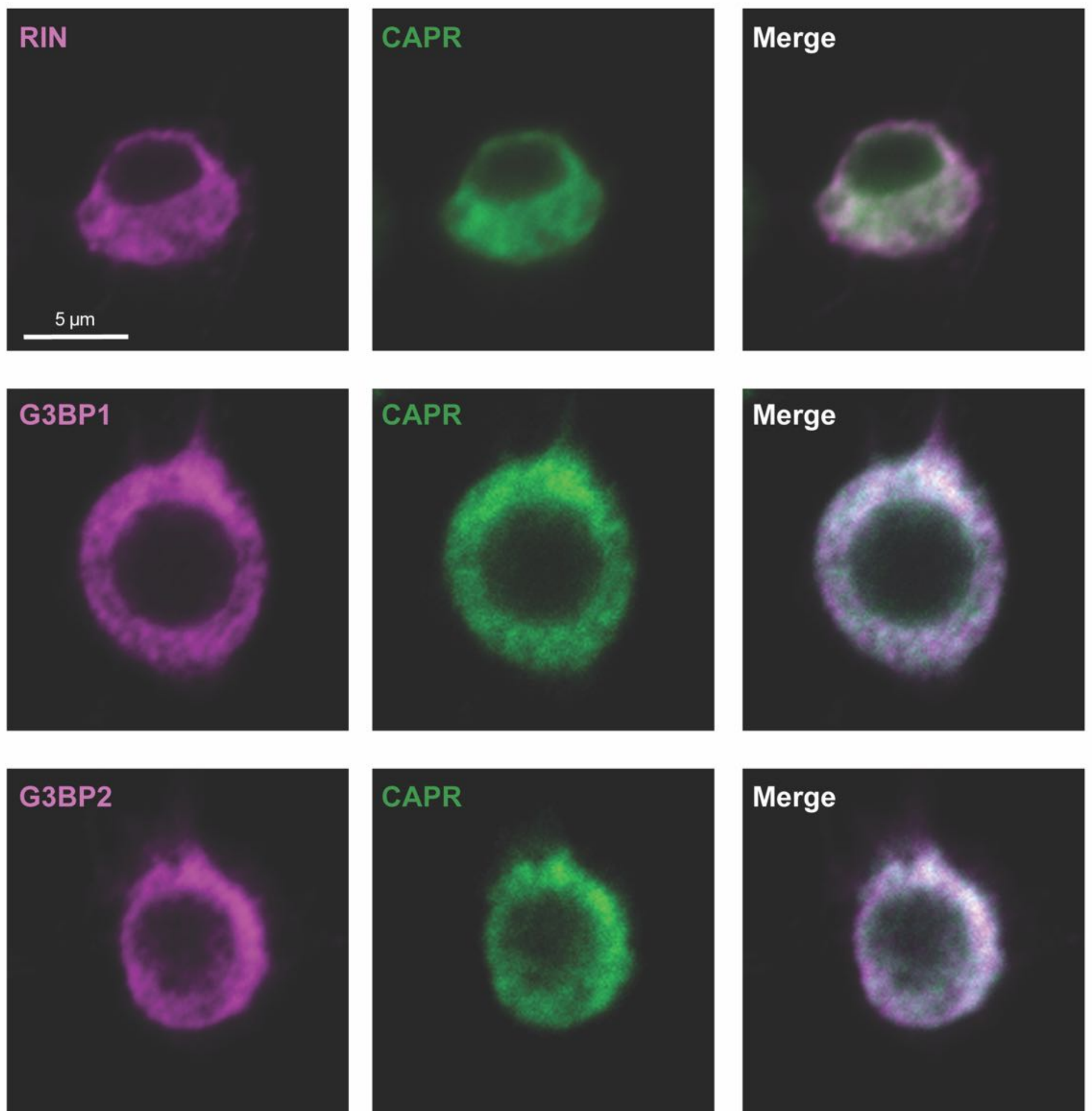